\title{
Steam Reforming as a Method to Treat Hanford Underground Storage Tank (UST) Wastes
}

\author{
Edited By \\ James E. Miller and Paul B. Kuehne \\ Sandia National Laboratories, New Mexico
}

Contributors

Larry D. Bustard, S. Jill Glass, Paul B. Kuehne, Vincent M. Loyola, James E. Miller, Jeremy L. Sprung Sandia National Laboratories, New Mexico

Robert W. Bradshaw, Linn W. Derickson, Patrick D. Gildea, Steven H. Goods, Davina M. Kim, Brad Meyer Sandia National Laboratories, Now Mexico

Robert J. Cena, Thomas T. Coburn

Lawrence Livermore National Laboratory

Enrique S. del Solar, Terry R. Galloway, Gene L. Pecci

Synthetica Technologies, Inc.

\section{Prepared by}

Sandia National Laboratories

Albuquerque, New Mexico 87185 and Livermore, California 94550

for the United States Departmient of Energy

under Contract DE-ACOA $94 A \mathrm{AL} 5000$

Approved for public releasey distribution is unlimited:
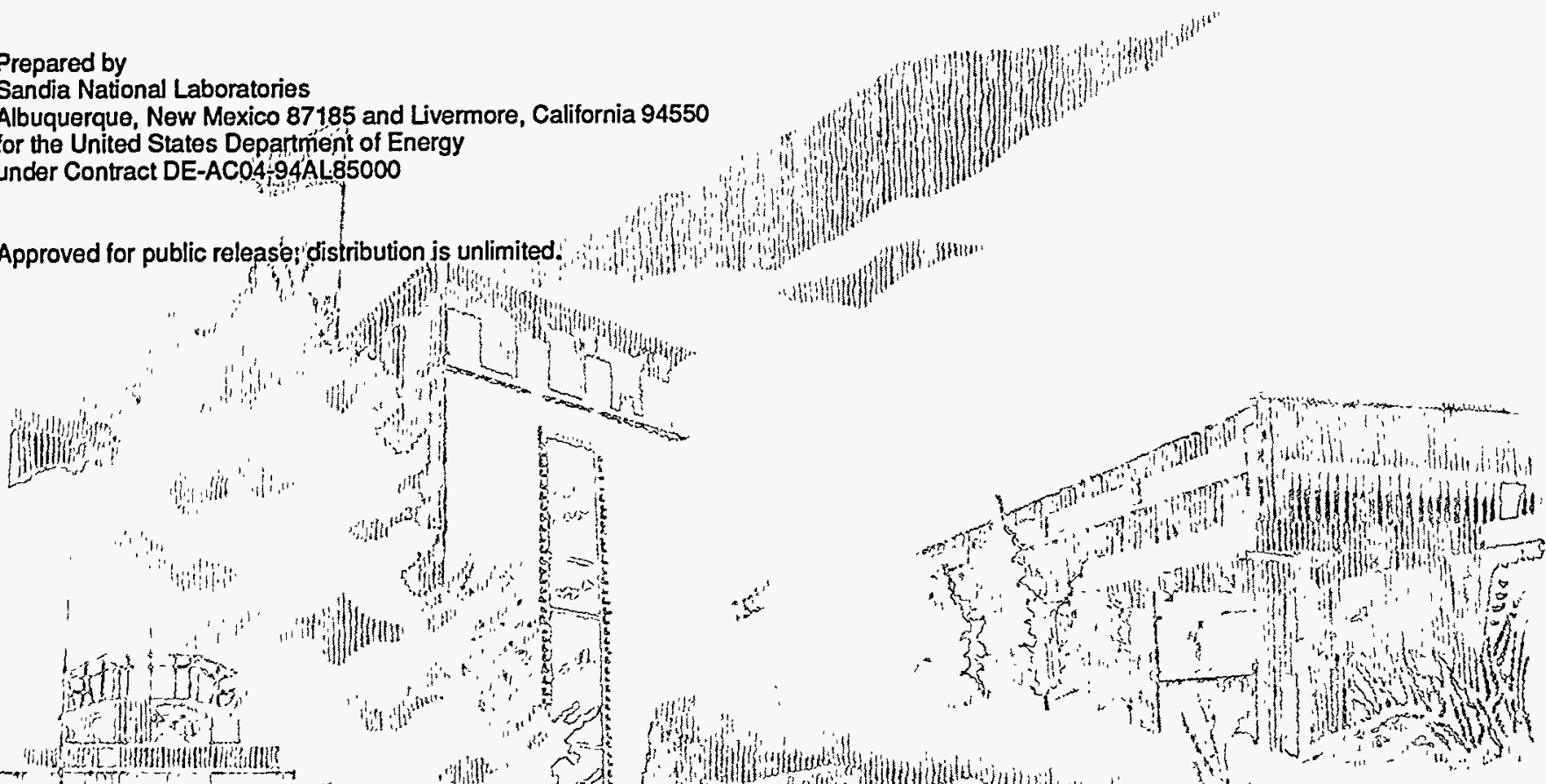

3
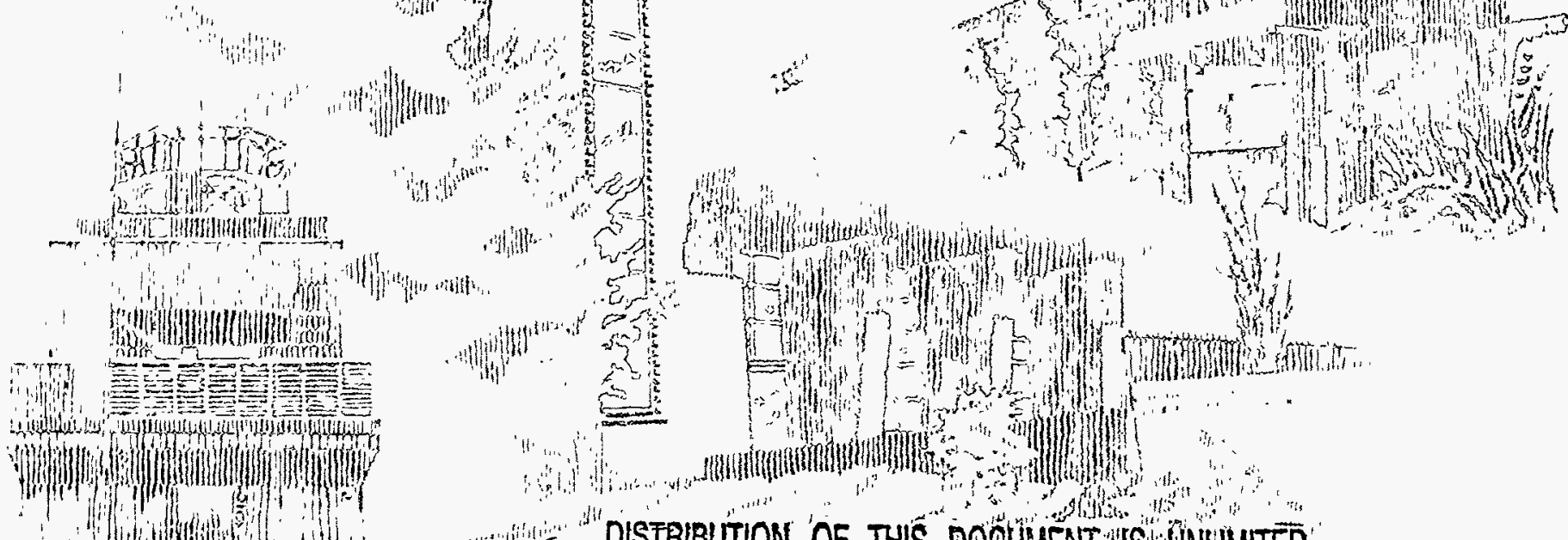

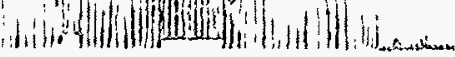

SF2900O(8-81)
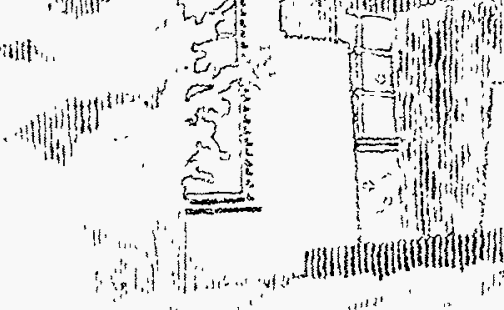

$\int_{G}$ 
Issued by Sandia National Laboratories, operated for the United States Department of Energy by Sandia Corporation.

NOTICE: This report was prepared as an account of work sponsored by an agency of the United States Government. Neither the United States Government nor any agency thereof, nor any of their employees, nor any of their contractors, subcontractors, or their employees, makes any warranty, express or implied, or assumes any legal liability or responsibility for the accuracy, completeness, or usefulness of any information, apparatus, product, or process disclosed, or represents that its use would not infringe privately owned rights. Reference herein to any specific commercial product, process, or service by trade name, trademark, manufacturer, or otherwise, does not necessarily constitute or imply its endorsement, recommendation, or favoring by the United States Government, any agency thereof or any of their contractors or subcontractors. The views and opinions expressed herein do not necessarily state or reflect those of the United States Government, any agency thereof or any of their contractors.

Printed in the United States of America. This report has been reproduced directly from the best available copy.

Available to DOE and DOE contractors from

Office of Scientific and Technical Information

PO Box 62

Oak Ridge, TN 37831

Prices available from (615) 576-8401, FTS 626-8401

Available to the public from

National Technical Information Service

US Department of Commerce

5285 Port Royal Rd

Springfield, VA 22161

NTIS price codes

Printed copy: A04

Microfiche copy: A01 


\section{DISCLAIMER}

Portions of this document may be illegible in electronic image products. Images are produced from the best available original document. 
Distribution Category UC-602

SAND $94-2571$

Unlimited Release

Printed July 1995

\title{
STEAM REFORMING AS A METHOD TO TREAT HANFORD UNDERGROUND STORAGE TANK (UST) WASTES
}

\author{
Edited By \\ James E. Miller and Paul B. Kuehne \\ Sandia National Laboratories, New Mexico \\ Contributors \\ Larry D. Bustard, S. Jill Glass, Paul B. Kuehne, \\ Vincent M. Loyola, James E. Miller, Jeremy L. Sprung \\ Sandia National Laboratories, New Mexico \\ Robert W. Bradshaw, Linn W. Derickson, Patrick D. Gildea, \\ Steven H. Goods, Davina M. Kim, Brad Meyer \\ Sandia National Laboratories, California \\ Robert J. Cena, Thomas T. Coburn \\ Lawrence Livermore National Laboratory \\ Enrique S. del Solar, Terry R. Galloway, Gene L. Pecci \\ Synthetica Technologies, Inc.
}

\begin{abstract}
This report summarizes a Sandia program that included partnerships with Lawrence Livermore National Laboratory and Synthetica Technologies, Inc. to design and test a steam reforming system for treating Hanford underground storage tank (UST) wastes. The benefits of steam reforming the wastes include the resolution of tank safety issues and improved radionuclide separations. Steam reforming destroys organic materials by first gasifying, then reacting them with high temperature steam. Tests indicate that up to $99 \%$ of the organics could be removed from the UST wastes by steam exposure. In addition, it was shown that nitrates in the wastes could be destroyed by steam exposure if they were first distributed as a thin layer on a surface. High purity alumina and nickel alloys were shown to be good candidates for materials to be used in the severe environment associated with steam reforming the highly alkaline, high nitrate content wastes. Work was performed on designing, building, and demonstrating components of a 0.5 gallon per minute (gpm) system suitable for radioactive waste treatment. Scale-up of the unit to 20 gpm was also considered and is feasible. Finally, process demonstrations conducted on non-radioactive waste surrogates were carried out, including a successful demonstration of the technology at the $0.1 \mathrm{gpm}$ scale.
\end{abstract}


1.0 INTRODUCTION

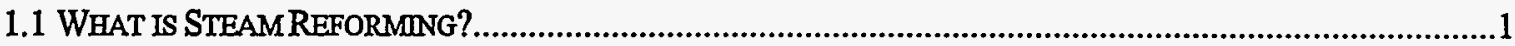

1.2 APPLICATION OF STEAMREFORMING TO HANFORD UNDERGROUND STORAGE TANK WASTES...................1

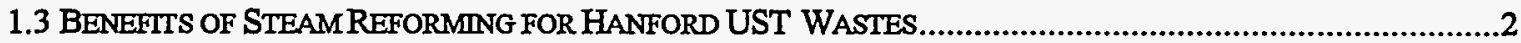

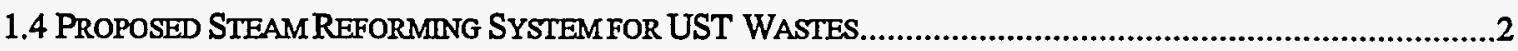

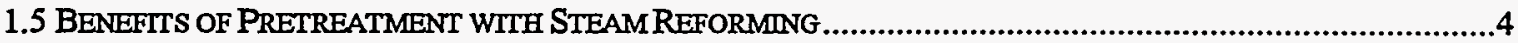

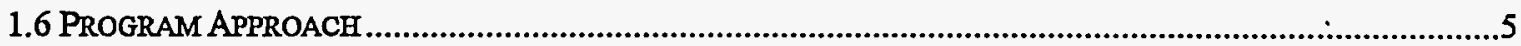

2.0 CHEMISTRY

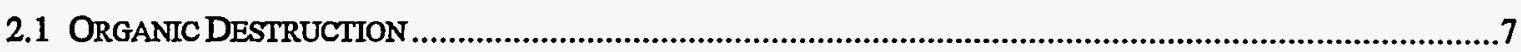

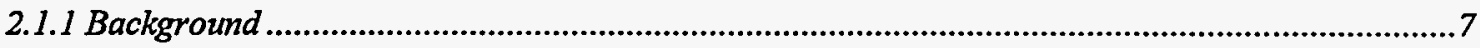

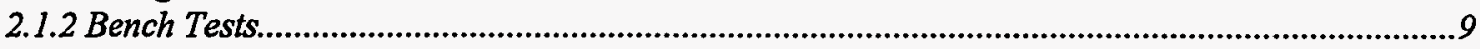

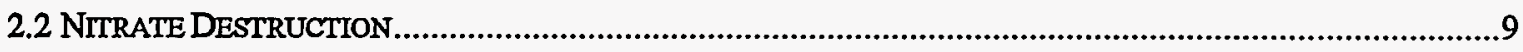

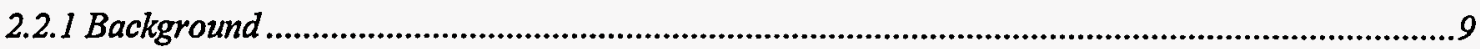

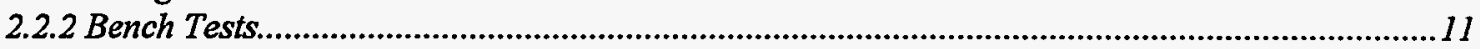

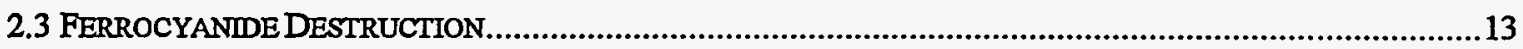

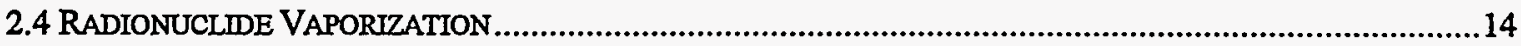

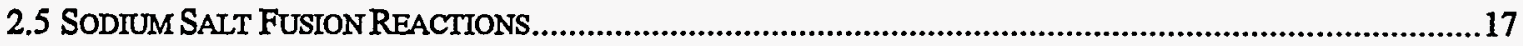

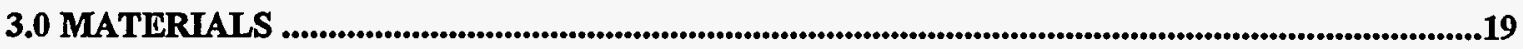

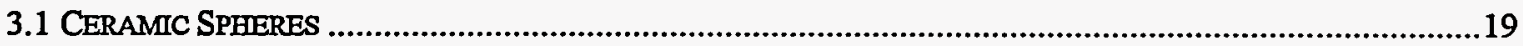

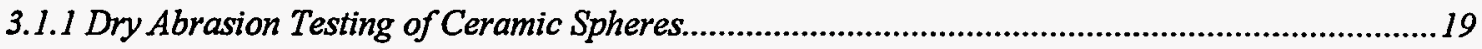

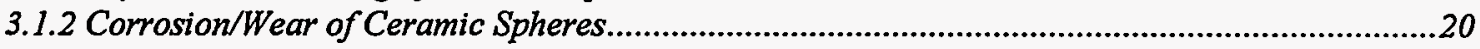

3.1.3 Static Caustic Corrosion of and Radionuclide Uptake by Ceramic Spheres................................20

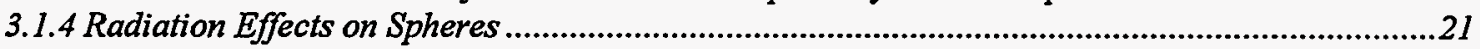

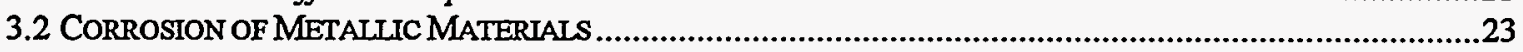

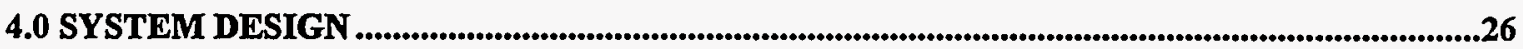

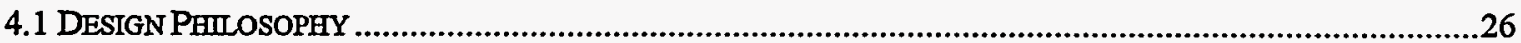

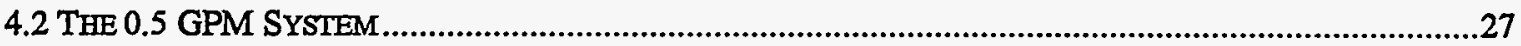

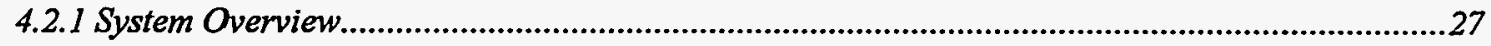

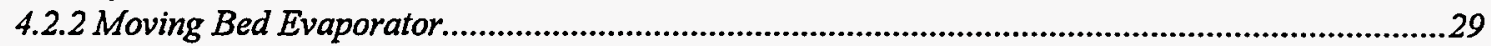

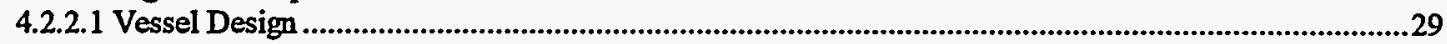

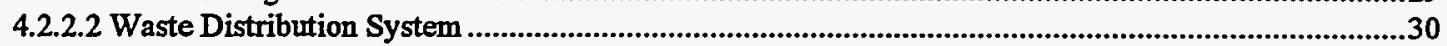

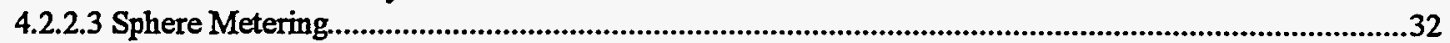

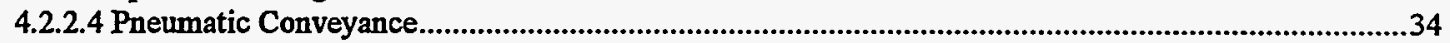

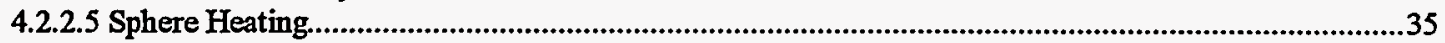

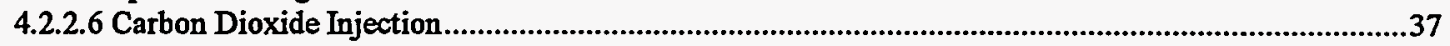

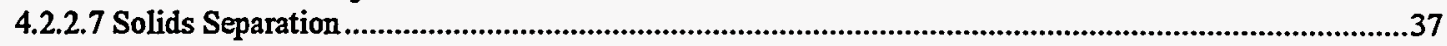

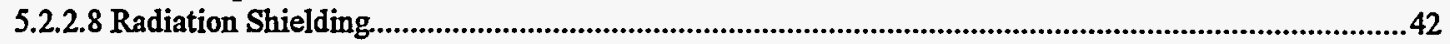

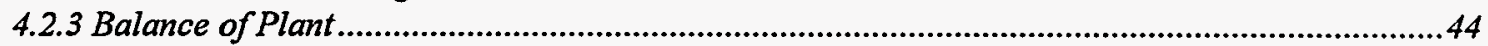

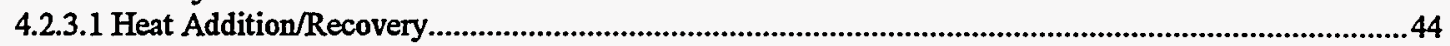

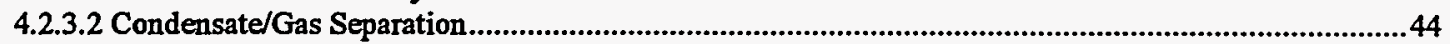

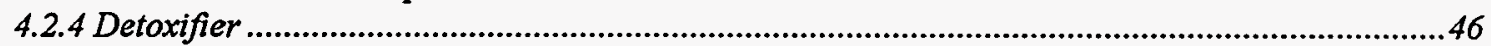

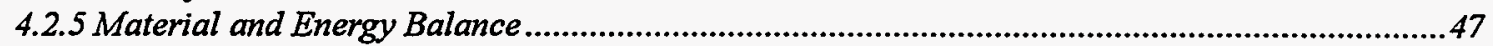

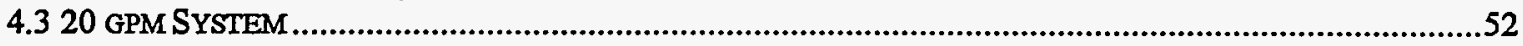

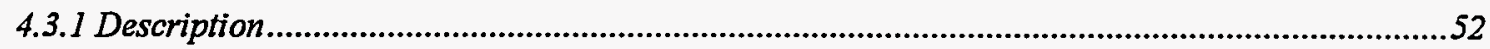

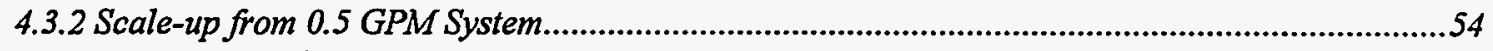

4.3.3 Environmental Issues and Permitting............................................................................................56

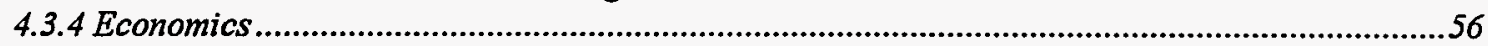

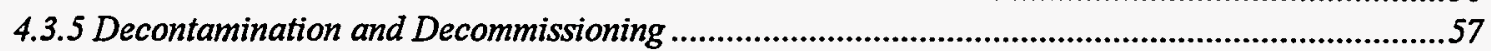

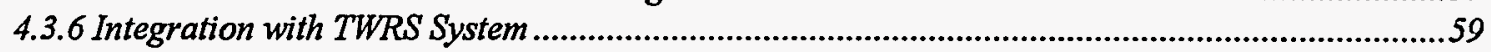


5.0 PROCESS DEMONSTRATION.............................................................................................61

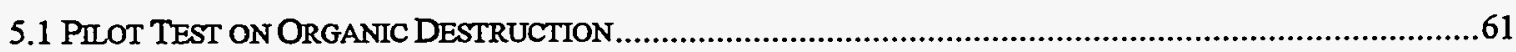

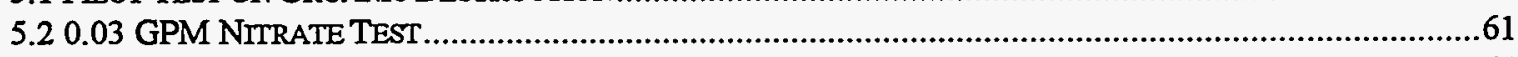

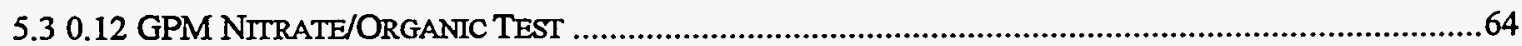


FIGURE 1.1 SIMPLIFIED SCHEMATIC OF STEAMREFORMING SYSTEM.

TABLE 2-1 POTENTIAL REACTIONS OF FERROCYANIDE WITH NITRATES AND/OR NITRITES...........................14

TABLE 2-2 VAPOR PRESSURE (IN ATMOSPHERES) OF CESTUM SPECIES CALCULATED USING VICTORIA

CODE.

TABLE 2-3 CONCENTRATIONS OF RADIONUCLIDES IN HIGH TEMPERATURE STEAM...................................15

TABLE 3-1 WeIght ChaNge of ALUMINA SPHERES DURING WEAR TeST AT $400^{\circ} \mathrm{C}$...............................20

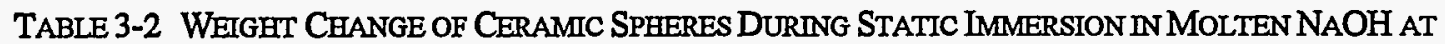
$605^{\circ} \mathrm{C}$

TABLE 3-3 MATERIALS PROPERTIES OF As-RECEIVED AND IRRADIATED CERAMIC SPHERES.......................22

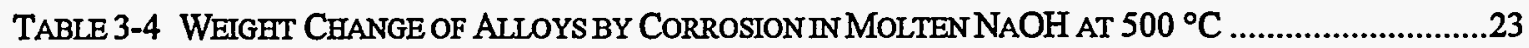

TABLE 3-5 Weight Change of Alloys By Corrostonin CAUSTIC Molten Salt Mixture at $500^{\circ} \mathrm{C}$ to $600^{\circ} \mathrm{C}$

TABLE 3-6 CONCENTRATIONS OF METALLIC ALLOYING ELEMENTS DiSSOLVED DURING CORROSION IN A CAUSTIC MOLTEN SALT MIXTURE AT $600^{\circ} \mathrm{C}$.

TABle 3-7 Depth of Corroston OF NiCKEL-BASE ALLOYS TESTED IN A CAUSTIC MOLTEN SALT MIXTURE

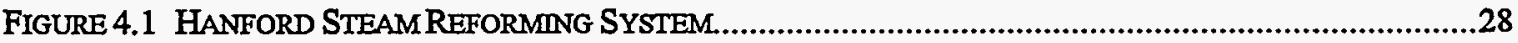

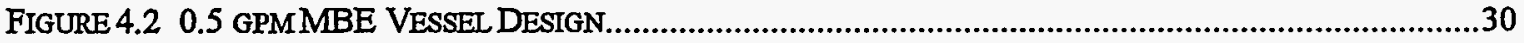

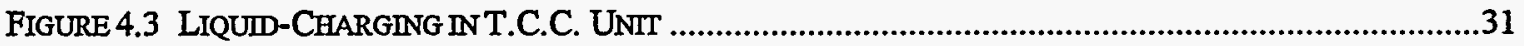

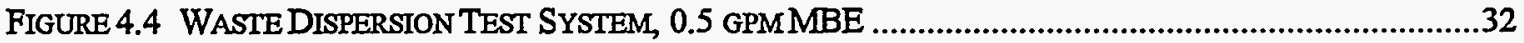

FIGURE 4.5 SCHEMATIC DIAGRAM OF SOLD FLOW CONTROL PMV ........................................................33

FIGURE 4.6 SPHERE FLow RATE VERSUS VERTICAL DISTANCE.............................................................34

FIGURE 4.7 SCHEMATIC DIAGRAM OF MOVING BED EVAPORATOR (MBE) ............................................38

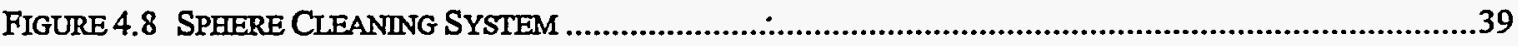

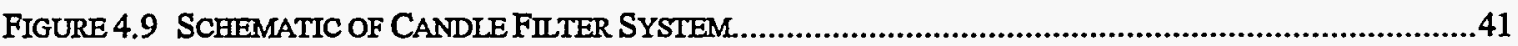

TABLE 4-1 SHIELDING THICKNESS TO REDUCE 2 METER DOSE RATE TO 10 MREM/HR .............................43

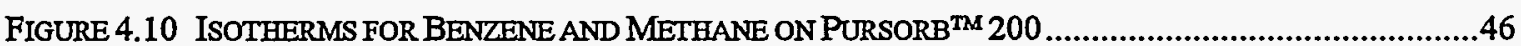

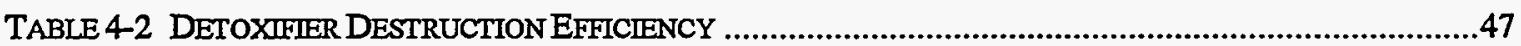

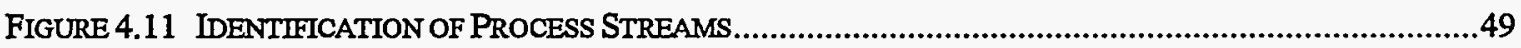

TABLE 4-3 MATERIAL BALANCE FOR 0.5 GPM MBE AND BALANCE OF PLANT .......................................50

TABLE 4-4 MATERIAL BALANCE FOR 0.5 GPM BALANCE OF PLANT AND DETOXIFIER .................................51

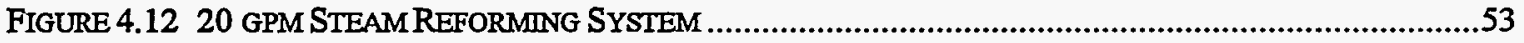

FIGURE 4.13 INIEGRATION OF ORGANIC DESTRUCTION PROCESS WITH TWRS TREATMENT.........................59

FIGURE 5.1 SCHEMATIC OF LLNL HOT-RECYCLED-SOLID (HRS) OLL SHALE RETORTING PILOT PLANT......62

FIGURE 5.2 SCHEMATIC OF HOT-RECYCLED-SOLID PILOT PLANT FOR DEMONSTRATION OF SODIUM NITRATE DECOMPOSTTION.

TABLE 5-1 COMPARISON OF NITROGEN CONTAINING PRODUCTS FROM LABORATORY AND LLNL PILOT SCALE SODIUM NITRATE TESTS (\% PRODUCTS IN OFF-GAS) .......................................................63

TABLE 5-2 COMPARISON OF NITROgEN CONTAINING PRODUCTS From LLNL PILOT SCALE SODIUM NITRATE TESTS (\% PRODUCTS IN OFF-GAS). 


\subsection{Introduction}

\subsection{What is Steam Reforming?}

Steam reforming is a versatile process that destroys organic materials through reactions with steam. Steam reforming has been used on a large scale by the petrochemical industry to produce hydrogen for at least sixty years. More recently, the process has been . commercialized for waste treatment at the drums/day scale. The chemistry of steam reforming can be simply illustrated by the reaction of $n$-heptane with superheated steam.

$$
\mathrm{n}-\mathrm{C}_{7} \mathrm{H}_{16}+7 \mathrm{H}_{2} \mathrm{O} \rightarrow 7 \mathrm{CO}+15 \mathrm{H}_{2}
$$

As currently commercially applied to waste treatment, steam reforming is a two step process. In the first step, the organic material is evaporated or gasified with extensive decomposition, by exposure to 300 to $600{ }^{\circ} \mathrm{C}$ steam. In the second step, the vaporized or gasified materials are converted to $\mathrm{H}_{2}, \mathrm{CO}, \mathrm{CO}_{2}$, and mineral acids by reaction with superheated steam at 1100 to $1200^{\circ} \mathrm{C}$. Mineral acids are formed if the organic material contains halogens, phosphorus, or sulfur atoms which are converted respectively to halogen acids (e.g., chlorine to hydrochloric acid), phosphorous acid and phosphoric acid, and hydrogen sulfide. ${ }^{1,2}$ Organic nitrogen is converted to $\mathrm{N}_{2}{ }^{1}$ and organic oxygen is converted to $\mathrm{CO}$ or $\mathrm{CO}_{2}$. In principle, all organic compounds can be steam reformed. The process has been demonstrated on a number of organic liquids (e.g., simple hydrocarbons, alcohols, ketones, and chlorocarbons) and a variety of polymeric organic materials (paint residues, caulks, shredded paper, plastics, and wood products; organics adsorbed on soils, debris, activated carbon and ash). Steam reforming is not incineration and oxidative combustion does not occur.

In addition to destroying organics, steam exposure can also provide beneficial treatment to other components found in underground storage tank wastes. For example, steam reforming can be used to destroy nitrates/nitrites and ferrocyanides. Therefore, steam reforming of tank wastes was studied using funds provided by the Underground Storage Tank Integrated Demonstration, DOE's EM-36, and DOE-RL. This report summarizes those tank waste studies.

\subsection{Application of Steam Reforming to Hanford Underground Storage Tank Wastes}

Sandia National Laboratories led a program that included parternerships with Lawrence Livermore National Laboratory and Synthetica Technologies Inc. to design and test a steam reforming system specifically aimed at treating Hanford underground storage tank

\footnotetext{
1 M. R. Nimlos and T. A. Milne, Environ. Sci. Technol., 26, 545 (1992).

2 M. Nimlos and T. Milne, "Preliminary Screening of Steam Reforming Efficacy of Rhodium Catalysts for Destroying Halon 1301 ( $\mathrm{CF}_{3} \mathrm{Br}$ )," Letter Report to Sandia from SERI dated June 28, 1990.
} 
(UST) wastes. ${ }^{3}$ The Hanford tanks contain large quantities of sodium nitrate mixed with smaller amounts of organic complexants and solvents, ferrocyanides, radionuclides and other inorganic compounds. Water is a primary constituent of many of the tanks. There is concern that the Hanford tanks may leak, thereby contaminating the ground around the tanks and eventually the Columbia River. Sixty-seven of the tanks are presumed to have leaked. ${ }^{4}$ Retrieval of the tank wastes is mandated by the current Tri-Party Agreement. After retrieval, steam reforming would destroy the organics, thus facilitating the necessary radionuclide separations that precedes high-level waste (HLW) and low-level waste (LLW) glass production. Destruction of organics and ferrocyanides would also provide added assurance that safety issues are resolved. ${ }^{5}$ Steam reforming can also decompose sodium nitrate, thereby supporting efforts to convert the tank waste into a more stable and retrievable glass waste form.

\subsection{Benefits of Steam Reforming for Hanford UST Wastes}

Pretreating the Hanford UST wastes with steam reforming has a number of potential benefits. First, Hanford tank wastes contain strontium and transuranic waste (TRU) that are complexed with organics that may interfere with separation processes. Organic destruction removes this impediment to efficient separation. In the absence of efficient separation, a low-level waste (LLW) stream that allows a glass vitrification plant to be operated using contact maintenance approaches ( a goal of the revised Tri-Party Agreement) cannot be obtained. Hanford tank wastes may also contain significant quantities of organics within the sludge that is to be sent to the high-level waste (HLW) vitrification facility. Concerns that the high organic content will interfere with the vitrification process through gas generation have been expressed. Hence, destruction of organics within sludge is also potentially desirable. Third, steam reforming can be implemented to resolve tank safety concerns if the current sanctioned approach proves unfeasible. Finally, the large variability in Hanford tank wastes requiring organic destruction (both chemical and physical composition) suggests that organic destruction be performed by a thermal destruction process that has the flexibility to process numerous waste stream compositions, all with significant nitrate/nitrite content. As described below, steam reforming is such a technology.

\subsection{Proposed Steam Reforming System for UST Wastes}

Steam reforming of Hanford UST wastes would be carried out in a moving bed evaporator (MBE) and Synthetica Detoxifier. These units would be supported by other operations collectively referred to as the balance of plant (BOP). A very simplified

\footnotetext{
${ }^{3}$ Primary sources of funding for these efforts were EM-36, Office of Hanford Programs and DOERichland Field Office (RL) in support of Hanford Tank Waste Remediation System (TWRS) work.

${ }^{4}$ W. T. Alumkal, H. Babad, H. D. Harmon, D. D. Wodrich, "The Hanford Site Tank Waste Remediation System: An Update," presented at the Waste Management 1994 Conference, Tucson, Az.

${ }^{5}$ H. Babad, J. L. Deichman, "Hanford High-Activity Waste Tank Safety Issues," presented at the Waste Management 1991 Conference, Tucson, Az.
} 
schematic of the overall operation is shown in Figure 1.1. Radioactive wastes enter the MBE mixed with water and are coated on hot ceramic spheres. The spheres spend approximately 9 minutes flowing down and out the MBE vessel. Hot steam and recycle gas are fed into the bottom of the MBE and flow upward through the bed of coated spheres. The $550^{\circ} \mathrm{C}$ steam exposure converts the sodium nitrate in the waste to sodium hydroxide, oxygen, nitrogen, and oxides of nitrogen. The organics are gasified and partially decomposed; ferrocyanides are destroyed. Carbon dioxide is added to the gases in the MBE to convert the sodium hydroxide to the less corrosive solid product, sodium carbonate. After the ceramic spheres leave the MBE, they are separated from the residual waste solids and pneumatically conveyed to the top of the MBE for recycle. The residual solids may be slurried with water for transport to further processing operations such as strontium and transuranic separations and glass vitrification.

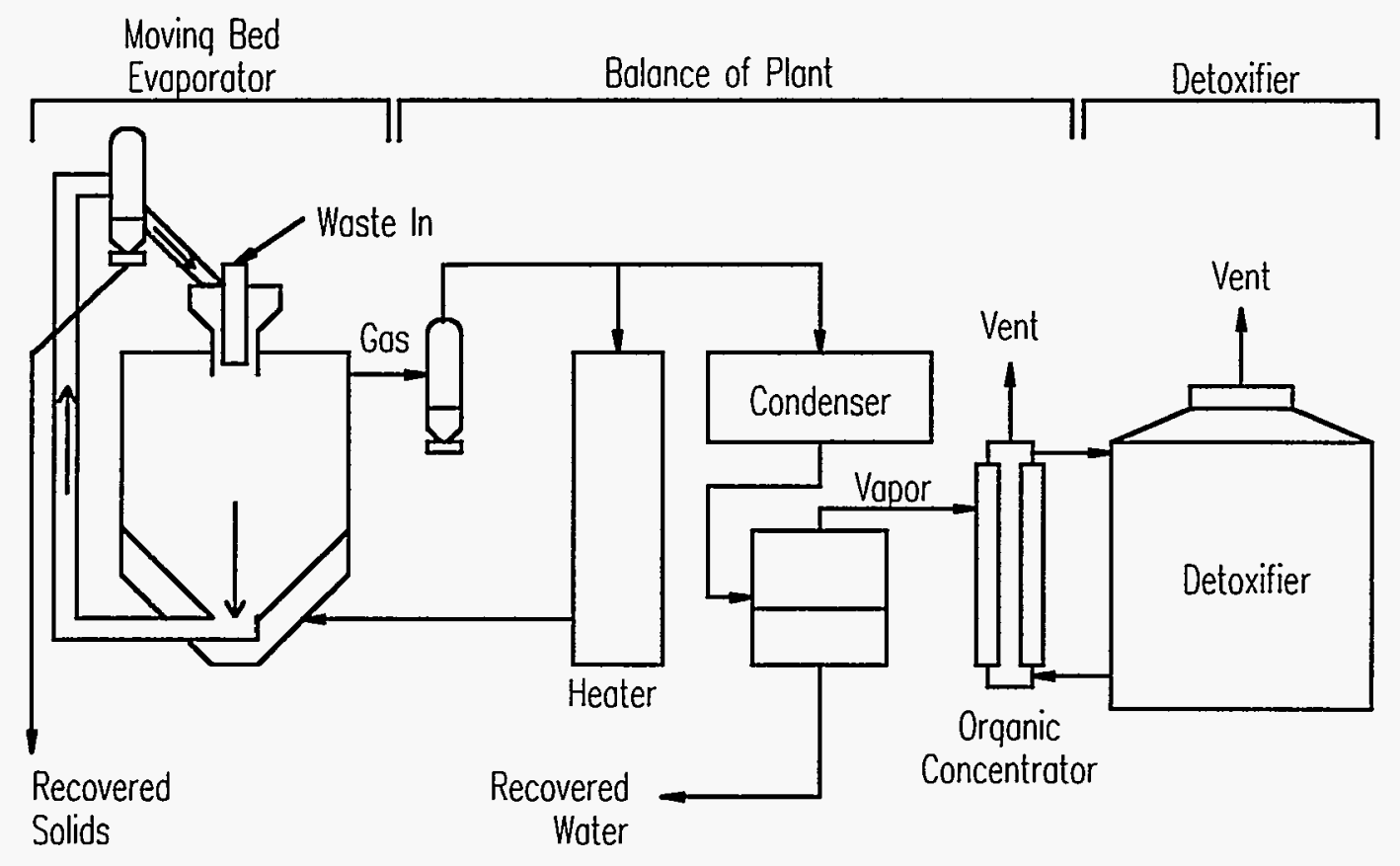

Figure 1.1 Simplified Schematic of Steam Reforming System

The gas stream from the MBE passes through a system to remove any solid particles which may have been entrained in the gas. A portion of this stream is heated and recycled through the MBE. The remainder is cooled and further treated by balance of plant components to recover water and remove any volatilized radionuclides. The organics are removed from the remaining gas stream and sent to the detoxifier where final destruction occurs. The Synthetica detoxifier contains an electrically heated reactor where organics react with and are destroyed by exposure to high temperature $\left(1150^{\circ} \mathrm{C}\right)$ steam. The detoxifier is not an incinerator and oxidative combustion does not occur. 


\subsection{Benefits of Pretreatment with Steam Reforming}

The steam reforming system previously outlined provides numerous benefits compared to competing technologies for treating Hanford tank wastes. These can be summarized as follows:

- Destruction of organics within the solids residue should be greater than $95 \%$; destruction of gasified organics will be greater than $99.99 \%$, consistent with RCRA air emission standards.

- Ferrocyanides will be destroyed.

- Nitrates/nitrites are decomposed.

- The system operates at a pressure near one atmosphere (1 atm). Safety and operational issues associated with high pressure operation are avoided.

- Waste characterization requirements prior to organic destruction are minimal since the process does not require detailed chemical composition control.

- Steam reforming is a non-incineration technology, but rather endothermic and fundamentally stable.

- The process is mechanically simple. Pneumatic conveyance is a proven industrial practice and eliminates the need for moving parts in the waste stream.

- The steam reforming process is amenable to both compact processing unit and fixed site deployment.

- The two stage processing system (a low temperature feed evaporator and a high temperature detoxifier) allows for low temperature initial treatment to minimize radionuclide volatilization and corrosion followed by high temperature, high efficiency organic gas destruction.

- Corrosion associated with processing of molten sodium hydroxide can be mitigated by injecting carbon dioxide into the MBE thereby converting sodium hydroxide to sodium carbonate.

- Volatilization of cesium should be substantially reduced by converting cesium oxides and hydroxides to carbonates through injection of carbon dioxide into the MBE.

- The moving bed evaporator should be tolerant of slurry particulate size variations, minimizing the need for extensive waste slurry preconditioning.

Finally, Synthetica's steam reforming process has been chosen as a thermal destruction process for treating "drummed" low-level and mixed waste. Synthetica has formed a partnership with the Westinghouse subsidiary, Scientific Ecology Group (SEG), to test the applicability of Synthetica's equipment to process various low-level waste streams. While the activities discussed in this document pertain to steam reforming at a different scale than that required for tank wastes, utilization of the same concepts and some of the same equipment apply. For treating drummed wastes, evaporation will occur in a drum feeder rather than in an MBE, and the balance of plant will be unnecessary. The detoxifier will be identical in both applications. Therefore, these activities should provide important operating data and facilitate obtaining regulatory approvals for Hanford tank waste treatment by steam reforming. 


\subsection{Program Approach}

Four parallel paths were pursued in this program to position steam reforming for implementation at Hanford. A chemistry database was developed as was a materials database required for design. A system and components for that system were designed, built and tested, and the applicability of the technology for Hanford UST waste was demonstrated. Experimentation and design were carried out on a variety of scales. These include bench scale, pilot scales $(0.03$ to $0.12 \mathrm{gpm})$, intermediate scale $(0.5 \mathrm{gpm})$, and full scale (5 gpm). A $20 \mathrm{gpm}$ operating limit can be achieved by ganging a number of full scale units together. At each scale tested, instrumentation was used to probe the process and provide information for future design and operation. This approach was adopted to facilitate orderly scaleup of the process and ensure safe and successful operation of the full scale system in a highly radioactive environment. 


\subsection{Chemistry}

A program was undertaken to define the chemistry of steam reforming as it pertains to Hanford UST waste. This effort was combined with mechanical design and development testing to define the appropriate parameters for processing Hanford UST wastes in a steam reforming environment. Important chemistry issues that were identified inchude gasification and destruction of organics, decomposition of nitrates, decomposition of ferrocyanides, volatilization of radionuclides, and the solubility of solid products. As a result of literature searches and bench-scale tests, the following important chemistry insights have been obtained.

- Organic Destruction

- Nitrate/Nitrite Destruction

- Ferrocyanide Destruction

- Radionuclide Vaporization
-Bench-scale simulant studies indicate that $99 \%$ of the organics will be gasified.

-Destruction efficiencies for gasified organics will approach or exceed $99.99 \%$.

-The rate of thermal nitrate destruction can be enhanced by dispersing the nitrate on a surface. $-\mathrm{CO}_{2}$ injection during the steam reforming reaction will generate $\mathrm{Na}_{2} \mathrm{CO}_{3}$ from decomposition of nitrates.

-The thermal decomposition of nitrates will generate some $\mathrm{NO}_{\mathrm{x}}$.

${ }^{*} \mathrm{NO}_{\mathrm{x}}$ may lead to partial regeneration of nitrates during downstream processing and recycle.

* Selection of system parameters may allow maximization of $\mathrm{N}_{2}$ and $\mathrm{O}_{2}$ rather than $\mathrm{NO}_{\mathrm{x}}$.

-Destruction efficiencies exceeding $99 \%$ are expected.

-Explosive decomposition within the steam reforming system will not occur due to the low pressure, high water content, and large thermal mass of the system.

-Radionuclide volatility will be suppressed by steam reforming operating conditions and $\mathrm{CO}_{2}$ injection.

-Volatile radionuclides will be mainly confined to the MBE.

-Cs ion exchange may not be required prior to organic destruction. 
- Sodium Salt Fusion Reactions -MBE operating conditions provide a high temperature, several minute exposure.

$-\mathrm{CO}_{2}$ injection will reduce the solubility of $\mathrm{Sr}$, possibly enhancing its separation to the HLW waste stream.

-Aluminum and chromium compounds may become more soluble, consistent with TWRS pretreatment goals.

These insights are further discussed in sections 2.1 through 2.5 .

\subsection{Organic Destruction}

\subsubsection{Background}

Steam reforming has been used commercially for six decades to produce molecular hydrogen from simple hydrocarbons and has been studied exhaustively for three decades as an important process in the gasification of coal. In the last ten years, extensive investigation has been undertaken to evaluate the process as a way to destroy or generate energy from cellulosic wastes. Most recently, it has been commercialized as a method of destroying hazardous organic wastes.

Production of hydrogen by reaction of simple hydrocarbons with steam was first performed in 1868 without a catalyst ${ }^{6}$ and in 1890 using nickel as the catalyst. ${ }^{7}$ The chemistry of $\mathrm{H}_{2}$ production from hydrocarbons can be illustrated by the reaction of nheptane with superheated steam.

$$
\mathrm{n}-\mathrm{C}_{7} \mathrm{H}_{16}+7 \mathrm{H}_{2} \mathrm{O} \rightarrow 7 \mathrm{CO}+15 \mathrm{H}_{2}
$$

$\mathrm{CO}$ reacts further with both steam and $\mathrm{H}_{2}$.

$$
\begin{aligned}
& \mathrm{CO}+\mathrm{H}_{2} \mathrm{O} \rightarrow \mathrm{CO}_{2}+\mathrm{H}_{2} \\
& \mathrm{CO}+3 \mathrm{H}_{2} \rightarrow \mathrm{CH}_{4}+\mathrm{H}_{2} \mathrm{O}
\end{aligned}
$$

Consumption of $\mathrm{CO}$ and $\mathrm{H}_{2}$ drives reaction (1) strongly towards products. In addition, because the reaction of steam with organics is highly endothermic, steam reforming reactions can be driven essentially to completion by increasing normal operating temperatures by 100 to $200^{\circ} \mathrm{C}$. Finally, formation of carbon and poly nuclear aromatic (PNA) byproducts can be almost completely suppressed by operating with a moderate excess of steam.

Coal (carbon) can be gasified by reaction with oxygen, hydrogen, carbon dioxide, and/or steam. ${ }^{8}$ Unfortunately, the reaction of steam with carbon is quite endothermic. This makes gasification of coal by steam energetically unattractive, even though it yields an attractive product, molecular hydrogen. Therefore, coal gasification is usually performed

\footnotetext{
${ }^{6}$ M. Tessie du Motay and M. Marechal, Bull. Soc. Chim. France, 9 , 334 (1868).

${ }^{7}$ L. Mond and C. Langer, Chem. Zentralbl., II, 32 (1890).

${ }^{8}$ Chemistry of Coal Utilization, 2nd Suppl. Vol., M. A. Elliott, Ed., Wiley-Interscience, New York, 1981, p. 1500 .
} 
with a mixture of steam and air or oxygen so that the exothermicity of the reaction with oxygen (which yields the unattractive product $\mathrm{CO}_{2}$ ), can be used to drive the endothermic reaction with steam. The ability to gasify coal with steam illustrates the capability of steam to gasify intractable organic materials.

Steam gasification of cellulosic wastes has been studied as a way to produce energy and reduce biomass waste volumes. ${ }^{9}$ Cellulosic wastes are not hazardous, and thus studies emphasized energy production rather than high biomass destruction efficiencies.

Never-the-less, the studies do show that steam efficiently gasifies polymeric organic materials and that conversion efficiencies of $90 \%$ can be attained with brief exposures at temperatures near $850^{\circ} \mathrm{C}$.

In 1984, Dr. Terry Galloway founded Thermolytica, the predecessor company to Synthetica Technologies, Inc. to conduct basic and applied studies of steam reforming as a new, non-incineration approach to the destruction of hazardous organic wastes. The studies conducted led to a series of patents including a broad chemistry patent (US Patent $\# 4,874,587)$ for the use of superheated steam to destroy organic wastes. A commercial system capable of treating up to one ton/day of organics was designed, fabricated, extensively tested, and brought to market. Demonstrations performed by Synthetica using their commercial steam reforming system have shown that the destruction efficiency for liquid organic chemicals (e.g., simple hydrocarbons, alcohols, ketones, and chlorocarbons) by steam reforming approaches or exceeds $99.99 \%$. The destruction of a variety of polymeric organic materials (paint residues, caulks, shredded paper, plastics, and wood products; organics adsorbed on soils, debris, and ash) has also been demonstrated.

Steam reforming as applied to organics in tank wastes can be viewed as consisting of two consecutive processes. First the organics are vaporized or gasified in the moving bed evaporator. Then, after some additional processing, the gasified organics are destroyed with high efficiency in the detoxifier. In addition to the effects of high temperature steam, the nitrates in the tank waste are anticipated to play a role in gasifying and destroying the organics in the MBE. Several processes that utilize molten nitrate salts for cleaning metals or destroying wastes have been described. ${ }^{10}$ In addition, the mechanisms of homogeneous reactions involving simple organic acids or esters and molten nitrate salts have been investigated. ${ }^{11}$ More complex systems, for example the reactivity of nitrates with graphite ${ }^{12}$, or nylon, ${ }^{13}$ have also been investigated. These and other studies suggest that

\footnotetext{
9 See for example M. J. Antal et al., A Study of the Steam Gasification of Organic Wastes, Final Progress Report to the U.S. Environmental Protection Agency, Princeton University, Princeton, NJ, 1979.

10 See for example R. H. Shoemaker and W. G. Ward "Production cleaning systems involving molten salt baths" Met. Eng. Quart., 11, 38, (1971), or S. G. Howell and W. R. Birchall U. S. Patent 4,497,782 "Method for Destroying Toxic Chemical Products; Reaction with Molten Alkali Metal Hydroxide and Alkali Metal Nitrate", Feb 5, 1985.

${ }^{11}$ D. H. Kerridge, in The Chemistry of Non-Aqueous Solvents, Vol. VB, J. J. Lagowski, editor, p. 298ff, Academic Press (1978) and references therein.

12 R. W. Bradshaw, "An evaluation of Valve Packing Materials for Long-Term Use in Molten Nitrate Salt" Sandia National Laboratories, SAND86-8207, March 1986.

13 E. G. Bohlmann, "Heat Transfer Salt for High Temperature Steam Generation", Oak Ridge National Laboratory, ORNL-TM-3777, December 1972.
} 
reactions between some of the organic components and the nitrates in the tank waste will occur under the conditions present in the MBE.

\subsubsection{Bench Tests}

Destruction of organics found in tank wastes was examined by both bench and pilot scale tests (see section 5.1) using a tank waste simulant, prepared according to a recipe supplied by Pacific Northwest Laboratories (PNL). ${ }^{14}$ Fifty pounds of the PNL surrogate was prepared in a 55 gallon drum. After the surrogate preparation was completed, the resulting thick slurry, which consisted mainly of metal nitrates but also contained small amounts of EDTA and citric acid as sodium salts, was spiked with 0.2 gmoles each of ndecane, $\mathrm{CCl}_{4}$, and tributyl phosphate.

A set of porous alumina spheres was soaked in a mixture of $\mathrm{CCl}_{4}, \mathrm{n}$-decane, and tributyl phosphate and a second set was soaked in an aqueous solution of the sodium salts of EDTA and citric acid. After being soaked, the spheres were coated with the tank waste surrogate and then exposed to $600^{\circ} \mathrm{C}$ steam in a muffle furnace quartz tube reactor. Both sets of spheres were crushed and analyzed for Total Organic Carbon (TOC) before and after exposure to steam. The analysis gave TOC concentrations of $16,000 \mathrm{ppm}$ before exposure to steam and $160 \mathrm{ppm}$ after exposure. This indicates that $99 \%$ of the organics soaked into and coated onto the spheres were successfully gasified by exposure to the steam.

\subsection{Nitrate Destruction}

\subsubsection{Background}

The complete thermal decomposition of $\mathrm{NaNO}_{3}$ is not well understood. Thermodynamic analysis indicates that $\mathrm{N}_{2}$ and $\mathrm{O}_{2}$ are the thermodynamically favored products and should be formed instead of $\mathrm{NO}_{x}$ if a kinetic pathway exists for their formation and the system is allowed to come to thermodynamic equilibrium.

There is general agreement in the literature that the first reaction in the thermal decomposition of $\mathrm{NaNO}_{3}$ is the loss of oxygen to form $\mathrm{NaNO}_{2}$.

$$
2 \mathrm{NaNO}_{3} \rightarrow 2 \mathrm{NaNO}_{2}+\mathrm{O}_{2}
$$

In fact, at higher temperatures $\left(600-750^{\circ} \mathrm{C}\right)$, the equilibrium between $\mathrm{NaNO}_{3}, \mathrm{NaNO}_{2}$, and $\mathrm{O}_{2}$ has been studied and quantified. ${ }^{15}$ The mechanism of interest therefore becomes the decomposition of $\mathrm{NaNO}_{2}$.

The decomposition of $\mathrm{NaNO}_{2}$ has been reported as probably first producing $\mathrm{NO}_{\mathbf{x}}{ }^{16}$

${ }^{14}$ E. O. Jones, N. G. Colton, and J. R. Bloom, "Hanford Single-shell Tank Waste, Preliminary Pretreatment of Simulated Waste," unpublished report (available from PNL).

${ }_{15}$ E. S. Freeman, J. Phys. Chem., 60, 1487 (1956).

${ }^{16}$ C.C. Addison and N. Logan, "Anhydrous Metal Nitrates," Adv. Inorg. Chem. Radiochem., $\underline{6} 71$ (1964). 


$$
\begin{aligned}
& 2 \mathrm{NaNO}_{2} \rightarrow \mathrm{Na}_{2} \mathrm{O}+\mathrm{N}_{2} \mathrm{O}_{3} \\
& \mathrm{~N}_{2} \mathrm{O}_{3} \rightarrow \mathrm{NO}_{2}+\mathrm{NO}
\end{aligned}
$$

The $\mathrm{NO}_{\mathrm{x}}$ can then undergo further reactions. ${ }^{17}$

$$
\begin{aligned}
& 2 \mathrm{NaNO}_{2}+2 \mathrm{NO} \rightarrow 2 \mathrm{NaNO}_{3}+\mathrm{N}_{2} \\
& \mathrm{Na}_{2} \mathrm{O}+2 \mathrm{NO}_{2} \rightarrow \mathrm{NaNO}_{2}+\mathrm{NaNO}_{3} \\
& \mathrm{NaNO}_{2}+\mathrm{NO}_{2} \leftrightarrow \mathrm{NaNO}_{3}+\mathrm{NO}
\end{aligned}
$$

At least reaction 6 is reversible. The net result of these reactions is the production of $\mathrm{NaNO}_{3}$ and $\mathrm{N}_{2}$. When coupled with the decomposition of $\mathrm{NaNO}_{3}$ to $\mathrm{NaNO}_{2}$, the net result is the conversion of $\mathrm{NaNO}_{3}$ to $\mathrm{Na}_{2} \mathrm{O}, \mathrm{N}_{2}$ and $\mathrm{O}_{2}$. In the presence of steam, $\mathrm{Na}_{2} \mathrm{O}$ will convert to $\mathrm{NaOH}$; in the presence of $\mathrm{CO}_{2}$ it will convert to $\mathrm{Na}_{2} \mathrm{CO}_{3}$.

Many other reactions, some involving the direct conversion of $\mathrm{NaNO}_{3}$ to products other than $\mathrm{NaNO}_{2}$, have been postulated in the literature. ${ }^{18} \mathrm{~N}_{2} \mathrm{O}$ has also occasionally been reported as being a product of nitrate decomposition. ${ }^{19,20}$ Although reaction mechanisms were not reported, $\mathrm{N}_{2} \mathrm{O}$ can be produced from $\mathrm{NO}_{\mathrm{x}}$, especially in the presence of a catalyst or a reducing agent such as $\mathrm{SO}_{2}{ }^{21}$

The reactions above illustrate one possible route for $\mathrm{NaNO}_{3}$ decomposition. In reality, it is likely that many of the above reactions occur in parallel with others such as the reaction of nitrogen dioxide to nitric oxide and oxygen.

$$
2 \mathrm{NO}_{2} \leftrightarrow 2 \mathrm{NO}+\mathrm{O}_{2}
$$

The dominant reactions and hence dominant products may well be determined by system conditions such as residence time or temperature. For example, in reactions 2-6 above, the decomposition first yields $\mathrm{NO}_{\mathrm{x}}$. The $\mathrm{NO}_{\mathrm{x}}$ is then consumed by consecutive reactions that eventually lead to the formation of $\mathrm{N}_{2}$ and $\mathrm{O}_{2}$. Note that according to the reaction scheme shown, $\mathrm{N}_{2}$ and $\mathrm{O}_{2}$ are only the ultimate products if the reaction is carried out in a closed system. That is, if $\mathrm{NO}_{\mathrm{x}}$ is removed from the reaction chamber as it is formed, the consecutive $\mathrm{NO}_{\mathrm{x}}$ destroying reactions will not occur. This suggests that system parameters such as residence time and recycle ratio may be manipulated to favor the formation of the environmentally benign and desirable products $\mathrm{N}_{2}$ and $\mathrm{O}_{2}$.

Although the desired chemistry of nitrate destruction in the MBE is the conversion of nitrate ion into $\mathrm{N}_{2}$ and $\mathrm{O}_{2}$ gas, the extent to which this chemistry can be maximized is uncertain. It is therefore useful to consider the implications of and options for dealing with $\mathrm{NO}_{\mathrm{x}}$ production in the MBE. There are two issues associated with the production of $\mathrm{NO}_{\mathrm{x}}$. First, $\mathrm{NO}_{2}$ will likely be captured and converted to nitric acid by water condensed downstream of the MBE.

$$
3 \mathrm{NO}_{2}+\mathrm{H}_{2} \mathrm{O} \rightarrow 2 \mathrm{HNO}_{3}+\mathrm{NO}
$$

${ }^{17}$ K.H. Stern, J. Phys. Chem. Ref. Data, 1, 747 (1972) and references therein.

${ }^{18}$ C. M. Kramer et al., High Temperature Science, 16, 257 (1983).

19 H. R. Bartos, J. L. Margrave, J. Phys. Chem., 160, 256 (1956).

${ }^{20}$ R. W. Brown, J. H. Lippiat, D. Price, D. C. A. Izod, Intl. J. Mass Spect. Ion Phys., 16, 101 (1975).

21 A. N. Hayhurst, A. D. Lawrence, Prog. Energy Combust. Sci., 18, 529 (1992). 
The reverse of reaction 7 drives this process further to the right. Obviously, these reactions negatively impact the overall nitrate destruction efficiency. The fact that the water is slated for recycle (see section 4.2.1) complicates matters even further. The magnitude of this problem will be determined by the relative amounts of nitrate that are converted to $\mathrm{NO}_{x}$ and $\mathrm{N}_{2}$ in the MBE and the operation of the condenser and scrubber systems. $\mathrm{NO}_{\mathrm{x}}$ will probably also interact with the gas adsorption media in the gas separation system (section 4.2.3.2). The second issue is probable limitations on the amount of $\mathrm{NO}_{x}$ that can be released to the environment.

There are two basic approaches to $\mathrm{NO}_{\mathrm{x}}$ treatment: chemical treatment with a reducing agent, and absorption into a scrubbing solution. A third option is to prevent the formation of $\mathrm{NO}_{x}$ by directly reacting the nitrate with a reducing agent. The issue of nitrate destruction efficiency can only be addressed through chemical reduction. Emission limitations can be addressed by either method. Therefore, as the efficiency of the conversion of nitrate to $\mathrm{N}_{2}$ in the MBE increases, more options become available.

Chemical reduction of $\mathrm{NO}_{\mathrm{x}}$ may be either catalytic or non-catalytic and selective or nonselective. Non-catalytic reduction can be carried out selectively with $\mathrm{NH}_{3}$ at $800-1000$ ${ }^{\circ} \mathrm{C}$. ${ }^{22}$ The high temperature makes this approach unattractive for our purposes. Catalytic reduction may be carried out selectively with $\mathrm{NH}_{3}$ at $250-500^{\circ} \mathrm{C}$ or non-selectively with hydrocarbons at $450-800^{\circ} \mathrm{C}$. Recalling that the desired chemistry is the conversion of nitrate into $\mathrm{N}_{2}$ and $\mathrm{O}_{2}$ in the $\mathrm{MBE}$, the non-selective catalytic approach is also inappropriate for our purposes since the gas stream can contain a maximum of $3 \% \mathrm{O}_{2}$ to protect the catalyst from overheating. ${ }^{23}$ Furthermore, the catalytic approach in general is unattractive due to potential problems such as poisoning or contamination of the catalyst bed. The disadvantages of scrubbing methods are related to the scrub liquor and include concerns about cost, regeneration, quantity, and environmental impact. ${ }^{24}$

Given the limitations of $\mathrm{NO}_{\mathrm{x}}$ treatment technologies, the best course of action if an acceptable level of $\mathrm{NO}_{3}$ to $\mathrm{N}_{2}$ conversion is not achieved in the $\mathrm{MBE}$ is probably the direct reduction of the nitrate. Ammonia and ammonium compounds have been reported to reduce nitrates directly to $\mathrm{N}_{2}$ at temperatures of $300-600^{\circ} \mathrm{C}$. $^{25}$ Coke has also been successfully used to directly reduce nitrates to $\mathrm{N}_{2}$ although higher temperatures were required. ${ }^{26}$

\subsubsection{Bench Tests}

Thermogravimetric Analysis (TGA) was used to study the thermal decomposition of sodium nitrate. The nitrate was studied in the bulk crystalline form, and dispersed on the

22 J. D. Mobley, K. J. Lim in Handbook of Air Pollution Technology, S. Calvert, H. M. Englund, eds. Wiley \& Sons, New York (1984).

${ }^{23}$ B. Bretschneider, J. Kurfürst, Air Pollution Control Technology, Elsevier, New York (1987).

${ }^{24}$ M. Thiemann, E. Scheibler, K. W. Wiegand in Ulmann's Encyclopedia of Industrial Chemistry, 5th ed., Vol. A17, B. Elvers, S. Hawkins, G. Schulz, eds., VCH (1991).

${ }^{25}$ J. M. Dotson, T. E. Peters, U. S. Patent 3,862,296 (1975).

${ }^{26}$ L. J. Meile, A. J. Johnson, "Waste Generation Reduction - Nitrates FY 1982 Status Report," Rockwell International, RFP-3465, DOE/TIC-4500 (Rev. 72), January 1984. 
surface of silica. These studies suggested that the decomposition of $\mathrm{NaNO}_{3}$ could be significantly enhanced by dispersal of the nitrate on a surface. Steam also seemed to have a small positive effect on the decomposition.

The conclusion that dispersal of sodium nitrate on a surface enhances its decomposition was verified at the bench scale using a muffle furnace quartz tube reactor. The effect was examined as follows. First, $1 / 4$ inch diameter non-porous vitrified alumina spheres were dipped in a sodium nitrate solution and then air dried many times, thereby coating the spheres with sodium nitrate. Next, the coated spheres were exposed to $600{ }^{\circ} \mathrm{C}$ steam for about 30 minutes in the quartz reactor. Then, small representative samples of uncoated spheres, coated spheres, and coated spheres that had been exposed to steam were crushed and analyzed for nitrate ion by EPA Method 300 which utilizes Ion Chromatography (IC). These analyses gave a nitrate ion level of $1425 \mathrm{mg} /(\mathrm{kg}$ crushed spheres) for the coated spheres not exposed to steam and $<5 \mathrm{mg} / \mathrm{kg}$ (the detection limit) for the other samples. Thus, dispersing the sodium nitrate on the surface of alumina spheres led to complete decomposition of the nitrate. In contrast, when a porcelain boat containing sodium nitrate crystals was exposed to $600^{\circ} \mathrm{C}$ steam for 30 minutes in the quartz tube reactor, a weight loss of only $12 \%$ resulted. Complete conversion to sodium hydroxide would have produced a weight loss of $64 \%$.

To support pilot plant studies (chapter 5), the rate of $\mathrm{NaNO}_{3}$ decomposition was examined using a small fluidized bed reactor. Specifically, $\alpha$-alumina was coated with sodium nitrate ( $4 \mathrm{wt} \% \mathrm{NaNO}_{3}$ on $-60 /+100$ mesh $\alpha$-alumina) using a Rotavac. Samples of this material weighing $0.5 \mathrm{~g}$ were dropped into a $100 \mathrm{~g}$ fluidized bed of alumina that had been preheated to the desired reaction temperature. For most sample drops, the fluidizing gas was 2:1 v/v steam in $\mathrm{Ar}$, although for some drops the mixture included $\mathrm{CO}$ or $\mathrm{CO}_{2}$. $\mathrm{CO}$ was added to examine the effect of scavenging $\mathrm{O}_{2}$ with $\mathrm{CO}$ on the rate of nitrate decomposition. $\mathrm{CO}_{2}$ was added to examine the effect of converting $\mathrm{Na}_{2} \mathrm{O}$ or $\mathrm{NaOH}$ to $\mathrm{Na}_{2} \mathrm{CO}_{3}$. Gases exiting the bed were analyzed at 3 second intervals by mass spectrometry. A cold trap in the exhaust line condensed steam and collected $\mathrm{NO}_{2}$ for IC analysis.

At $550{ }^{\circ} \mathrm{C}$ in a mixture of steam and argon, greater than $95 \%$ decomposition of $\mathrm{NaNO}_{3}$ could be obtained in 10 minutes. Neither steam nor $\mathrm{CO}_{2}$ affected the reaction rate at this temperature. However the addition of $\mathrm{CO}$ as an oxygen scavenger increased the rate of reaction. Use of silica both as the bed material and as the support for the $\mathrm{NaNO}_{3}$ produced significant decomposition (23\%) of $\mathrm{NaNO}_{3}$ at a substantially lower temperature, $450^{\circ} \mathrm{C}$. However, subsequent drops led to less and less decomposition, possibly due to the consumption of the acids present on the surface of the uncoated silica in the fluidized bed, since the acidity of silica surfaces is reported to enhance the decomposition of nitrate. $^{27}$

${ }^{27}$ Y. Hoshino et al., Bull. Chem. Soc. Japan, 54, 1385 (1981). 


\subsection{Ferrocyanide Destruction}

Some of the USTs at Hanford are known to contain solid precipitates of Disodium Nickel Ferrocyanide $\left(\mathrm{Na}_{2} \mathrm{Ni}\left[\mathrm{Fe}(\mathrm{CN})_{6}\right]\right)$ and Dicesium Nickel Ferrocyanide $\left(\mathrm{Cs}_{2} \mathrm{Ni}\left[\mathrm{Fe}(\mathrm{CN})_{6}\right]\right)$ in sludge and/or solid deposits which are rich in Sodium Nitrate and Sodium Nitrite. It is well known that mixtures of ferrocyanides with nitrates and/or nitrites can and do react exothermically at elevated temperatures. ${ }^{28-32}$ It has also been shown ${ }^{29,32}$ that under certain conditions such mixtures can react violently.

The chemistry occurring in these systems is neither well known nor well understood. A list of potential reactions is shown in Table 2-1. Reactions marked with an asterisk $\left({ }^{*}\right)$ are the simplest, theoretically most energetic reactions of the pure materials. The $\mathrm{FeCN}$ indicates either $\mathrm{Na}_{2} \mathrm{Ni}\left[\mathrm{Fe}(\mathrm{CN})_{6}\right]$ or $\mathrm{Cs}_{2} \mathrm{Ni}\left[\mathrm{Fe}(\mathrm{CN})_{6}\right]$. Any or all of the reactions in Table 2-1 could be significant. Extensive discussions of these and other possible reactions are found in references 25-29 as well as in documents referenced therein. It is apparent, from the studies referenced, that reactions between the ferrocyanide and the oxidizer(s) begin at temperatures as low as $220^{\circ} \mathrm{C}$. The precise temperature at which these reactions begins varies depending on a variety of parameters such as sample purity, ratio of $\mathrm{NaNO}_{3}$ to $\mathrm{NaNO}_{2}$, rate of heating, etc. Also, the reactions occurring while the oxidizer(s) is/are molten may or may not be the same as when the oxidizers have decomposed to gaseous products. In fact there is evidence ${ }^{29}$ that the reaction mechanisms do change at temperatures above $\sim 300^{\circ} \mathrm{C}$.

Given that the studies cited have shown that exothermic reactions can be induced in the ferrocyanide tank wastes at temperatures as low as $220^{\circ} \mathrm{C}$, and that extensive reactions between the ferrocyanides and oxidizers can be expected at higher temperatures, there is little question that thermal treatment of these wastes will result in destruction of the ferrocyanides. Since the residence time for the ferrocyanides within the MBE will be several minutes at temperatures of $550^{\circ} \mathrm{C}$, an efficiency that exceeds $99 \%$ is not unreasonable to expect. However, the destruction efficiency of ferrocyanides in the steam reforming system will likely be dependent on both the nature of the tank waste, which may change from tank to tank, and the residence time of the waste in the MBE. Reduced efficiencies may occur as the fuel/oxidizer ratio becomes either very low or very high

\footnotetext{
${ }^{28}$ Burger, L.L., and Scheele, R.D., "The Reactivity of Cesium Nickel Ferrocyanide Towards Nitrate and Nitrite Salts," PNL-7550, Pacific Northwest Laboratory, Richland, Washington, September, 1991.

${ }^{29}$ Scheele, R.D., and Cady, H.H., "Preliminary Safe-Handling Experiments on a Mixture of Cesium Nickel Ferrocyanide and Equimolar Sodium Nitrate/Nitrite," PNL-7928, Pacific Northwest Laboratory, Richland Washington, January, 1992.

30 Scheele, R.D., et. al., "Chemical Reactivity of Potential Ferrocyanide Precipitates in Hanford Tanks With Nitrates and Nitrites," PNL-SA-19971, Pacific Northwest Laboratory, March 1992, Presented at the Waste Management ' 92 Conference, March 1-5, 1992, Tucson, AZ.

31 Scheele, R.D., et. al., "Hanford Ferrocyanide Waste Chemistry and Reactivity-Preliminary Catalyst and Initiator Screening Studies," PNL-8089, Pacific Northwest Laboratory, Richland, Washington, May, 1992.

32 Jeppson, D.W., and Wong, J.J., "Ferrocyanide Waste Simulant Characterization," WHC-EP-0631, Westinghouse Hanford Company, Richland, Washington, January, 1993.
} 
where the excess of either fuel or oxidizer becomes a heat sink to keep the local reaction temperatures low.

Further examination of the literature leads to the conclusion that conditions in the steam reforming system will not lead to explosive decomposition. Explosive decomposition does not occur in ferrocyanide/nitrate/nitrite waste simulants if the simulant contains more than $12 \mathrm{wt} \%$ water, if the system is at atmospheric pressure, if ferrocyanide/salt ratios are below 0.1 , and/or if energy transfer to the environment is efficient. Therefore in the steam

\begin{tabular}{|c|c|}
\hline 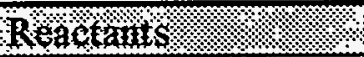 & Poulusts. \\
\hline $\mathrm{NaNO}_{3}, \mathrm{FeCN}$ & $\mathrm{FeO}, \mathrm{NiO}, \mathrm{CO}_{2}, \mathrm{~N}_{2}, \mathrm{Na}$ and/or $\mathrm{Cs}$ Hydroxides \\
\hline $\mathrm{NaNO}_{3}, \mathrm{FeCN}$ & $\mathrm{FeO}, \mathrm{NiO}, \mathrm{CO}_{2}, \mathrm{~N}_{2}, \mathrm{Na}$ and/or Cs Carbonates \\
\hline $\mathrm{NaNO}_{3}, \mathrm{FeCN}$ & $\mathrm{FeO}, \mathrm{NiO}, \mathrm{CO}_{2}, \mathrm{~N}_{2}, \mathrm{Na}$ and/or Cs Oxides \\
\hline $\mathrm{NaNO}_{2}, \mathrm{FeCN}$ & $\mathrm{FeO}, \mathrm{NiO}, \mathrm{CO}_{2}, \mathrm{~N}_{2}, \mathrm{Na}$ and/or Cs Hydroxides \\
\hline $\mathrm{NaNO}_{2}, \mathrm{FeCN}$ & $\mathrm{FeO}, \mathrm{NiO}, \mathrm{CO}_{2}, \mathrm{~N}_{2}, \mathrm{Na}$ and/or Cs Carbonates \\
\hline $\mathrm{NaNO}_{2}, \mathrm{FeCN}$ & $\mathrm{FeO}, \mathrm{NiO}, \mathrm{CO}_{2}, \mathrm{~N}_{2}, \mathrm{Na}$ and/or $\mathrm{Cs}$ Oxides \\
\hline $\mathrm{NaNO}_{3}, \mathrm{FeCN}$ & $\mathrm{FeO}, \mathrm{NiO}, \mathrm{CO}, \mathrm{N}_{2}, \mathrm{Na}$ and/or $\mathrm{Cs}$ Hydroxides \\
\hline $\mathrm{NaNO}_{3}, \mathrm{FeCN}$ & $\mathrm{FeO}, \mathrm{NiO}, \mathrm{CO}, \mathrm{NO}, \mathrm{Na}$ and/or Cs Hydroxides \\
\hline$* 6 \mathrm{NaNO}_{3}+\mathrm{FeCN}$ & $\left(\mathrm{Cs}_{2} \mathrm{O}\right.$ or $\left.\mathrm{Na}_{2} \mathrm{O}\right)+3 \mathrm{Na}_{2} \mathrm{O}+\mathrm{NiO}+\mathrm{FeO}+6 \mathrm{CO}_{2}+6 \mathrm{~N}_{2}$ \\
\hline$* 10 \mathrm{NaNO}_{2}+\mathrm{FeCN}$ & $\left(\mathrm{Cs}_{2} \mathrm{O}\right.$ or $\left.\mathrm{Na}_{2} \mathrm{O}\right)+5 \mathrm{Na}_{2} \mathrm{O}+\mathrm{NiO}+\mathrm{FeO}+6 \mathrm{CO}_{2}+6 \mathrm{~N}_{2}$ \\
\hline
\end{tabular}

Table 2-1 Potential Reactions of Ferrocyanide with Nitrates and/or Nitrites

reforming system ferrocyanide destruction should not be explosive for the following reasons:

- The waste slurry entering the moving bed evaporator will have a water content that greatly exceeds $12 \%$ by weight.

- The MBE operates at atmospheric pressure.

- The steam atmosphere and ceramic spheres in the MBE provide a large heat sink.

- The ferrocyanides will decompose in a thin film dispersed on the surface of ceramic spheres so that the energy of decomposition is efficiently transferred away.

\subsection{Radionuclide Vaporization}

Much of the work on high temperature volatilization of radionuclear elements has been theoretical and has focused on the temperature ranges expected for severe loss-of-coolantaccidents ( LOCA ). ${ }^{33,34}$ In the case of the severe LOCA, the extreme heating of the core $\left(1500-3000^{\circ} \mathrm{C}\right)$ results in the volatilization of a variety of fission products as well as of the fuel itself. In the Hanford steam reforming system, the temperatures are considerably lower than those expected in a LOCA. The species of primary concern are the oxides

${ }^{33}$ D. Cubicciotti and B. R. Sehgal, "Vapor Transport of Fission Products in Postulated Severe Light Water Reactor Accidents," Nuclear Technology, 65, 266, May 1984.

${ }^{34}$ D. Cubicciotti and B. R. Sehgal, "Vaporization of Core Materials in Postulated Severe Light Water Reactor Accidents," Nuclear Technology, 67, 191, Nov. 1984. 
and/or hydroxides of radioactive Cs and Sr. However, other radioactive species including iodine and oxides and hydroxides of $\mathrm{U}, \mathrm{Pu}, \mathrm{Te}$ and $\mathrm{Ru}$ will also be present.

Data calculated for Cesium species using the VICTORIA ${ }^{35}$ code in the temperature range of the moving bed evaporator are presented in Table 2-2. The code, which is a model for the behavior of radionuclides in a severe LOCA, uses thermochemical data for the species of interest to calculate the vapor pressures. The code indicates that species with high vapor pressures at the operating temperatures of the $\mathrm{MBE}$ include cesium peroxide, $(\mathrm{CsO})_{2}$, ruthenium tetroxide, $\mathrm{RuO}_{4}$, and iodine, $\mathrm{I}_{2}$.

\begin{tabular}{|c|c|c|c|}
\hline spectes 1 & $\% \%,-40 \mathrm{~s} \%$ & $600 \% 0$ & 00.20 \\
\hline $\mathrm{Cs}$ & 0.12 & 0.44 & 1.1 \\
\hline $\mathrm{Cs}_{2} \mathrm{O}$ & 0.0002 & 0.007 & 0.1 \\
\hline$(\mathrm{CsO})_{2}$ & 0.13 & 0.5 & 1.8 \\
\hline $\mathrm{CsOH}$ & 0.0006 & 0.005 & 0.03 \\
\hline$(\mathrm{CsOH})_{2}$ & 0.0003 & 0.002 & 0.02 \\
\hline
\end{tabular}

Table 2-2 Vapor Pressure (in atmospheres) of Cesium Species Calculated using VICTORIA Code

Similar predictions are made by the work of Cubicciotti and Sehgal. ${ }^{33,34}$ An application of their data to the temperature range of the MBE is shown in Table 2-3.

\begin{tabular}{|c|c|c|c|c|c|}
\hline \multirow[b]{2}{*}{ Fissiom rraduct } & \multicolumn{2}{|c|}{ Constants $S^{6} \%$} & \multicolumn{3}{|c|}{ Concentual ton } \\
\hline & 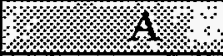 & $\mathrm{B}$ & $500 \%$ & $12600 . \mathrm{C}$ & $1700 \%$ \\
\hline $\begin{array}{c}\text { Ruthenium [RuOH \& } \\
\left.\text { Ru(OH })_{2}\right]\end{array}$ & $-35,710$ & 11.78 & $3.8 \times 10^{-35}$ & $7.5 \times 10^{-30}$ & $1.2 \times 10^{-25}$ \\
\hline $\begin{array}{c}\text { Tellurium }[\mathrm{TeOH} \& \\
\left.\mathrm{Te}(\mathrm{OH})_{2}\right]\end{array}$ & $-9,495$ & 0.00 & $5.2 \times 10^{-13}$ & $1.3 \times 10^{-11}$ & $1.7 \times 10^{-10}$ \\
\hline Iodine [CsI] & $-8,570$ & 4.71 & $4.2 \times 10^{-7}$ & $7.8 \times 10^{-6}$ & $8.0 \times 10^{-5}$ \\
\hline $\begin{array}{c}\text { Cesium }[\mathrm{CsOH} \& \\
\left.(\mathrm{CsOH})_{2}\right]\end{array}$ & $-4,515$ & 2.53 & $4.9 \times 10^{-4}$ & $2.3 \times 10^{-3}$ & $7.8 \times 10^{-3}$ \\
\hline $\begin{array}{c}\text { Strontium [SrOH \& } \\
\left.\operatorname{Sr}(\mathrm{OH})_{2}\right]\end{array}$ & $-18,405$ & 2.02 & $1.6 \times 10^{-22}$ & $8.7 \times 10^{-20}$ & $1.3 \times 10^{-17}$ \\
\hline
\end{tabular}

${ }^{a}$ Species in brackets identify those species which are believed to be the most prevalent under the conditions studied.

b The equation used was $\log B=A / T+B$, where $R$ is the equilibrium ratio of moles of fission product in the gas phase to moles of $\left(\mathrm{H}_{2} \mathrm{O}+\mathrm{H}_{2}\right)$ in the gas phase and $\mathrm{T}$ is temperature.

- Cubicciotti and Sehgal's work applied to conditions where concentrations of $\mathrm{H}_{2}$ were expected to be large. See references 33 and 34 for a full set of conditions.

Table 2-3 Concentrations of Radionuclides in High Temperature Steam

${ }^{35}$ T. J. Heames, et. al.; "VICTORIA: A Mechanistic Model of Radionuclide Behavior in the Reactor Coolant System Under Severe Accident Conditions," NUREG/CR-5545, SAND90-0756, Rev. 1; Sandia National Laboratories, December, 1992. 
The species listed are those expected to be prevalent in a steam $/ \mathrm{H}_{2}$ environment. It should be noted that Cubicciotti and Sehgal's data apply most strictly to severe LOCA conditions. Their calculations attempt to account for the presence of hydrogen in the steam atmosphere and the reactions it might undergo with volatilized species. Relatively little hydrogen is expected in the steam reforming system. Therefore the calculated concentrations in Table 2-3 are more appropriately visualized as being in relatively pure steam.

Despite the indication that some radionuclide species have higher vapor pressures at MBE operating temperatures, a close analysis of the data suggests that the radionuclides will be present in less volatile forms at the conditions present in the steam reforming system. Therefore most of the radioactive species will be confined to the MBE. For example, consistent with Cubicciotti and Sehgal, thermodynamic equilibria calculations performed using the software HSC Chemistry, indicate that the more volatile cesium peroxide will convert to the less volatile hydroxide species in the presence of excess steam. The same calculations indicate that conversion of the hydroxide to carbonate suppresses the volatility even more. Molecular iodine is not expected to be a problem for two reasons. First, iodine is expected at only very low levels. Second, the iodine is likely to exist as a salt with either $\mathrm{Cs}$ or $\mathrm{Na}$, neither of which is expected to exhibit significant vapor pressure at the MBE's operating temperature (Table 2-3).

Regarding ruthenium tetroxide, studies have shown ${ }^{36-38}$ that $\mathrm{RuO}_{4}$ is readily volatilized from nitric acid solutions with volatilization being most pronounced when the nitric acid is $\sim$ 8-13 molar. However, there are indications that conditions in the MBE will suppress the volatilization of the $\mathrm{Ru}$. Cubicciotti and Sehgal's work indicates that the most prevalent $\mathrm{Ru}$ species should be the less volatile hydroxides. Furthermore, although there is ample evidence of the volatility of $\mathrm{RuO}_{4}$ from nitric acid solutions, it has also been observed ${ }^{36}$ that the volatility is suppressed in fuming nitric acid (nitric acid saturated with $\mathrm{NO}_{2}$ ). This same study showed that volatility was suppressed by the addition of $\mathrm{NaNO}_{2}$ to the nitric acid solutions. In these cases the suppression is believed to occur due to gas phase reactions of the $\mathrm{RuO}_{4}$ with $\mathrm{NO}$ and/or $\mathrm{NO}_{2}$ to form $\mathrm{RuO}_{2}$ which is both less volatile than the tetroxide and soluble in fused $\mathrm{NaOH}$. Other studies ${ }^{38}$ carried out in the temperature range $\sim 120-160^{\circ} \mathrm{C}$ suggest that $\mathrm{RuO}_{4}$ is susceptible to thermal degradation to $\mathrm{RuO}_{2}$.

Thus, indications are that the majority of the radionuclides will not migrate downstream from the MBE to balance of plant equipment. In the event that radioisotopic materials do escape the MBE, balance of plant components, specifically filters and a venturi scrubber, should prevent those species from contaminating the high temperature steam reforming

${ }^{36}$ T. Sato, "Volatilization Behavior of Ruthenium From Boiling Nitric Acid," Journal of Radioanalytical Chemistry, 129, 77, 1989.

37 A. Sasahira and F. Kawamura, "Formation Rate of Ruthenium Tetroxide During Nitric Acid Distillation," Journal of Nuclear Science and Technology, 25, 603, 1988.

${ }^{38}$ M. Philippe, J. P. Mercier, J. P. Gue, "Behavior of Ruthenium In The Case Of Shutdown Of The Cooling System Of HLLW Storage Tanks," 21st DOE/NRC Nuclear Air Cleaning Conference; NUREG/CP-0116, Vol. 2. 
reactor. This should relax shielding and design requirements for downstream processing and simplify maintenance operations.

\subsection{Sodium Salt Fusion Reactions}

There is ample evidence in the literature ${ }^{39-49}$ that molten sodium salts, including the hydroxide and nitrate salts, either alone or in mixtures with other salts will quite efficiently solubilize refractory oxides of many metals including $\mathrm{Al}, \mathrm{Cr}, \mathrm{Fe}, \mathrm{Si}$ as well as $\mathrm{U}, \mathrm{Pu}$ and other radionuclides. Dissolution of metal oxides or hydroxides in molten sodium or potassium salts ordinarily results in the formation of oxy-anions of the metals of interest, which in turn form soluble compounds with the $\mathrm{Na}^{+}$or $\mathrm{K}^{+}$counter ions. The compounds thus formed are generally more soluble than the parent compounds in aqueous or acidified aqueous solution. Such a fused matrix could be subjected to additional treatment to render the fused wastes water soluble and treatable with ion-exchange. This could ultimately lead to a decrease in the volume of vitrified high level waste. Under the proper conditions sodium fusion reactions are expected in the steam reforming environment. However, the low operating temperature of the $\mathrm{MBE}$ and the injection of $\mathrm{CO}_{2}$ into the $\mathrm{MBE}$ as well as the limited residence time will all likely impact these reactions. The formation of carbonates will likely enhance the solubility of actinides, however, it will greatly decrease the solubility of Sr. Thus Sr separation might be achieved via precipitation. Experiments to determine the degree of $\mathrm{Na}$ fusion reactions occurring in the $\mathrm{MBE}$ and the impact of temperature and $\mathrm{CO}_{2}$ injection on them remain to be carried out.

39 C. E. Hedrick, "Dissolution of Silicon Carbide-Coated Uranium-Thorium Carbide Fuel Pellets," NBL 265, 28, October, 1972.

${ }^{40}$ H. Zibulsky, J. S. Paller and T. J. Siddons "Dissolution of Silicon Carbide-Coated Uranium-Thorium Carbide Fuel Pellets-Ignition and Sodium Carbonate and Sodium Bisulfate Fusion Procedure," NBL 265 , 32, October, 1972.

41 J. W. Koenst, Jr., E. L. Lewis and D. F. Luthy, "Decontamination of HEPA Filters," 15th DOE Nuclear Air Cleaning Conference, Boston, MA, August, 1978.

${ }^{42}$ F. W. Postma, Jr., and R. E. Barringer, "A Dissolution Study of High-Fired BeO-UO 2 Ceramics by Fusion," Union Carbide Nuclear Co., Report No.: Y-1377, Feb. 1962.

${ }^{43}$ G. W. C. Milner and D. Crossley, "The Rapid Dissolution of Plutonium Dioxide by a Sodium PeroxideSodium Hydroxide Fusion, Followed by Determination of the Plutonium Content by Controlled Potential Coulometry," Analyst, 93, 429, July, 1968.

44 J. A. Pierret, H. A. Wilhelm, "Caustic Fusion of Columbite-Tantalite Concentrates With Subsequent Separation of Niobium and Tantalum," ISC-796, Iowa State College, Ames Laboratory, August, 1956.

45 N. Ramasubramanian "Oxide Ion Chemistry and Corrosion in Molten Alkali Nitrates and Nitrites," Proceedings of the Fourth International Symposium on Molten Salts, Vol. 84-2, 474, 1984.

${ }_{46}$ G. S. Picard, H. M. Lefebvre, B. L. Tremillon, "Thermodynamic Study of Iron Corrosion In $\mathrm{NaNO}_{3}-$ $\mathrm{NaNO}_{2}$ Mixtures," Proceedings of the Fifth International Symposium on Molten Salts, Vol. 86-1, 428, 1985.

${ }^{47}$ R. L. Barrett, "Refractories in the Presence of Fluxes," High Temperature Chemistry of Inorganic and Ceramic Materials; F. P. Glasser, P. E. Potter, Editors; The Chemical Society, London, 1976.

48 Robert A. Rapp, "Hot Corrosion of Materials," Selected Topics in High Temperature Chemistry; $O$. Johannesen, Editor; Elsevier, 1989. 
49 William J. Knapp, "Structural Aspects of Liquid Silicates,". Selected Topics in High Temperature Chemistry; T. Forland, K. Grjotheim, K. Motzfeldt, S. Urnes, Editors; Scandinavian University Books, 1966. 


\subsection{Materials}

Evaluation of the abrasion resistance and chemical compatibility of various types of ceramic spheres for the moving bed evaporator (MBE) and corrosion-resistant metallic materials for constructing the MBE was carried out. Insights obtained are summarized in the following bullets and discussed in detail in sections 3.1 and 3.2.

- Ceramic Spheres

- Metallic Corrosion
-The best choice of materials tested appears to be high purity alumina.

*Abrasion and caustic corrosion cause minor volume/weight reductions during MBE operation.

*Cesium unreactive with alumina.

*Not seriously contaminated by strontium.

*Hardness not impacted by radiation exposure.

-Nickel-based alloys and aluminized nickel or stainless steel are promising materials for MBE construction.

\subsection{Ceramic Spheres}

\subsubsection{Dry Abrasion Testing of Ceramic Spheres}

Abrasion testing was carried out on two candidate spheres, 3/8 inch Coors AD-90 alumina $\left(90 \% \mathrm{Al}_{2} \mathrm{O}_{3}\right)$ and $1 / 4$ inch Alcoa T-162 alumina $\left(99 \% \mathrm{Al}_{2} \mathrm{O}_{3}\right)$. The Coors spheres are fabricated by dry pressing powder between dome-shaped cavities. After sintering, regions of micro cracks and higher porosity are sometimes found between the upper and lower hemispheres. The Alcoa spheres are fabricated by tumbling a seed crystal in a water alumina/slurry and firing to a final density. This leads to spheres formed of concentric alumina layers with the majority of the porosity occurring between the layers. Abrasion testing was conducted by circulating the dry spheres through Synthetica's mechanical MBE which consists of a vessel, a screw feeder, and a bucket elevator. This system provides a great deal of sphere against sphere grinding. After $300 \mathrm{hrs}$ of testing, the Alcoa T-162 spheres had lost $4.6 \%$ of their volume and produced significant quantities of a very fine powder. Volume loss was determined by taking a statistical sample of spheres and comparing their diameters to a similar sample taken prior to initiating the test. This method of measurement was chosen over weight loss for these tests due to the difficulty in separating the spheres from the adherent powder produced by abrasion. For comparison to results in the sections below, percent volume loss converts directly to percent weight loss if it is assumed that the spheres are uniformly dense. For the Alcoa T-162 spheres, most of the abrasion seemed to occur in the beginning of the test. Analysis of the powder revealed the majority consisted of alumina particles between 0.1 and $1.0 \mu \mathrm{m}$ in size. In contrast, very little dusting was seen when the Coors $\mathrm{AD}-90$ spheres underwent similar testing. After $177 \mathrm{hrs}$, the Coors spheres had lost only $1.3 \%$ of their original volume. 


\subsubsection{Corrosion/Wear of Ceramic Spheres}

Laboratory testing equipment was built so that promising sphere materials could be simultaneously subjected to a caustic molten salt and mechanical abrasion at high temperature. This was done to ascertain the combined effects of chemical corrosion and physical abrasion on the ceramic spheres. The apparatus consisted of a furnace-mounted, rotating Monel chamber in which the spheres could be tumbled at a fixed rotational speed. Coors AD-90 alumina spheres, that had performed well during dry abrasion testing, were tested at $400^{\circ} \mathrm{C}$. The temperature was restricted to $400^{\circ} \mathrm{C}$ because of the uncertainty regarding the chemical compatibility of the Monel vessel with the caustic melt.

Nitrate was added to the caustic mixture to more closely simulate the actual composition of a waste stream being processed in the MBE. The composition of the melt was $90 \%$ $\mathrm{NaOH}, 10 \% \mathrm{NaNO}_{3}$. A rotational speed of $12 \mathrm{rpm}$ was used so as to reproduce the modest abrasive environment of the MBE. After the test period, the spheres were removed and their durability was assessed by weight loss measurements. Weight loss after exposure to the corrosive environment was compared to weight loss of the spheres after a similar period of time in the dry chamber and in a static molten salt crucible test, and are summarized in Table 3-1. The observed weight losses suggest that the interaction of corrosion and wear may be important when evaluating the future performance of ceramic spheres.

\begin{tabular}{|c|c|c|c|c|}
\hline Matedial & Bnunoniments & Molvon & Gine $($ m) & 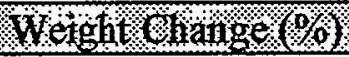 \\
\hline Coors AD-90 & molten $\mathrm{NaOH}$ & $12 \mathrm{rpm}$ & 50 & -3.3 \\
\hline Coors AD-90 & molten $\mathrm{NaOH}$ & static & 50 & -0.4 \\
\hline Coors AD-90 & dry (air) & $12 \mathrm{rpm}$ & 50 & nil \\
\hline
\end{tabular}

Table 3-1 Weight Change of Alumina Spheres During Wear Test at $400^{\circ} \mathrm{C}$

\subsubsection{Static Caustic Corrosion of and Radionuclide Uptake by Ceramic Spheres}

The chemical compatibility of ceramic spheres with caustic was characterized. Samples of the ceramic materials were examined at $605{ }^{\circ} \mathrm{C}$ to accelerate the corrosion processes. For these tests, the composition of the melt was $88 \% \mathrm{NaOH}, 10 \% \mathrm{NaNO}_{3}, 1 \% \mathrm{CsNO}_{3}, 1 \%$ $\mathrm{Sr}\left(\mathrm{NO}_{3}\right)_{2}$. The last two salts were added to evaluate the tendency of cesium and strontium to be taken up by the ceramic materials. Such a tendency would result in radioactive contamination of the ceramic after processing Hanford UST waste. The weight change results shown in Table 3-2 indicate that high-purity alumina and zirconia are the most resistant to attack by molten caustic. As expected, silica-rich ceramics (porcelain, AD-90, silicon nitride, silicon carbide) are not compatible with the caustic molten salt.

The surface composition of three corrosion-resistant ceramics was determined by EDS analysis. Strontium was taken up by Coors AD-995 (alumina), Tosoh YTZ and Zircoa Zycron-G (both zirconia) to some degree, while no cesium contamination at all was detected on these ceramics. The yttria-stabilized zirconia (YTZ) had a surface zone 


\begin{tabular}{|c|c|c|c|}
\hline Whaterat & \% $1 p 0$ ofoerantilo & 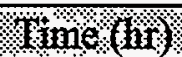 & Wetght $/ 4$ ange $(\%)$ \\
\hline Coors AD-90 & $90 \%$ alumina & 289 & -19.5 \\
\hline Coors AD-995 & $99.5 \%$ alumina & 259 & -0.8 \\
\hline Alcoa T-162 & $99.5 \%$ alumina & 259 & -1.1 \\
\hline Tosoh YTZ & 95\% zirconia (yttria) & 259 & nil \\
\hline Porox Porcelain & $78 \%$ silica & 3 & disintegrated \\
\hline Zircoa Zycron & $96 \%$ zirconia (magnesia) & 261 & 0.2 \\
\hline
\end{tabular}

Table 3-2 Weight Change of Ceramic Spheres During Static Immersion in Molten $\mathrm{NaOH}$ at $605^{\circ} \mathrm{C}$

about 2-3 microns thick in which strontium was detected. The magnesia-stabilized zirconia (Zycron-G) had a surface layer about 20 microns thick in which strontium was present. A small amount of strontium was incorporated into the surface of high-purity alumina (AD-995) spheres as scattered crystals a few microns in size. These results suggest that alumina and yttria-stabilized zirconia will not be seriously contaminated by strontium during MBE service. Furthermore, fully dense ceramics of these types are likely to minimize strontium exchange.

Overall, the dry abrasion tests, the wear/corrosion tests, and the static corrosion tests suggest that high purity alumina spheres (i.e. $99 \% \mathrm{Al}_{2} \mathrm{O}_{3}$ ) or yttria-stabilized zirconia spheres are preferable from a corrosion standpoint. Spheres fabricated by dry pressing appear to be the best choice for MBE application from an abrasion standpoint, as described earlier in section 3.1.1.

\subsubsection{Radiation Effects on Spheres}

Numerous studies have shown that radiation exposure affects the mechanical properties of ceramics. Changes in the mechanical properties of ceramic spheres brought about by radiation exposure could adversely affect their abrasion or wear resistance in the moving bed evaporator. Abrasion or wear resistance is related to both the hardness and fracture toughness of the ceramic. Evans and Marshall found theoretically that the wear rate was inversely proportional to the square root of toughness. ${ }^{50}$ Conversely, experimental studies showed that wear resistance increased with the fourth power of fracture toughness. Results also suggested that in the case of brittle materials, which wear by fracture, that increased hardness may cause inferior rather than superior wear resistance. ${ }^{51}$ This is in contrast with the behavior of metals.

so A. G. Evans, D. B. Marshall, "Wear Mechanisms in Ceramics, "Fundamentals of Friction and Wear of Materials, D. A. Rigney, editor; American Society for Metals, Metals Park, Ohio, 1980.

${ }^{51}$ T. E. Fischer, M. P. Anderson, S. Jahanmir, "Influence of Fracture Toughness on the Wear Resistance of Yttria-Doped Zirconium Oxide," J. Am. Ceram. Soc., 72,252 (1989). 
A brief review of much of the data for effects on the strength, fracture toughness, elastic modulus, and hardness of alumina can be found in a recent article by Pells. ${ }^{52}$ In various cases irradiation was found to improve, degrade, or not affect the mechanical properties. Variables that influence the test results include the temperature at which the ceramic was irradiated, and the composition of the ceramic. These variables may account for the lack of correlation between exposure and the change in mechanical properties. Ceramics such as $\mathrm{Al}_{2} \mathrm{O}_{3}$ and $\mathrm{ZrO}_{2}$ are not damaged by $\gamma$-radiation. However, most of these materials contain a significant amount of glassy phase at the grain boundary, and $\mathrm{SiO}_{2}$ bonds can be broken by $\gamma$-radiation. ${ }^{53}$ Swelling or shrinking may also occur. Although not significant for the Hanford waste case, a neutron flux can also lead to swelling of the ceramic phases, along with a probable degradation of the materials mechanical properties.

Ceramic spheres that are candidates for use in the MBE were exposed to $\gamma$-radiation levels of $0,1,10$, and $100 \mathrm{MRad}$. Preliminary tests of the hardness and fracture toughness of as-received and $100 \mathrm{MRad}$ exposed spheres were then conducted. It was expected these tests would be sufficient to reveal significant effects of radiation on the mechanical properties. The results are presented in Table 3-3 for $\mathrm{Y}$-stabilized $\mathrm{ZrO}_{2}$ and Coors $\mathrm{AD}-90$ $\mathrm{Al}_{2} \mathrm{O}_{3}$. The surface roughness and porosity of Alcoa T-162 alumina precluded measurements from being made. The hardness and fracture toughness were measured using a Vickers diamond indentor and the method of Anstis et al. ${ }^{54}$ Hardness is determined from the impression size and fracture toughness from the crack lengths. Crack lengths could not be measured for the Coors AD-90 material, even with a scanning electron microscope due to surface roughness. An elastic modulus value of $220 \mathrm{GPa}$ was assumed to calculate the fracture toughness of the $\mathrm{Y}$-stabilized $\mathrm{ZrO}_{2}$.

\begin{tabular}{|c|c|c|c|c|}
\hline \multirow{2}{*}{ Wateral } & \multicolumn{2}{|c|}{ Mardiness (GI) } & \multicolumn{2}{|c|}{ Oracture toughuess $(\mathrm{MM}, \mathrm{m} / \mathrm{h})$} \\
\hline & astrecaved & 100 MLad & as - edended & $100 \mathrm{MRad}$ \\
\hline $\begin{array}{c}\text { Tosoh YTZ } \\
\text { Coors AD-90 }\end{array}$ & $\begin{array}{l}13.8 \pm 0.5 \\
10.6 \pm 1.2\end{array}$ & $\begin{array}{l}13.7 \pm 0.7 \\
10.8 \pm 1.8\end{array}$ & $\begin{array}{c}6.3 \pm 1.9 \\
\text { Not Measurable }\end{array}$ & $\begin{array}{c}4.6 \pm 1.4 \\
\text { Not Measurable }\end{array}$ \\
\hline
\end{tabular}

${ }^{2}$ Indentation load of $20 \mathrm{~kg}, 14-16$ measurements.

${ }^{\mathrm{b}}$ Indentation load of $5 \mathrm{~kg}, 5$ measurements.

Table 3-3 Materials Properties of As-Received and Irradiated Ceramic Spheres

Using the student's t-test at the $=0.05$ level, the hardness values for the $\mathrm{Y}$-stabilized $\mathrm{ZrO}_{2}$ are the same for the as-received and irradiated material. However, the fracture toughness is significantly lower after $100 \mathrm{MRad}$ of radiation exposure. Similarly, the hardness of the Coors AD-90 appears unchanged. These results indicate that radiation exposure may impact the wear resistance of at least the $\mathrm{Y}$-stabilized $\mathrm{ZrO}_{2}$. Further testing is required to determine the impact of radiation on alumina.

52 G. P. Pells, "Radiation Damage Effects in Alumina," J. Am. Ceram. Soc. 77, 368 (1994).

53 S. J. Glass, personal communication with Frank Clinard at Los Alamos National Laboratory.

${ }^{54}$ G. R. Anstis, P. Chantikul, B. R. Lawn, D. B. Marshall, "A Critical Evaluation of Indention Techniques for Measuring Fracture Toughness: I, Direct Crack Measurements," J. Am. Ceram. Soc., 64 , 533 (1981). 


\subsection{Corrosion of Metallic Materials}

Several candidate metals and alloys were identified from a brief literature search, and preliminary corrosion tests conducted employing these materials. The extent of corrosion was determined by weight changes and visual examination and metallography. These screening tests were conducted in $90 \% \mathrm{NaOH}, 10 \% \mathrm{NaNO}_{3}$ at $500^{\circ} \mathrm{C}$ using air as the cover gas. The results shown in Table 3-4 indicate that nickel and nickel-base alloys such as Duranickel 301, are superior to iron-based alloys. Stainless steel with an aluminum-rich surface layer (Alonized 310SS) exhibited superior performance compared to a similar untreated alloy of similar composition (Incoloy 800).

\begin{tabular}{|c|c|c|c|}
\hline $4: 1110 \%$ & (hour) & \%er Toighiletiange & Vistalitappearance \\
\hline Nickel 200 & 164 & 4.0 & adherent scale \\
\hline Inconel 601 & 164 & -1.4 & adherent scale \\
\hline Duranickel 301 & 164 & -0.4 & adherent scale \\
\hline Incoloy 800 & 164 & -20.0 & non-adherent scale \\
\hline 310SS/Alonized & 659 & -17.6 & no scale observed \\
\hline
\end{tabular}

Table 3-4 Weight Change of Alloys by Corrosion in Molten $\mathrm{NaOH}$ at $500^{\circ} \mathrm{C}$

Metallographic examination of cross-sectioned samples of the alloys in Table 3-4 (except for the alonized steel) showed that corrosion proceeded by uniform oxide layer growth. No intergranular or internal oxidation was observed. The oxide layers varied in thickness from about 2 microns (Nickel 200) to 5 microns (Inconel 601) after 164 hours of immersion in the molten hydroxide. Chemical analysis of salt samples taken during the corrosion tests indicated the presence of chromium and aluminum; nickel and iron were much less soluble in the molten salt.

More extensive corrosion tests at higher temperatures and of longer duration were subsequently conducted. Because the process definition calls for injecting carbon dioxide into the $\mathrm{MBE}$, thereby forming $\mathrm{Na}_{2} \mathrm{CO}_{3}$ and reducing the alkalinity of the salt, we chose a salt mixture consisting of $80 \% \mathrm{NaNO}_{3}, 10 \% \mathrm{NaOH}, 10 \% \mathrm{Na}_{2} \mathrm{CO}_{3}$ for these tests. A broader group of alloys was included in the second test matrix as indicated in Table 3-5 and testing was performed at temperatures from $500^{\circ} \mathrm{C}$ to $600^{\circ} \mathrm{C}$. Visual inspection of these coupons revealed uniform corrosion without spalling, pitting or blistering of surface oxidation products for all materials except the iron-based alloys. The iron-base alloys formed corrosion products that hydrolyzed during rinsing. As a result, significant amounts of the surface layers appeared to be removed. The net weight change data for all the alloys are summarized in Table 3-5. Although corrosion rates cannot be calculated directly from these data, these results suggest that most materials corrode at moderate rates, except for Nickel 270 at $600^{\circ} \mathrm{C}$. Based on net weight changes, the nickel-base alloys were more corrosion resistant than Nickel 200. Negative values of net weight changes indicate dissolution of metallic constituents into the molten salt, a corrosion mechanism that occurs in addition to oxidation, or by spalling of surface oxide layers. 
Both mechanisms affect iron-base alloys at $550^{\circ} \mathrm{C}$ in the caustic molten salt environment, although the corrosion behavior improves as the nickel content of the alloys increases. Aluminum-rich surface coatings, both on nickel and stainless steel, experienced small weight losses apparently due to the slow dissolution of the coating. The weight loss was greater for aluminized stainless steel than for aluminized nickel.

\begin{tabular}{|c|c|c|c|}
\hline & (minas & Tenopranime & 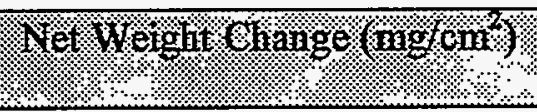 \\
\hline Nickel 200 & 527 & 600 & 1.74 \\
\hline$"$ & 573 & 550 & 0.77 \\
\hline Nickel 270 & 527 & 600 & 20.70 \\
\hline$"$ & 524 & 550 & 1.11 \\
\hline " & 524 & 500 & 0.27 \\
\hline Inconel 600 & 527 & 600 & 0.09 \\
\hline$"$ & 524 & 550 & 0.23 \\
\hline " & 524 & 500 & 0.04 \\
\hline Inconel 601 & 527 & 600 & -0.13 \\
\hline Duranickel 301 & 527 & 600 & 0.73 \\
\hline " & 573 & 550 & 0.72 \\
\hline Haynes 214 & 527 & 600 & 0.07 \\
\hline " & 573 & 550 & 0.13 \\
\hline Hastelloy $\mathbf{N}$ & 527 & 600 & 0.30 \\
\hline$m$ & 573 & 550 & 0.20 \\
\hline Nickel 200/Alonized & 524 & 600 & -0.72 \\
\hline 316L SS/Alonized & 524 & 600 & -4.12 \\
\hline
\end{tabular}

Table 3-5 Weight Change of Alloys by Corrosion in Caustic Molten Salt Mixture at $500^{\circ} \mathrm{C}$ to $600^{\circ} \mathrm{C}$

Chemical analysis of salt samples from selected corrosion tests at $600{ }^{\circ} \mathrm{C}$ provided information regarding the solubility of various metallic alloying elements in this caustic molten salt. These results, presented in Table 3-6, are qualitative because alloys were tested in groups to facilitate completing the matrix. Group A alloys were Nickel 200, Hastelloy N, Inconel 600, and Inconel 601; Group B alloys were Nickel 270, Nickel 301, and Haynes 214. Chromium and aluminum were the most soluble of the alloying elements in the molten salt, presumably dissolving as complex anions such as chromate and aluminate. Iron and nickel were moderately soluble, while molybdenum was only sparingly soluble. 


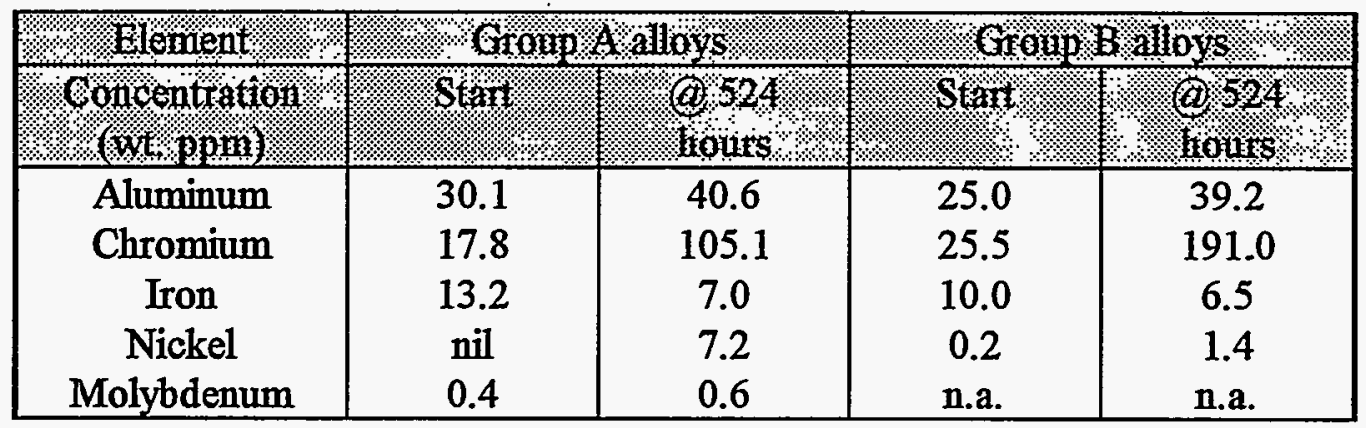

Table 3-6 Concentrations of Metallic Alloying Elements Dissolved during Corrosion in a Caustic Molten Salt Mixture at $600^{\circ} \mathrm{C}$

Metallographic examination of cross-sectioned coupons was performed to determine the extent and type of corrosion on the nickel-base alloys and the commercial grades of nickel. These observations are summarized in Table 3-7, which indicates the total depth affected by both surface layer formation and sub-surface oxide penetration after testing at $600^{\circ} \mathrm{C}$. The data clearly demonstrate that unalloyed nickel (both Nickel 200 and Nickel 270) suffered rapid intergranular oxidation and are not suitable for service under these conditions. In contrast, nickel-base alloys displayed relatively good corrosion resistance. These alloys all corroded by the same general mechanism that resulted in the formation of a thin oxide layer at the surface and varying degrees of sub-surface penetration by oxides. These results are described in detail in a separate report. ${ }^{55}$

\begin{tabular}{|c|c|c|c|}
\hline \%.\% & Hourd & monuerautue & $\begin{array}{c}\text { Affected } \\
\text { (ntuerous) }\end{array}$ \\
\hline Nickel 200 & 527 & 600 & 140 \\
\hline Nickel 270 & 527 & 600 & 350 \\
\hline Inconel 600 & 527 & 600 & 12 \\
\hline Inconel 601 & 527 & 600 & 9 \\
\hline Duranickel 301 & 527 & 600 & 14 \\
\hline Haynes 214 & 527 & 600 & 7 \\
\hline Hastelloy $\mathbf{N}$ & 527 & 600 & 15 \\
\hline
\end{tabular}

Table 3-7 Depth of Corrosion of Nickel-Base Alloys Tested in a Caustic Molten Salt Mixture

The results of these corrosion tests indicate that nickel-based alloys, especially those containing aluminum, and alloys prepared with an aluminide surface diffusion coating are the most promising materials for service in an MBE environment.

\footnotetext{
5s R. W. Bradshaw, S. H. Goods and D. R. Boehme, "Screening Tests of Corrosion Resistance of Alloys
} in Caustic Molten Salts", Sandia National Laboratories, report in preparation. 


\subsection{System Design}

In order to facilitate the orderly scaleup to an eventual $5 \mathrm{gpm} \mathrm{MBE}$ and $20 \mathrm{gpm}$ system, the steam reforming project team began to design, fabricate, and test a $0.5 \mathrm{gpm}$ steam reforming system. This system and the information and experience provided by it are valuable tools for designing and building a safe and reliable full scale steam reforming system for treating Hanford UST wastes.

\subsection{Design Philosophy}

The dominant requirement to be considered when developing a processing system for Hanford UST waste is the high radioactivity of the waste. This high-level radioactive environment imposes severe restrictions upon the accessibility of the equipment to personnel once waste treatment has begun and the system has been contaminated. Therefore, special design efforts were made to assure compliance with ALARA (As Low As Reasonably Achievable) criteria for personnel radiation exposure.

Successful treatment of Hanford UST waste mandates that the processing system be simple, reliable, robust and capable of operating for extended time periods with minimal operator intervention and maintenance. When maintenance operations are required, they must be carried out in a manner that achieves the least possible exposure to personnel.

The goals of simplicity, reliability and robustness, were achieved in the Hanford waste steam reforming treatment system by using the absolute minimum moving mechanical elements and selecting materials, components and systems whose compatibility and reliability have been proven through years of industrial service experience. To this end, the moving bed evaporator (MBE) and balance of plant (BOP) contain only two pieces of rotating equipment. These components are the two blowers that drive the ceramic sphere pneumatic conveyance system and circulate the steam, carbon dioxide and organic volatiles through the vessel and other balance of plant components.

The MBE performs the crucial roles of volatilizing the organics, destroying the ferrocyanides, nitrites and nitrates, and separating the radioactive solids from volatile components. It contains no mechanical moving parts in the flow stream and depends upon the force of gravity and gas flows to achieve sphere circulation and waste solids separation and collection. Reliable, industrially-proven techniques for bulk materials handling, conveyance, particulate separation and collection: i.e., simple pneumatic conveyance equipment and static elements such as cyclones, filters and hoppers are employed. Heated ceramic spheres provide most of the thermal energy and surface area in the MBE vessel for waste volatilization including water evaporation, and destruction of ferrocyanides and nitrates. Similar spheres have been used for decades in the petrochemical industry in such diverse applications as catalytic crackers, coal and shale oil pyrolysis systems and fluidized bed heaters. Based on this experience, they have been generally classified as mechanically rugged, thermally stable and chemically tolerant of the processes ongoing in the MBE.

The balance of plant is comprised of standard chemical processing equipment such as valves, blowers, steam generators, heaters, heat exchangers and condensers. The operating conditions for these components in the steam reforming system are typical of 
those used in the chemical processing industry. Selection of rugged, reliable, and chemically compatible off-the-shelf components is considered to be a strength of this application. Reliability and maintainability of rotating equipment such as blowers, can be enhanced by using redundant systems.

Energy efficiency is a high priority design requirement for the steam reforming waste processing system. Since up to $80 \%$ of the waste stream may be slurry water that is evaporated during the treatment process, large quantities of heat must be provided. Every available opportunity to recover this energy, such as heating the incoming waste stream was considered.

To facilitate the safety of maintenance operations, and enhanice our ability to achieve ALARA criteria, the Compact Processing/Modular Waste Treatment Unit approach was applied to the design of the waste treatment system. The processing system is divided into subunits based upon the radiation levels they are expected to experience. For example, the MBE contains the slurried high-level radioactive waste and is expected to be at the highest radiation levels. For this reason it is maintained as a separate subunit and placed within an appropriate shielded enclosure. Components of the MBE that are expected to require periodic maintenance are arranged within the enclosure in such a way that they are accessible through ports in the shielding. If necessary, they can be designed for remote maintenance/removal/replacement. Balance of plant components are expected to experience much lower radiation levels, and will be enclosed in separate modules with appropriate shielding and accessibility.

Rotating equipment such as blowers and filter systems that require routine maintenance are redundant. When maintenance is required on an operating unit, it can be switched out of the flow stream and the backup unit placed in operation without processing interruption.

Retention of radioactive by-products in the system will be minimized to further facilitate maintenance procedures. Radioactive solids collected after processing can be slurried and continuously pumped or pneumatically transported to the Hanford waste collection point.

\subsection{The 0.5 GPM System}

\subsubsection{System Overview}

A schematic of the $0.5 \mathrm{gpm}$ Hanford steam reforming system is shown in Figure 4.1. As previously described, the steam reforming system consists of a moving bed evaporator (MBE) and Synthetica detoxifier. These units would be supported by other operations collectively referred to as the balance of plant (BOP). The $0.5 \mathrm{gpm}$ system was designed to operate as follows.

Wastes are preheated with recovered energy and uniformly coated on hot ceramic spheres in the MBE. The spheres spend approximately 9 minutes flowing through the MBE vessel. The MBE is designed to operate isothermally at $550^{\circ} \mathrm{C}$. High temperature steam is fed into the bottom of the MBE and flows upward through the bed of coated spheres converting the sodium nitrate in the waste to sodium hydroxide, oxygen, nitrogen, and 
oxides of nitrogen. The steam also gasifies and partially decomposes organics. Carbon dioxide is injected to convert the sodium hydroxide to sodium carbonate.

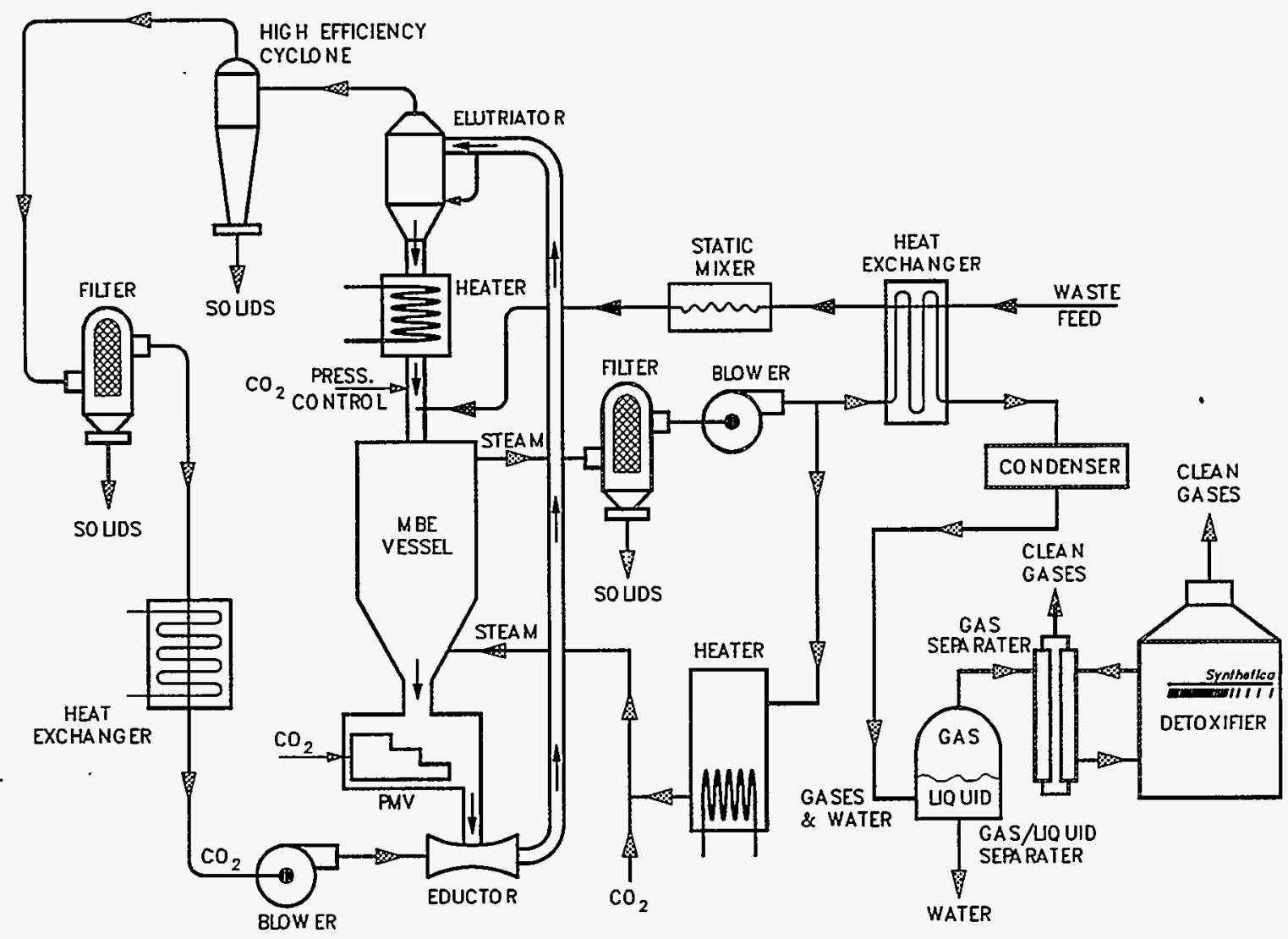

Figure 4.1 Hanford Steam Reforming System

The ceramic spheres exit the MBE vessel through a pneumatic metering valve (PMV), and are pneumatically conveyed to the top of the MBE for recycle. Pressures are balanced between the steam and conveyance systems to assure conveying gas is primarily maintained as $\mathrm{CO}_{2}$ by metering the $\mathrm{CO}_{2}$ as required between the sphere heater and the vessel. The spheres are then separated from the residual waste solids by an elutriation system and heated before being fed back into the MBE vessel. The waste solids that are separated from the spheres are collected by cyclones and filters. They may be slurried with water for transport or pneumatically transported to further processing operations such as glass vitrification. The entire pneumatic system operates closed loop with heating and cooling as necessary to protect equipment and carry out the desired operations.

The gas stream carrying the volatilized waste components from the MBE passes through a filter system to remove any solid particles which may have been entrained in the gas. A portion of the gas stream is heated and recycled through the MBE, while the remainder is condensed and further treated by a scrubber to recover water and remove any volatilized radionuclides and sub-micron particulates. The water that is recovered may be used to slurry collected solids for transport, or recycled to the waste retrieval operation. The gas stream exiting the scrubber is treated to remove organics and vented. Concentrated 
organics are sent to the detoxifier where final destruction occurs. The Synthetica detoxifier contains an electrically heated reactor where organics react with and are destroyed by $1100^{\circ} \mathrm{C}$ steam. The exit streams from the detoxifier consist of $\mathrm{H}_{2}, \mathrm{H}_{2} \mathrm{O}$, $\mathrm{CO}$, and $\mathrm{CO}_{2}$. However these gases may be easily converted to $\mathrm{H}_{2} \mathrm{O}$ and $\mathrm{CO}_{2}$.

Additional detail about the design and operation of the $0.5 \mathrm{gpm}$ system is provided in the paragraphs which follow.

\subsubsection{Moving Bed Evaporator}

Wastes are introduced to the UST steam reforming system in the moving bed evaporator. The down flowing bed of ceramic spheres accommodates a variety of waste streams, and provides a high bulk volume and surface area over which liquid and/or sludge wastes are thinly and uniformly distributed. This careful distribution prevents sticking or agglomeration and allows a uniform flow pattern to develop throughout the bed. Volatile components of the waste and decomposition products are released from the ceramic surfaces as vapors and flow out of the MBE through voids in the bed of ceramic spheres. Uniform plug (mass) flow of the bed of spheres is achieved as the spheres are metered and recirculated, using the pneumatic system. The entire solids recirculation process operates with no moving parts exposed to the waste. During recirculation, the spheres are cleaned sufficiently for reuse and preheated to provide energy for evaporating the water in the waste and maintaining the bed at a desired reaction temperature. Additional heat for carrying out endothermic processes and reactions is provided by steam which is circulated countercurrently through the bed. The designs of the $0.5 \mathrm{gpm} \mathrm{MBE}$ subsystems are described below.

\subsubsection{Vessel Design}

When constructed, the MBE vessel is essentially part of the building or main support structure. Considerable effort was expended to insure each aspect of vessel design was addressed. The $0.5 \mathrm{gpm} \mathrm{MBE}$ vessel contains $8.77 \mathrm{ft}^{3}$ or $1104 \mathrm{lbs}$ of $3 / 8$ inch $\mathrm{Al}_{2} \mathrm{O}_{3}$ spheres. A sketch of the vessel is shown in Figure 4.2.

After completion of a comprehensive literature search, experiments were performed to assure a uniform mass flow was being achieved in the vessel. In these tests, actual spherical ceramic media was timed as it flowed out of clear plastic conical vessels constructed with various angles. Using cone angles from 20 to 60 degrees, the results compared favorably with information in the literature. To avoid sphere interlocking, the vessel outlet size was designed to exceed the general rule of thumb $b^{56,57}$ that circular outlets must be sized six to eight times the largest particle diameter.

\footnotetext{
56 A. Jenike, "Storage and Flow of Solids," Bulletin 123, Utah Engineering Experiment Station (revised), March 1970.

37 J. Marinelli, J.W. Carson, "Solve Solids Flow Problems in Bins, Hoppers, and Feeders", Chem.Engr.Progress, 22, May 1992.
} 
It remains to validate these initial results on design shape with additional tests which use ceramic spheres coated with waste simulant. However, the current design is considered conservative enough that plugging should not occur within the MBE vessel for any envisioned test scenario.

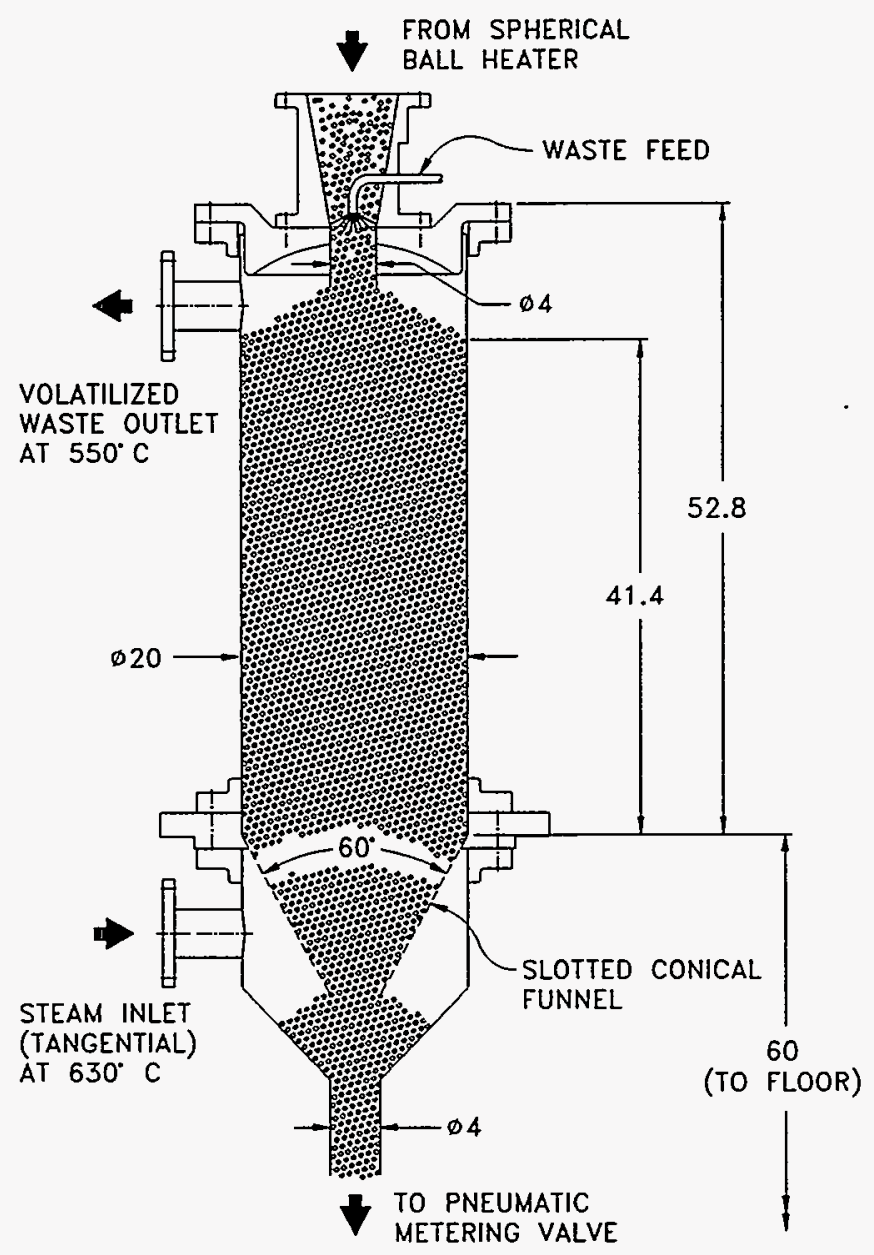

(units in inches)

Figure 4.2 0.5 gpm MBE Vessel Design

\subsubsection{Waste Distribution System}

Some design and conceptual work has been done on the waste distribution system, however considerable concept development and lab demonstration work remains to be accomplished. The engineering design concepts presented are based on experience gained at Synthetica, LLNL, and within the petrochemical industry. Together they form a basis for development and should be further refined and demonstrated with lab testing.

Three processing operations have been identified as being beneficial if performed on the incoming waste stream: 
- Waste stream is passed through a pulverizer and/or classifier to prevent the entrainment of oversize particles in the waste stream. The size requirement to ensure efficient processing remains to be determined.

- Waste stream is preheated to slightly less than the boiling point of water, $100^{\circ} \mathrm{C}$.

- Waste stream passes through a static mixer to establish a locally homogeneous mixture.

In order to efficiently process wastes, it is necessary to distribute or coat each ceramic sphere with a uniform layer of waste. The requirement as to how uniform the layer of waste needs to be has not yet been determined. However tests conducted at LLNL (chapter 5) suggest that in order to efficiently decompose sodium nitrate, the salt coating can be $>5 \mu \mathrm{m}$ but should be $<13 \mu \mathrm{m}$ thick (assuming perfectly uniform loading in the tests).

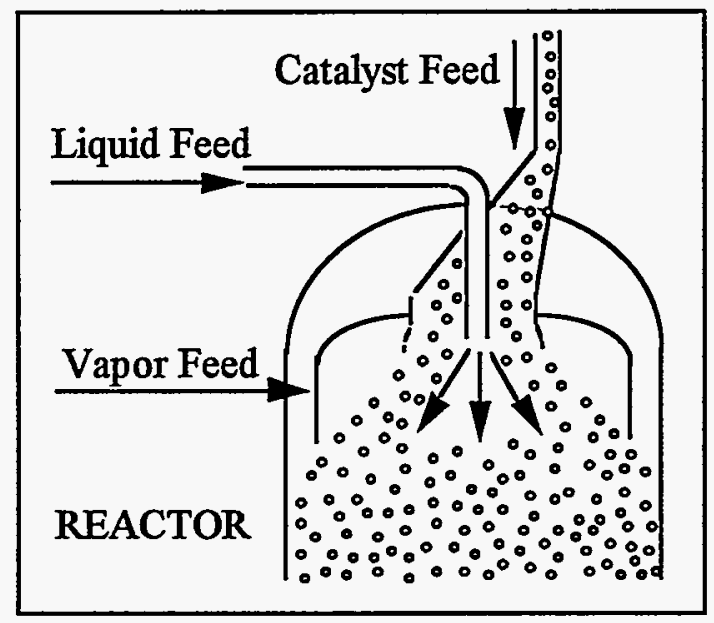

Figure 4.3 Liquid-Charging in T.C.C. Unit

Synthetica has been injecting waste simulant from a $3 / 8$ inch diameter cylindrical tube located on the centerline of their MBE. The waste is injected into the upper portion of the $M B E$ and is believed to disperse throughout the ceramic bed of spheres by forming a 120 degree conical plume from the point of injection. LLNL has also injected waste simulant on the centerline of their bed of spheres with success. For years, petroleum refiners ${ }^{58,59}$ have used on-center designs, (Figure 4.3) to inject heavy oils directly into Thermofor Catalytic Cracking (T.C.C.) units.

Based on these experiences, our approach is to inject the liquid waste on center with a scheme similar to that used by the petrochemical industry as shown in Figure 4.3. The location depicted permits the introduction of waste onto the sphere flow in an area of

${ }^{58}$ Simpson et al., "Liquid-Charge Technique in T.C.C. Processing," Oil and Gas Journal, 119, Nov. 24, 1945.

39 Simpson, T.P., "T.C.C. Announces Liquid Processing Using Pelleted Clay or Beaded Catalyst," Oil and Gas Journal, 88, May 12, 1945. 
maximum confinement, thus facilitating the dispersion of waste onto all spheres which enter the MBE.

Simple laboratory tests conducted at Sandia National Labs (Figure 4.4), have shown that injecting liquid solutions on-centerline from a tangential feed disperser, does indeed distribute the waste simulant uniformly onto the mass of moving spheres.

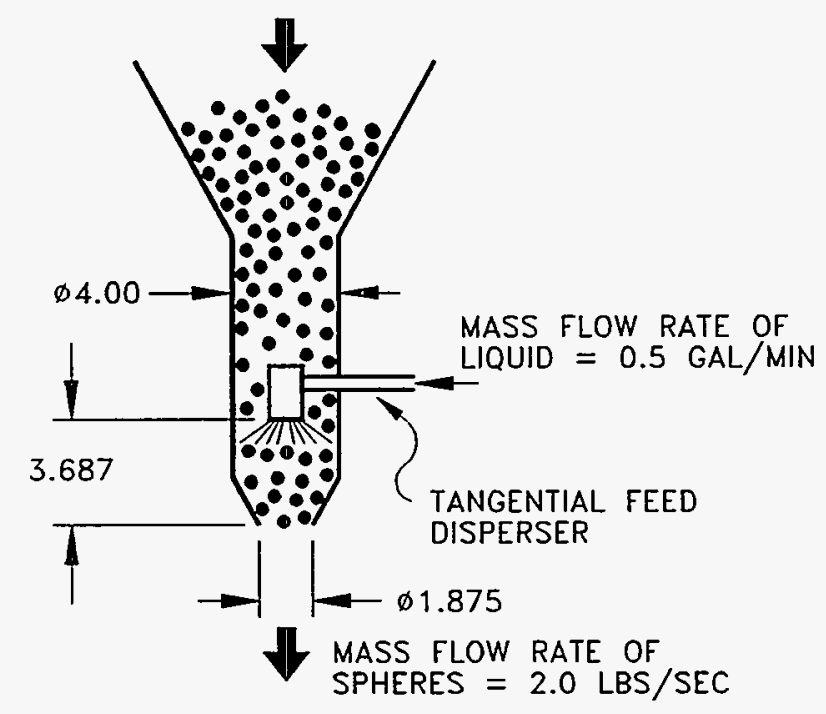

Figure 4.4 Waste Dispersion Test System, 0.5 gpm MBE

In these tests, $3 / 8$ inch ceramic spheres were metered by means of a fixed orifice through a four inch diameter clear plastic tube. While the spheres moved down the tube, liquid mixed with food coloring was injected on-center. The liquid waste simulant was uniformly dispersed onto the spheres using a shallow hollow-cone pattern, as shown. Waste dispersion testing using slurried solutions of dolomite, $\mathrm{CaMg}\left(\mathrm{CO}_{3}\right)_{2}$, and water was also carried out. This solution highlighted the need for employing more elaborate approaches for moving slurry in the $0.5 \mathrm{gpm}$ pilot scale system. The problems arose due to the small diameter pipes used at such small feed rates. As the size of the MBE is scaled-up, the need for these approaches should diminish. Some of the concepts investigated include: steam jet pumps, continuous agitation, pulsed feeding and progressive cavity pumps. One idea that merits further investigation is that of augmenting the slurry flow at this low feed rate with a secondary steam flow.

\subsubsection{Sphere Metering}

Sphere flow control and metering are accomplished by a Pneumatic Metering Valve (PMV). The PMV has no moving components, is easy to operate, and requires little maintenance. The PMV design is an adaptation of horizontal conveyance based on 
LLNL's "L" valve ${ }^{60}$ that has been used for metering oil shale in their retorting facility. Modifications have been made to the " $L$ " valve so that it can accurately meter $3 / 8$ inch diameter alumina spheres rather than oil shale. The oil shale used by LLNL has an irregular geometry ranging in size from $6 \mathrm{~mm}$ down to microns.

The PMV is located below the four inch diameter outlet of the $0.5 \mathrm{gpm}$ MBE vessel. As spheres leave the PMV they enter the eductor which entrains and accelerates them in the large volumetric flow of the pneumatic conveyance system. Figure 4.5 is a diagram of the PMV and its components.

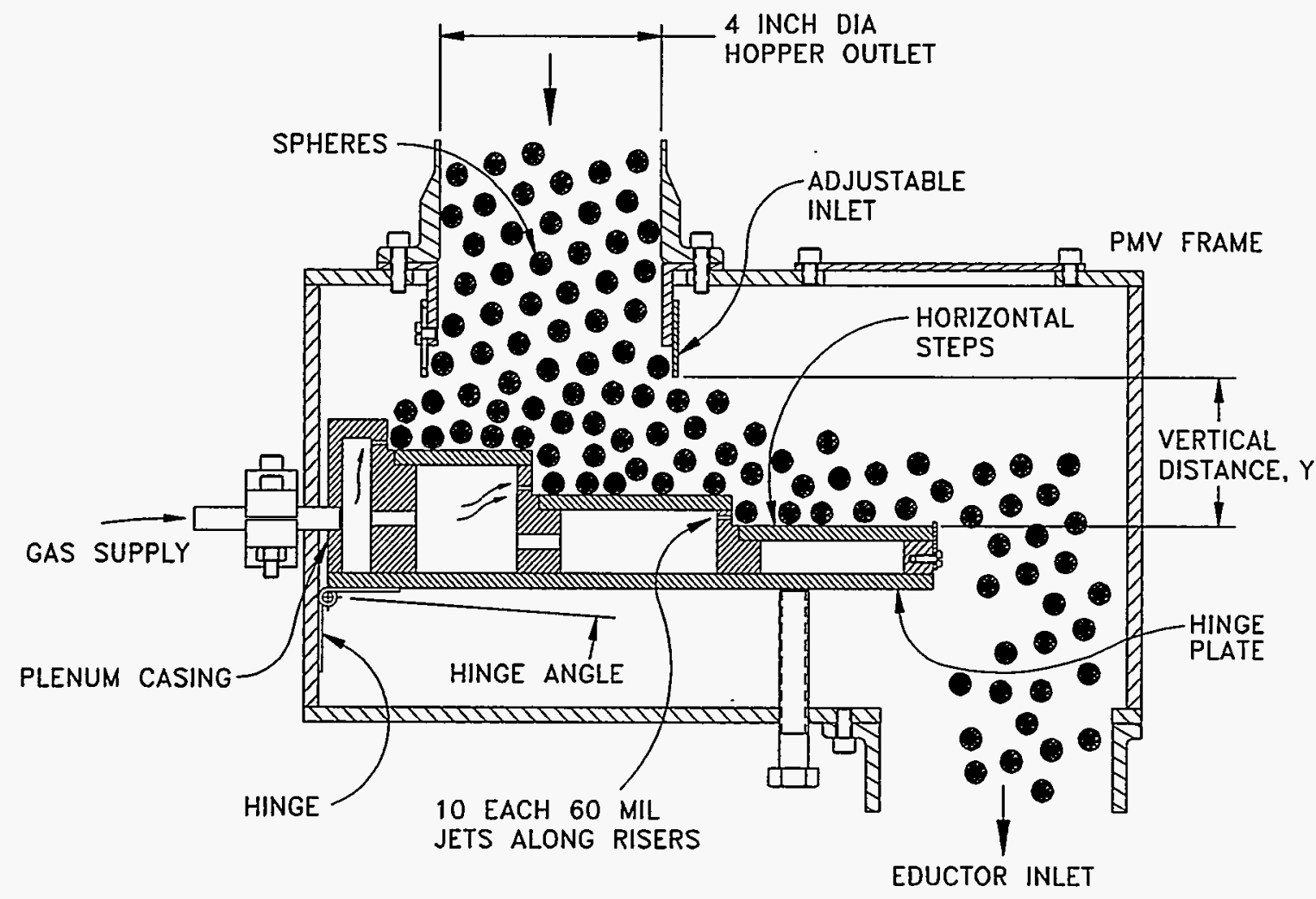

Figure 4.5 Schematic Diagram of Solid Flow Control PMV

Each of the three risers for the PMV is equipped with ten 60 mil diameter holes. As the regulated gas supply enters the plenum casing, ports on the risers act as nozzles which discharge high-velocity jets of gas and drive the spheres down the steps and into the eductor inlet.

Flow control and metering of the spheres are achieved by adjusting the gas flow rate and the hinge plate angle. Gas flow rate adjustments are easily attained by varying the plenum casing inlet pressure. The sphere flow rate can also be varied by utilizing the hinge mechanism.

${ }^{60}$ C.B. Thorsness and R.J. Cena, "LLNL Oil Shale Pilot Plant Status Report," 1990 Eastern Oil Shale Symposium, November 6-8, 1990. 
Another important parameter that can provide coarse adjustments to the maximum attainable sphere flow rate is the vertical distance, denoted as $\mathrm{Y}$, in Figure 4.5. This adjustment can be achieved by either moving the plenum casing up and down along the slotted hole of the PMV frame or by sliding the adjustable inlet tube up and down.

Figure 4.6 is a plot of experimental data showing the relationship between the sphere mass flow rate and vertical distance, $Y$. This plot shows that the sphere flow rate changes linearly with the vertical distance. By taking such data, we were able to determine an appropriate $\mathrm{Y}$ distance to meet sphere flow rate design requirements ranging from 1.0 to 5.0 pounds per second. This flow range should allow sphere loadings that result in complete nitrate destruction in the MBE.

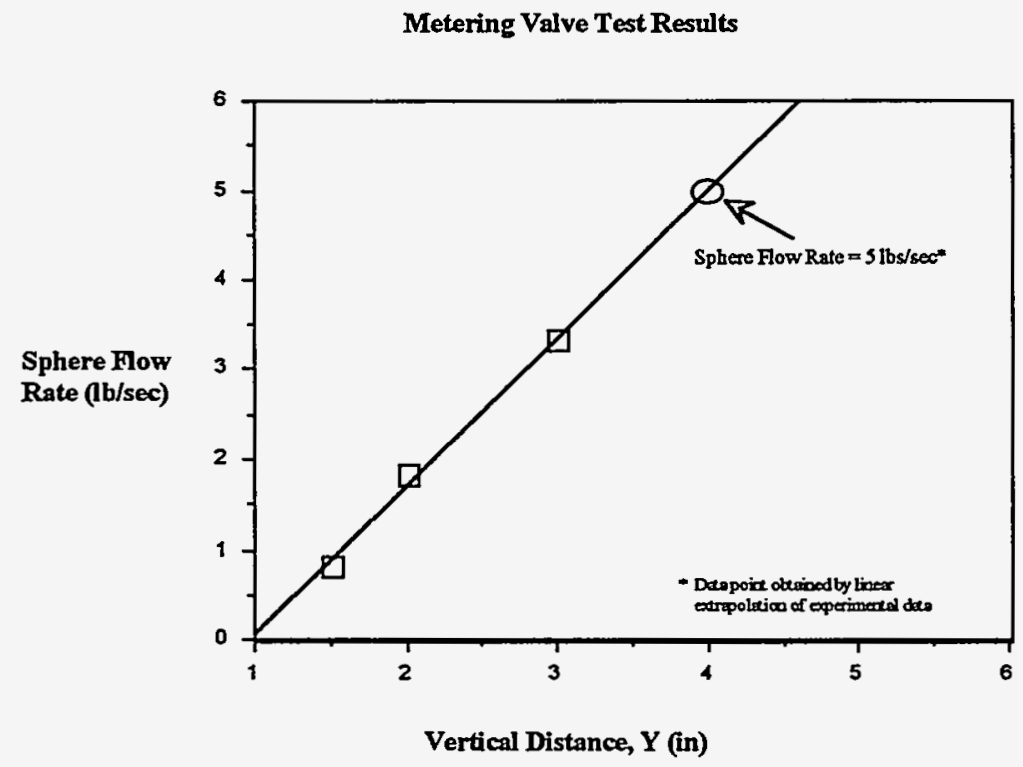

Figure 4.6 Sphere Flow Rate Versus Vertical Distance

Stopping the sphere flow is achieved by turning off the gas supply. Lab experiments demonstrated that with a hinge plate angle of negative five degrees (upward five degree angle), the sphere flow will indeed stop when the gas supply is shut off. Having the capability to control the flow to the extent of stopping it is as important to the system as being able to maintain the flow in a steady state operation.

\subsubsection{Pneumatic Conveyance}

After passing through the pneumatic metering valve, the ceramic spheres are pneumatically returned to the top of the MBE vessel. Pneumatic conveyance is a proven industrial practice for transporting solids where reliability and low maintenance are required. It is used extensively in the transport of grains, coals and a wide range of other granular material. Pneumatic transport lends itself well to the handling of "problem" 
materials which must be contained for reasons of safety or accountability. ${ }^{61}$ These systems $^{2}$ are especially suited for solid handling applications where hot or corrosive material is involved, since pneumatic systems use no moving parts exposed to the waste stream. Dilute phase pneumatic conveyance in the petrochemical industry is widespread with a primary application being recycling cracking catalysts in refineries. Recent developments in combined cycle power generation and oil shale processing have used pneumatic conveyance to not only transport material but provide the oxidant for combustion.

An initial design for the pneumatic conveyance system of the $0.5 \mathrm{gpm}$ MBE has been built/procured and tested. Subsequently, the design was refined as a result of functional testing to improve the flow and power consumption characteristics. The initial design of the pneumatic conveyance system for the $0.5 \mathrm{gpm}$ MBE specified a 4 inch diameter ceramic-lined eductor, with the nozzle sized to pass $475 \mathrm{SCFM}$ of air (at $70^{\circ} \mathrm{C}$ ) using a pressure differential of $5 \mathrm{psi}$. The specified eductor was procured from Fox Valve Development Corp. of Dover, NJ. The system also included lengths of 4 inch diameter stainless steel pipe through which Coors AD-90 alumina spheres were vertically lifted 13 feet before returning to the MBE bed. The system contained two sharp 90 degree elbows which represented a worst case for ball circulation and breakage. Conveyance air was supplied by a compressor previously installed in the building and available for our use.

Testing of this pneumatic system was performed at ambient temperature and open loop, in contrast to a closed loop system in which the conveyance air would be recycled. This was done for expediency and to develop data required to confidently specify a recirculating blower design. Testing revealed two design deficiencies. The first deficiency was the 4 inch diameter pipe only permitted a continuous sphere flow rate of $1.0 \mathrm{lb} / \mathrm{sec}$ with the available blower. The capacity was increased to more than $2.5 \mathrm{lb} / \mathrm{sec}$ by reducing the pipe diameter to 3 inches and operating at 350 SCFM airflow. Second, some sphere breakage was observed after circulating $80 \mathrm{lbs}$ for $4 \mathrm{hrs}$ at $1 \mathrm{lb} / \mathrm{sec}$. The sphere breakage concern was resolved by replacing the sharp elbows with a gradual 3 foot radius elbow in the return pipe. This initial testing confirmed the feasibility of conveying ceramic spheres at the specified circulation rate using pneumatic methods. The discussed improvements have been included in the current design of the $0.5 \mathrm{gpm} \mathrm{MBE}$. A recirculating blower for the system has been specified and a supplier located.

Long term ceramic sphere abrasion with a recirculating blower loop and elutriation cleaning system remains to be evaluated.

\subsubsection{Sphere Heating}

Hot ceramic spheres provide the thermal energy required in the MBE to volatilize the slurry water and organics that comprise up to $80 \%$ of the waste stream. The heat capacity of the spheres is also used to thermally stabilize the reaction vessel and maintain the appropriate temperatures for ferrocyanide and nitrite/nitrate destruction. This temperature stabilization allows the vessel to operate essentially isothermally. If the MBE is to be

${ }^{61}$ E. E. Smeltzer, M. C. Skriba, "Dilute Phase Conveyance of Fine Nuclear Fuel Powders Under Negative Pressure Conditions", Int'l. Powder \& Bulk Solids Handling \& Process, 509, May 15-17, 1979. 
operated at $550^{\circ} \mathrm{C}$, the spheres must be heated to approximately $650{ }^{\circ} \mathrm{C}$ to supply the thermal energy required to volatilize the waste stream at the vessel inlet. The additional heat required to support the endothermic nitrate/carbonate conversion is provided by superheated steam circulating countercurrently through the vessel. Heat loss during pneumatic conveyance is estimated to be on the order of $10 \%$ requiring an equivalent increase in sphere heater capacity.

About $80 \mathrm{~kW}$ of thermal energy must be provided by the spheres for waste volatilization in the $0.5 \mathrm{gpm}$ steam reforming system. To supply this energy, we have been pursuing three basic sphere heating techniques: (1) gas heating, (2) contact heating and (3) direct energy deposition. The results of this effort are summarized in the paragraphs which follow.

Gas heating: Hot gas appears more efficient than contact heating as it provides heat transfer over the entire sphere surface. Since hot gas spherical pellet heaters, referred to as "pebble heaters," have been successfully developed and operated by the petrochemical industry ${ }^{62}$, they were initially examined as a baseline design for the MBE. The design considered used a closed-loop hot carbon dioxide packed-bed heater design where gas flow velocities were somewhat below incipient fluidization of the spheres. A closed loop system is required to assure that no radioactive constituents are released to the environment. After exploring this design, we determined that it was a feasible way to heat the ceramic spheres. The major deficiencies associated with this approach were the large blower capacity required and the excessive amount of heat rejection that could not be easily recovered after reducing the gas temperature for blower inlet conditions.

Contact heating: As a result of the gas heating study, the baseline design was changed to an electrically powered contact heater located between the elutriator and the MBE vessel as illustrated in Figure 4.1. Heating the spheres with an electrical source allows the blower to be sized for sphere conveyance only and minimizes heat removal for blower inlet temperature limitations. The contact heater is envisioned as a cylindrical unit with appropriate baffling to assure adequate contact between the spheres and hot heater surfaces. External metallic band type heaters, which can be easily removed and replaced during maintenance operations, are used as the heat source. Heater manufacturers are being contacted to determine the effectiveness of band heating and the heater size required for the $0.5 \mathrm{gpm} \mathrm{MBE}$. A laboratory scale prototype design was specified and procured. This unit is available for laboratory testing to measure the overall heat transfer coefficient under anticipated operating conditions. Testing of this type would determine the feasibility of such a heater and allow its energy efficiency to be compared to the closedloop pebble bed (gas heating) concept. Ultimately, a combination of these approaches could provide an optimal sphere heating method.

Direct energy deposition: As a third option, direct energy deposition into the spheres was aggressively investigated. Methods for directly depositing energy into the ceramic spheres would appear to provide the largest potential for gains in both increased efficiency and balance of plant simplification. Two options, infra-red and microwave heating

62 C. L. Morton Jr., "Pebble Heater, New Heat Transfer Unit for Industry",Chemical and Metallurgical Engineering, 116, July 1946. 
techniques were considered. Heating the spheres with infra-red energy appears to be very inefficient due to poor coupling between the $\mathbb{R}$ radiation and the ceramic spheres, and thus unfeasible.

Microwave heating has the important potential advantages of directly depositing the thermal energy into the spheres and not into the transport gas which has to be cooled prior to the blower inlet and also of requiring minimal mechanical maintenance. An overall microwave heating system efficiency is expected to range from $40-50$ percent.

Discussions with technical microwave applications personnel have confirmed the feasibility of heating alumina or zirconia spheres for the MBE application. Zirconia should be easier than alumina to couple to microwave radiation. Also, impure alumina should be easier to couple than high purity alumina. The major unknown is whether the effective loss factor of the hot spheres is high enough to allow heating them in a reasonable time at the 24.5 $\mathrm{GHz}$ frequency for which power supply systems currently exist. In order to develop a heater concept for evaluation, scoping tests are needed to determine the heating rate of the hot spheres at $24.5 \mathrm{GHz}$. The details of the heater design depend strongly on the microwave frequency needed for an acceptable heating rate and higher frequencies may be required.

\subsubsection{Carbon Diaxide Injection}

Carbon dioxide, $\mathrm{CO}_{2}$, will be injected into the MBE, and used as the transport gas in the pneumatic lift and separation system. Reactions of $\mathrm{CO}_{2}$ with sodrum oxides and hydroxide formed during the decomposition of $\mathrm{NaNO}_{3}$ or reactions between $\mathrm{CO}_{2}$ and $\mathrm{NaNO}_{2}$ or $\mathrm{NaNO}_{3}$ yield $\mathrm{Na}_{2} \mathrm{CO}_{3}$. The melting point of $\mathrm{Na}_{2} \mathrm{CO}_{3}$ is $851^{\circ} \mathrm{C}$ while that of $\mathrm{NaOH}$ is 318 ${ }^{\circ} \mathrm{C}$. Therefore, injecting $\mathrm{CO}_{2}$ into the $\mathrm{MBE}$ will lead to the formation of a solid product at the expected operating temperatures (near $550^{\circ} \mathrm{C}$ ).

In the absence of $\mathrm{CO}_{2}$, the $\mathrm{MBE}$ would likely contain a molten phase consisting primarily of $\mathrm{NaOH}$. A cooling step to convert the $\mathrm{NaOH}$ to a solid would therefore be required before it could be transported and centrifugally separated from the spheres as described in sections 4.2.2.4 and 4.2.2.7. This additional step complicates the design as well as compromises the energy efficiency of the system. An additional incentive for injecting $\mathrm{CO}_{2}$ into the system is the less corrosive nature of $\mathrm{Na}_{2} \mathrm{CO}_{3}$ as compared to $\mathrm{NaOH}$. The highly corrosive nature of high temperature $\mathrm{NaOH}$ melts is described in Chapter 3 of this report. A final reason for injecting $\mathrm{CO}_{2}$ into the system is the expected impact on Cs volatilization. Oxides and hydroxides of cesium are some of the most volatile species anticipated in the MBE. These species should undergo reactions with $\mathrm{CO}_{2}$ analogous to those of sodium oxide and hydroxide to form less volatile $\mathrm{Cs}_{2} \mathrm{CO}_{3}$ (section 2.4).

\subsubsection{Solids Separation}

The sphere cleaning and filtration system for the $0.5 \mathrm{gpm} \mathrm{MBE}$ is designed to remove solids, primarily sodium carbonate $\left(\mathrm{Na}_{2} \mathrm{CO}_{3}\right)$, from the surface of the ceramic spheres. The sodium carbonate is formed in the MBE due to the carbon dioxide injection into the 


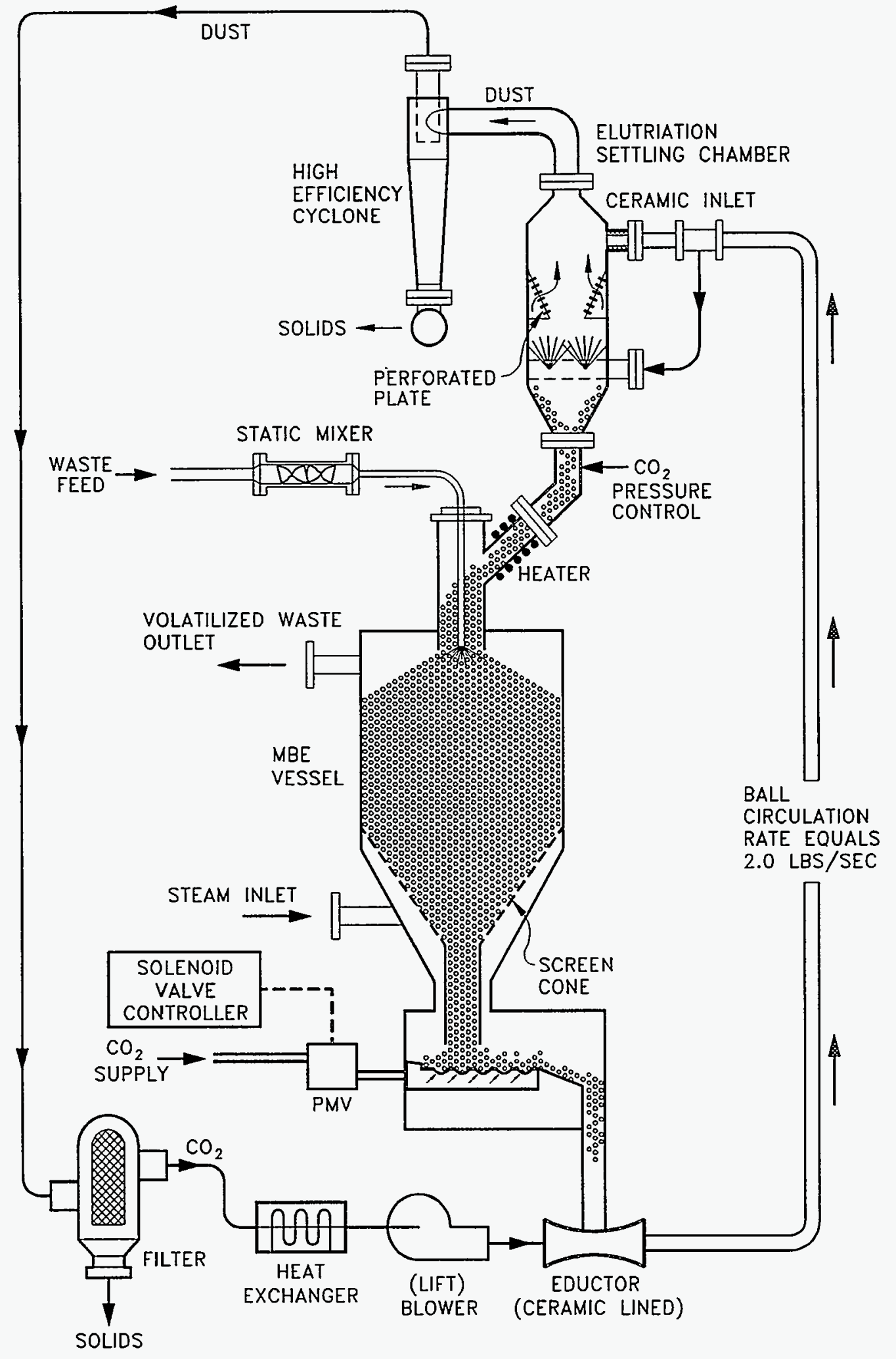

Figure 4.7 Schematic Diagram of Moving Bed Evaporator (MBE) 
reaction zone. Even though sodium carbonate is the main residual product of the MBE decomposition reaction, the sphere cleaning system is believed to be robust enough that other solids such as metal contaminants (vanadium, nickel, iron, copper, etc.) will also be removed from the surface of the spheres. Grinding trace metals off the surface of silicaalumina synthetic bead catalysts ${ }^{63}$ by natural erosion is quite common in catalytic cracking operations. The sphere cleaning/filtration system for the MBE is shown schematically as the outside conveyance loop in Figure 4.7. Recall that pressure balances isolate the conveyance loop from the MBE vessel.

After the sodium carbonate $\left(\mathrm{Na}_{2} \mathrm{CO}_{3}\right)$ laden ceramic spheres leave the $\mathrm{MBE}$ reactor and the pneumatic metering valve, they enter the eductor where they are "hit" with a large volume of driving gas. This near instantaneous acceleration acts to dislodge any loosely attached $\mathrm{Na}_{2} \mathrm{CO}_{3}$ from the spherical surfaces. The spheres then travel through the eductor lift pipe, where "rolling contact" and "sphere-over-sphere" abrasion occurs.

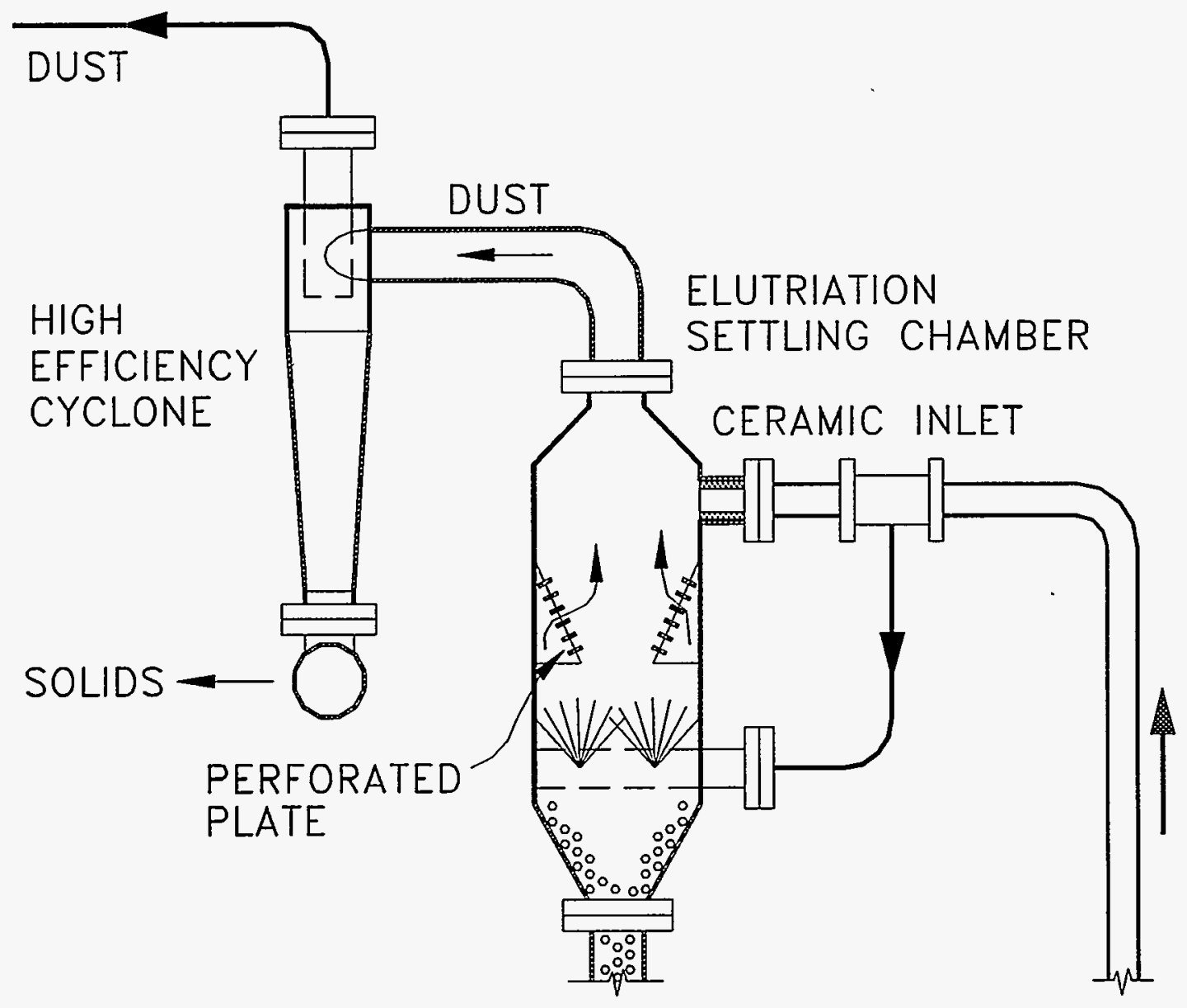

Figure 4.8 Sphere Cleaning System

${ }^{63}$ Bergstrom et al., "Recent Developments in T.C.C. Cracking," Proc. Fourth World Pet. Congress, Sec. III, Rome, 1955. 
Next, the spheres tangentially enter the elutriation settling chamber, Figure 4.8, at high velocities (approx. $85 \mathrm{ft} / \mathrm{sec}$ ). This part of the $0.5 \mathrm{gpm}$ MBE was designed by Ducon Environmental Systems, Farmingdale, New York. Ducon has been a leader in dust control and product recovery systems for refineries since 1938. The particle flow internal to the cleaning/elutriation system was modeled by the Navier-Stokes equation. Such analysis was necessary to understand the internal flow pattern. The high velocity of the spheres entering the elutriator subjects them to both centrifugal and drag forces. Process gas is also being fed into the settling chamber from the bottom causing the waste particles to be fluidized and removed through the top of the chamber. Additional surface roughness and drag on the particles (and ceramic spheres) is provided by a cone shaped perforated plate within the settling chamber. The elutriator also has a ceramic inlet scroll, an area where high frictional forces are anticipated.

The ceramic spheres, substantially free of the waste particles are removed from the bottom of the settling chamber to be fed back into the MBE vessel. Process gas carrying the waste particles enters a high efficiency cyclone where particles are removed from the process stream and the clean gas is sent on to the filtration system and recirculating blower. A filtration system is necessary because cyclone separators can efficiently remove only particles larger than 10 microns ${ }^{64}$. The requirements for dust removal by the filtration system will be dictated by the nature of the recycle pump and will not be based on exit emissions criteria.

Demonstration of the sphere cleaning concept was provided by the $0.03 \mathrm{gpm}$ pilot-scale MBE run at LLNL (section 5.2), the agitation which occurred during recirculation was sufficient to keep the spheres clean, with only a thin coating of $\mathrm{Na}_{2} \mathrm{CO}_{3}$ being deposited on the sphere surface during the tests. Build-up of $\mathrm{Na}_{2} \mathrm{CO}_{3}$ was apparently precluded by the agitation of the spheres during recirculation, which entrained the fine grained $\mathrm{NaNO}_{3}$ crystals in the gas phase. A large fraction of these crystals was removed from the gas using a cyclone separator and subsequently collected in a waste hopper. In addition, a sintered metal filter was employed to capture any micron sized dust remaining in the gas. Only a small quantity of dust ( 200 grams or $<4 \%$ of the injected sodium) was collected in the sintered metal filter. As stated, the current system design recycles the lift gas to eliminate this exit stream.

${ }^{64}$ W. L. Nelson, Petroleum Refinery Engineering, McGraw-Hill, 784,1958. 


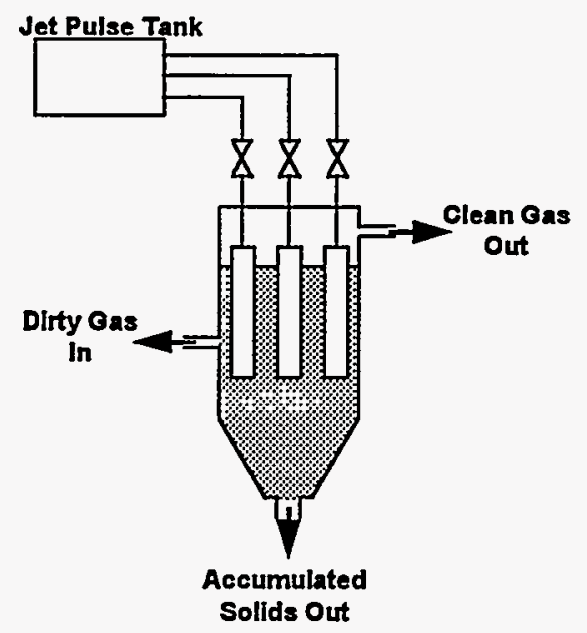

Figure 4.9 Schematic of Candle Filter System

Particulate matter not removed by the high efficiency cyclone will travel to the solids filter system as shown in Figure 4.7. The majority of the particulate matter to be filtered out at this stage is expected to be $<10$ microns with the sphere conveyance recycle gas temperature at the filters being approximately $550^{\circ} \mathrm{C}$. Based on these operating conditions, a ceramic candle filter system will be utilized. Considerable information is available on the use of porous ceramics for removing particulate matter from high temperature gas. ${ }^{65-68}$ These filters are in use at several international locations including: the Karlsruhe Nuclear Research Center, the Swiss Wurenlingen Nuclear Research Center, the Austrian Nuclear Research Center of Seibersdorf and two nuclear power plants at Tsuruga and Mihama in Japan. Additional plants employing candle filter technology are under construction in Europe and Japan. Incineration activities at the Karslruhe site include both low level radioactive waste and alpha contaminated waste. The filtration system for the $0.5 \mathrm{gpm} \mathrm{MBE}$ would contain seventeen silicon-carbide ( $\mathrm{SiC}$ ), candle filters with a superheated steam backpulse flushing system. Figure 4.9 is a simplistic view of the candle filter system.

Refinement of the entire solids separation system design will require demonstrations of cleaning efficiency and extended duration abrasion testing. These will be opportunities to "fine-tune" the solids removal system for optimal operation.

${ }^{65}$ H. Leibold, F. Dirks, V. Rudinger, Kerforschungszentrum Karlsruhe, "Particulate Emissions from a LLW Incinerator and OFF-Gas Cleaning with a New Type of Ceramic Candle Filter", Proceedings, International Conference on Incineration of Hazardous, Radioactive \& Mixed Wastes, San Francisco, California, May 3-6, 1988.

${ }^{66}$ Ing. W. Hempelmann, "The Incineration of Low Level Radioactive Waste", Kernforschungszentrum Karlsruhe, August 9, 1978.

${ }^{67}$ O. J. Tassicker, "Gas Stream Filtration for Pressurized Fluidized Bed Combustion-An EPRI Perspective", Second Annual Contractors Meeting on Contaminant Control in Hot Coal Derived Gas Streams, U.S. Department of Energy, Morgantown, WV, February 17-19, 1982.

${ }^{68}$ J. F. Zeivers, P. Eggerstedt, E. C. Zeivers, "Porous Ceramics for Gas Filtration", American Ceramic Society Bulletin, 70, 1991. 


\subsubsection{Radiation Shielding}

The high-level radioactive environment associated with Hanford UST waste imposes severe restrictions upon accessibility to the equipment by personnel once waste treatment has begun and the system has been contaminated. In order to develop an estimate of the magnitude of the radiation environment and the limitations it imposes on maintenance protocol, the radiation fluence was calculated for two UST waste compositions and three MBE operating scenarios. ${ }^{69}$ Calculations were performed for various combinations of these parameters for both a $0.5 \mathrm{gpm}$ and $5.0 \mathrm{gpm}$ scale MBE. Finally, shielding thickness for lead, 304 stainless steel and concrete were estimated for various combinations of waste composition, with a goal of limiting 2 meter dose rates to $10 \mathrm{mrem} / \mathrm{hr}$. The 2 meter, 10 $\mathrm{mrem} / \mathrm{hr}$ dose rate was selected because it is specified in Title $10 \mathrm{CFR}$, Parts $71 \& 72$ as the limit for contact handling during radioactive material handling and transportation operations.

The Hanford site contains 177 underground storage tanks that contain approximately 61 million gallons of waste. Since the exact UST waste composition and radionuclide content is unknown and no two of these tanks are considered to have identical wastes, an attempt was made to select a "worst-case" radiation source tank as well as a "nominalcomposition" tank for the shielding analysis. Tank 101-SY was selected as a nominal waste tank and Tank 106-C was chosen as the worst-case radiation source. Since the waste composition of Tank 101-SY was felt to be better known than the composition of Tank 106-C, worst case calculations were performed for a hypothetical waste consisting of 101-SY chemical components and 106-C radionuclides. The radionuclides were assumed to be the mixture present if the waste recovered was $75 \%$ liquid and $25 \%$ solid. However, since the solids of 106-C present the "worst worst-case" for radionuclides, one calculation assuming the waste recovered was $100 \%$ solids was made for comparison purposes. The nominal operating condition was calculated using Tank 101-SY composition and radionuclide content. Based upon the results for Cs and Sr uptake by ceramic spheres (section 3.1.3), the calculations assumed that radionuclides did not accumulate in the MBE.

Analyses were performed for three cases. Case 1 represents a possible worst case condition where the MBE vessel, completely empty of ceramic spheres, fills up with slurried waste. Case 2 represents the nominal operating condition for the MBE vessel where the MBE vessel is filled with ceramic spheres coated with a solidified sodium carbonate/radionuclide residue. Finally, Case 3 represents an operating upset condition where the sphere circulation system fails and the MBE vessel, filled with ceramic spheres, fills up with slurried waste. For cases 1 and 3, slurried waste implies the stated waste stream has been diluted with 3 parts water.

The multi-dimensional point-kernel code QADS was used to perform the shielding analyses of the MBE vessel. ${ }^{70}$ The QADS input file consists of four types of information:

${ }^{69}$ K. D. Seager, P. D. Gildea, J. D. Smith, "Radiation Shielding Analyses for Steam Reforming Processing of Hanford UST Wastes", Draft Report TTC-1309, April 1994.

${ }^{70}$ B. L. Broadhead, QADS: A Multidimensional Point Kernel Analysis Module, NUREG/CR-5468, ORNL/CSD/TM-270, Oak Ridge National Laboratory, Oak Ridge,TN, 1990. 
(1) standard composition data, (2) the source specification, (3) the problem geometry specification and (4) the dose and detector specification. The material compositions for the waste, stainless steel vessel, calcium silicate thermal insulation and radiation shield material were defined using the QADS standard composition specification data. The source specification for the QADS input file were obtained by using Microshield 3.12. ${ }^{71}$ The problem geometry specification for the QADS input file was developed by modeling the MBE vessel as a series of concentric right circular cylindrical bodies. Finally, the dose and detector specification for the QADS input file were given. The buildup factors utilized the geometrical progression approximation and the doses were given as an air exposure response with penetration through the given radiation shield. Ten detectors were used to determine the isodose contours. The applicable results of the analysis are summarized in Table 4-1.

The foregoing analysis was made only to provide first order estimates of the radiation environment that could be expected for operations that involve Hanford UST waste. The three scenarios selected may not include the ultimate worst-case condition. For this reason, it should not be considered complete and should only be used for initial design and planning purposes. However, in view of these limitations, some preliminary assessments can be made. It appears that either 1.0 inches of lead, 2.0 inches of 304 stainless steel or 7.0 inches of concrete around the MBE vessel will provide adequate protection for contact maintenance for nominal operating conditions (i. e. for processing $20 \mathrm{gpm}$ of Tank 101-SY waste using parallel operation of four $5.0 \mathrm{gpm}$ MBEs ). Shielding protection to this same level for a worst case scenario (e.g. an MBE vessel filled completely with Tank 106-C waste slurry) would require about twice this thickness.

\begin{tabular}{|l|l|l|l|l|l|l|}
\hline $\begin{array}{l}\text { MBE } \\
\text { capacity }\end{array}$ & $\begin{array}{l}\text { Scenario } \\
\text { Radionuclide }\end{array}$ & $\begin{array}{l}\text { Surface dose } \\
\text { source }\end{array}$ & rate mrem/hr & \multicolumn{4}{|l|}{ Lhead thickness; (in); for 10 mrem/hr } \\
\hline $5.0 \mathrm{gpm}$ & Case 1 & $75 / 25106-\mathrm{C}$ & N. C. $*$ & 2.0 & 4.0 & 14.0 \\
\hline $5.0 \mathrm{gpm}$ & Case 2 & $101-\mathrm{SY}$ & $7.91 \times 10^{2}$ & 1.0 & 2.0 & 7.0 \\
\hline $5.0 \mathrm{gpm}$ & Case 3 & $75 / 25106-\mathrm{C}$ & N. C. & 1.0 & 3.0 & N. C. \\
\hline $0.5 \mathrm{gpm}$ & Case 2 & $100106-\mathrm{C}$ & $7.83 \times 10^{3}$ & N. C. & 3.0 & N. C. \\
\hline $0.5 \mathrm{gpm}$ & Case 2 & $101-\mathrm{SY}$ & $9.54 \times 10^{2}$ & 0.5 & 2.0 & N. C. \\
\hline
\end{tabular}

$* \mathrm{~N}$. C. $=$ not calculated

Table 4-1 Shielding Thickness to Reduce 2 Meter Dose Rate to 10 $\mathrm{mrem} / \mathrm{hr}$

The actual thickness and composition of radiation shielding materials to be used for Hanford waste processing will depend on cost tradeoffs between such factors as maintenance, construction and personnel exposure costs. These evaluations will be made when the actual processing technology is selected. For this reason it is premature to pursue the specification of shielding beyond the present preliminary stage, and conclude that adequate shielding for contact maintenance will require 1-2 inches of lead, 2-4 inches of stainless steel, or 7-14 inches of concrete.

${ }^{11}$ C. A. Negin, et al., MicroShield 3.12, Grove Engineering Inc. Rockville, MD, 1988. 


\subsubsection{Balance of Plant}

The balance of plant (BOP) consists of those components which connect and support the two main processing units, the MBE and the Synthetica detoxifier. A portion of the steam and other gases leaving the MBE are heated by BOP components and recycled. The remaining portion of the gas is cooled to recover the steam as water. The water and any carried over solids or radionuclides are separated from the gas. The water may be recycled to the waste recovery system. Organics in the gas are concentrated before being sent to the detoxifier for final destruction. The following sections briefly describe BOP component designs.

\subsubsection{Heat Addition/Recovery}

In general, proven chemical processing industry heat addition and recovery techniques and equipment are employed in the $0.5 \mathrm{gpm}$ steam reforming system balance of plant design. Electric heaters have been emphasized because of the nearly universal availability of electric power. Compatible off-the-shelf heat exchangers are specified for heat recovery operations whenever possible. However, since much of the heat available for recovery is at temperatures below that of the sphere heater, special applications of high temperature heat pump equipment may offer significant improvement over more conventional approaches.

\subsubsection{Condensate/Gas Separation}

Gas/liquid separation can be accomplished, for example, by a G. R. Clark triple-stage "VenturiPak" scrubber. This scrubber will remove sub-micron particulates as well as condensible radionuclides. The scrubber incorporates multiple stages (quencher, impingement plates, and venturi) that are adaptable to changing requirements. For example, if chemical scrubbing is desired, different chemical scrubbing liquids can be used in different stages. The scrubbing liquid can be collected, reused, or recycled. Tray stages may be used to selectively absorb or condense gaseous species by chemical or thermal treatment of the scrubbing liquid. The venturi stage is used to capture sub-micron particles and condensables not captured by the quencher and tray stages.

Volatile organic fragments from the MBE that will be fed into the scrubber can be divided into two groups: those that are light (i.e. $\mathrm{CH}_{4}$ to $\mathrm{C}_{2} \mathrm{H}_{2}$ ) and appear in the scrubber exit gases, and traces of those heavier (i.e. benzene to naphthalene) that appear in the recovered scrubber water to be recycled. The latter components will have some distribution between vapor and liquid, and are unlikely to appear in just a single phase. The net result of the scrubber physio-chemical effects is that the overhead vapor stream will contain a majority of the light hydrocarbons and a small fraction of the heavy organics.

The gas stream exiting the scrubber is fed to two columns that adsorb the heavier organics and allow the lighter gases to pass. The two columns operate alternately, with one column 
being loaded with organics while the second column is being regenerated with synthesis gas and steam from the Synthetica detoxifier. The gas separation minimizes the quantity of gas which must be treated by the high temperature reactor. During the regeneration step, the organics that are adsorbed on the column are swept into the detoxifier where they are destroyed by the steam-reforming process. We anticipate the bed will contain new technology inorganic sorbents such as zeolites. These sorbents have a significantly longer cycle life (i.e. 1000 cycles) than conventional carbon. Inorganic materials should not be degraded by the presence of radioactive species such as ${ }^{3} \mathrm{H}$ or ${ }^{14} \mathrm{C}$ that might reach this point in the process.

The baseline design considers separating only the higher molecular weight compounds such as benzene and higher from the gas stream. Benzene is an important reference compound because of its carcinogenic nature. In general, the separation ratio is proportional to the molecular weight ratio, with this ratio only slightly modified by molecular size and polarity. The separation ratio of benzene/ethylene is typically 200 , and for the lighter gases such as methane, the separation ratio can be as great as 2000 . Similar molecular weight gases, such as hexane, have nearly identical separation ratios. Purus, Inc. Has provided some information regarding the design and manufacture of an gas separation system. Figure 4.10 is data provided by Purus for their adsorbent PurSorb ${ }^{\mathrm{TM}}$ 200. Note that even for the case of high methane concentration and low benzene concentration, benzene will be removed with high selectivity.

An alternative to the sorbent column separation technique is a polymeric membrane separation. In this method, the separation ratio is roughly equal to the ratio of gas permeabilities that are fundamentally related to the sieving molecular diameters. As an example, the selectivity of $\mathrm{O}_{2}$ of $\mathrm{CH}_{4}$ is about 8 to 40 depending on the membrane composition, and the selectivity of $\mathrm{O}_{2}$ to benzene is expected to be (using kinetic diameter arguments) $400-880 .^{72}$ Thus polymeric membranes and sorbent columns are likely to offer comparable performance. However, column separation has been designated as baseline due to its ruggedness and the ease of integrating its temperature swing cycling with the detoxifier.

12 R. E. Kesting, A. K. Fritzsche, Polymeric Gas Separation Membranes, John Wiley and Sons, New York, 1993. 


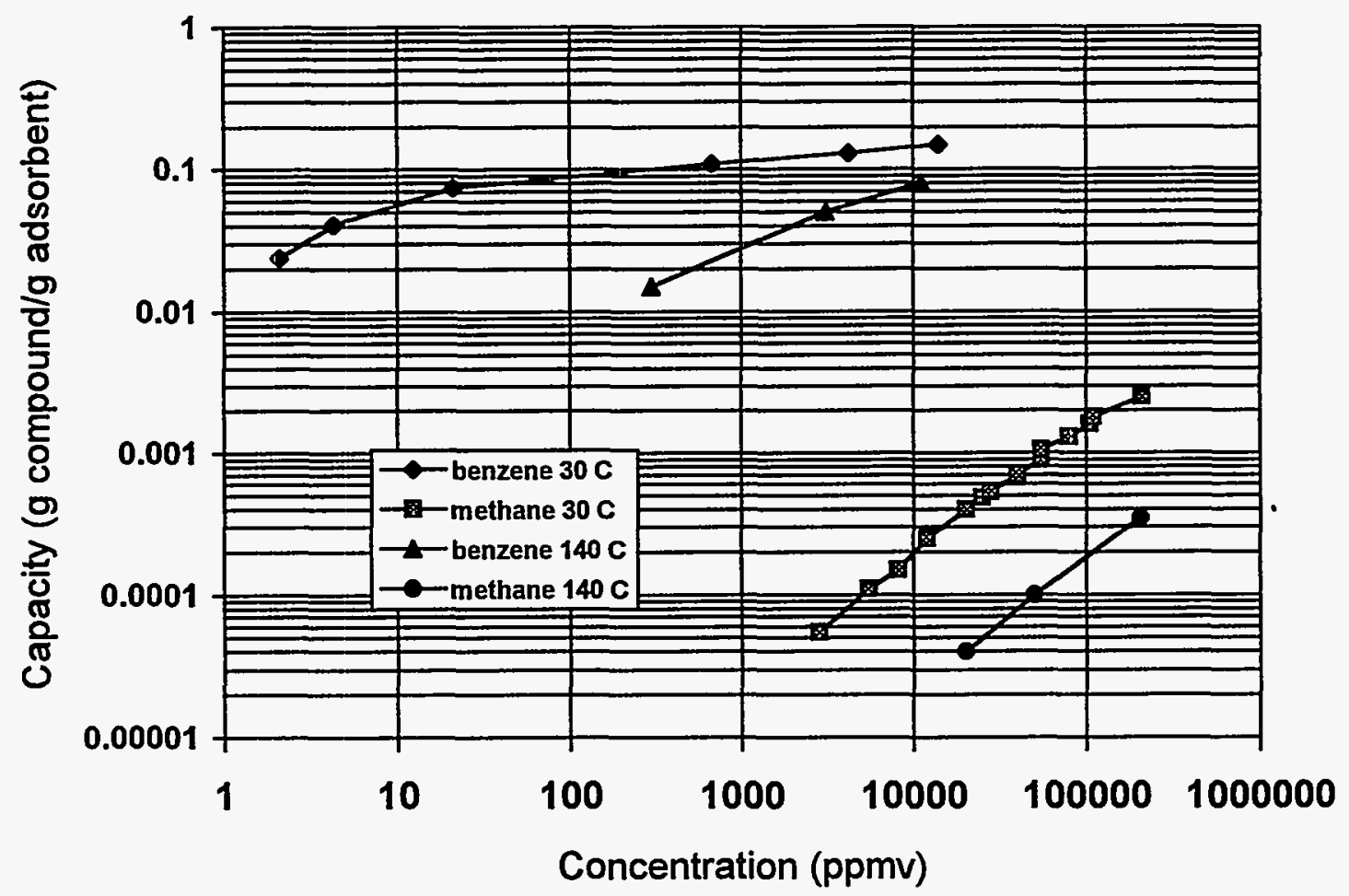

Figure 4.10 Isotherms for Benzene and Methane on Pursorb ${ }^{\text {TM }} 200$

\subsubsection{Detoxifier}

The final processing unit of the Hanford UST steam reforming system is a detoxifier that is commercially available from Synthetica Technologies, Inc. This unit steam reforms organics to $\mathrm{CO}, \mathrm{CO}_{2}$ and $\mathrm{H}_{2}$ in a reactor operating near $1150^{\circ} \mathrm{C}$. Its role in this application is to destroy organic fragments from the MBE, thus enabling the offgas to meet emission requirements. Table 4-2 presents destruction efficiency data generated by Synthetica in a California Grant Program. A greater than $(>)$ symbol preceding the value in the destruction efficiency column indicate that the analytical results were at the limit of instrument detection, and thus only a lower bound could be determined.

Steam and synthesis gas from the detoxifier are used to strip organics off the adsorption columns (section 4.2.3.2). The gas stream with the stripped organics is fed into the high temperature reactor of the detoxifier where the organics are destroyed. After the organics are destroyed, a portion of the gas stream is vented in order to maintain the pressure balance. The remainder of the gas is recycled to the adsorption columns. If a high molecular weight cut is used in the gas separation columns, the organics fed into the detoxifier would consist principally of components such as benzene, naphthalene, toluene, styrene, ethynyl benzene and 1,3-butadiyne. Under RCRA, these compounds must be destroyed to at least $99.99 \%$, and this is accomplished by the Synthetica detoxifier without 


\begin{tabular}{|c|c|c|c|}
\hline 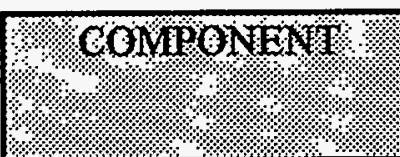 & 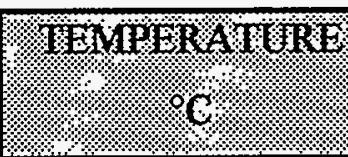 & \% & DESTROUCMON \\
\hline Acetone & 1150 & 9 & 99.9963 \\
\hline Carbon Tetrachloride & 1150 & 33 & 99.9952 \\
\hline Chloroform & 1150 & 33 & 99.9992 \\
\hline Dichlorobenzene & 1115 & 1 & $>99.9510$ \\
\hline Isopropanol & 1150 & 16.4 & $>99.9990$ \\
\hline Methanol & 1150 & 10 & 99.9972 \\
\hline Methylene Chloride & 1150 & 33 & 99.9978 \\
\hline $\begin{array}{l}\text { Methyl Isobutyl } \\
\text { Ketone }\end{array}$ & 983 & 25 & $>99.99$ \\
\hline 1,1,1-Trichloroethane & 1188 & 1 & $>99.9700$ \\
\hline Xylene & 1150 & 0.8 & $>99.9815$ \\
\hline
\end{tabular}

Table 4-2 Detoxifier Destruction Efficiency

the formation of polychlorinated dibenzodioxins and dibenzofurans. This is achieved because steam reforming is a non-incineration technology that excludes oxygen. Since steam-reforming is a non-incineration technology, many permitting issues associated with incineration may be avoided.

\subsubsection{Material and Energy Balance}

Preliminary material and energy balances have been developed for the 0.5 gpm steam reforming system. The first step in developing the balances was to define the input to the system. This was necessary due to the compositional variability in Hanford UST waste. This variability exists not only from tank to tank but within single tanks as the wastes have segregated into layers of supernate, sludge, and saltcake. Variability is also found between the single shell tanks which primarily contain sludge and saltcake and the double shell tanks in which liquids are primarily stored. In addition many tanks are known to contain unique items such as railroad ties, steel tapes, plastic, rocks, concrete, clothing and glass. Furthermore, estimates of tank contents vary widely. However, it is clear that the USTs contain large amounts of $\mathrm{H}_{2} \mathrm{O}, \mathrm{NaNO}_{3}, \mathrm{NaNO}_{2}, \mathrm{Na}_{2} \mathrm{CO}_{3}, \mathrm{NaAlO}_{2}$, and $\mathrm{Na}_{3} \mathrm{PO}_{4}$. Although present in smaller amounts, organics and ferrocyanides are also important constituents of the tanks. ${ }^{73}$ The radioactive load of the UST wastes is also variable. Specific activities range up to $0.85 \mathrm{Ci} / \mathrm{L}$ for supernate, saltcake, and slurry, to over 2.5

73 J. K. Rouse, T. J. McLaughlin, S. P. Airhart, E. J. Jensen, S. L. Lindberg, D. D. Robinson, J. M. Cruse, "Underground Storage Tank - Integrated Demonstration Participant Site Characteristic Summary," WHC-EP-0566, Westinghouse Hanford Company, Richland, Washington, January, 1993. 
$\mathrm{Ci} / \mathrm{L}$ for sludge. The principle radionuclides in the waste are TRUs including uranium and plutonium, and fission products and decay daughters including ${ }^{137} \mathrm{Cs}$ and ${ }^{90} \mathrm{Sr}^{73}$ Since the steam reforming process is robust and may operate at a wide range of feed compositions, a representative waste was chosen as the input.

First it was assumed that for reasons of retrieval and transport the UST waste will be diluted 3:1 by volume with water. (Note that the treatment scheme allows the added water to be recycled to the waste retrieval operation.) The basis for the waste composition was analytical data for liquid taken from tank 101-SY. ${ }^{74}$ The waste was assumed to have a density of $1.3 \mathrm{~g} / \mathrm{cc}^{73}$ It was then assumed that the mass flowrate of each anion obtained by using the concentrations in reference 74, a density of $1.3 \mathrm{~g} / \mathrm{cc}$, and a volumetric flowrate of $0.125 \mathrm{gpm}$ was the correct value. Likewise, values for the mass flowrates of water, metals, $\mathrm{NH}_{3}$ and organics were obtained. Enough $\mathrm{Na}$ was then added to achieve a charge balance. In the charge balance calculation, all ammonia and organics were assumed to be neutral, and of the metals, only $\mathrm{Ca}$ and $\mathrm{K}$ were included as positive species. The other metals are present only in trace quantities and are therefore negligible to the calculation. A check of the final composition gives a density of $1.36 \mathrm{~g} / \mathrm{cc}$.

Radionuclides were included as given in reference 74 .

Figure 4.11 is a schematic of the $0.5 \mathrm{gpm}$ system with the major process streams number coded for identification. The numbers correspond to columns in the material balance presented in tables 4-3 and 4-4.

In the process, $0.125 \mathrm{gpm}$ of the waste (stream 1) is slurried in $0.375 \mathrm{gpm}$ of water (as part of the recovery operation and not considered here) (stream 2) and fed to the MBE. The waste stream is preheated to near $100^{\circ} \mathrm{C}$ with about $10 \mathrm{~kW}$ of recovered heat. Hot ceramic spheres in the MBE provide about $80 \mathrm{~kW}$ of energy to evaporate the water from the waste and raise the temperature to $550^{\circ} \mathrm{C}$. However, about $100 \mathrm{~kW}$ of energy are added to the spheres to account for losses in the recirculation system. Enough additional energy is supplied by gases recycled to the MBE (stream 3 ) to support the endothermic nitrate decomposition. The energy required ranges from less than $1 \mathrm{~kW}$ for the case shown where the products are $\mathrm{Na}_{2} \mathrm{CO}_{3}, \mathrm{~N}_{2}$ and $\mathrm{O}_{2}$, to about $10 \mathrm{~kW}$ if the products were $\mathrm{NaOH}$ and nitrogen oxides. If a reducing agent such as $\mathrm{NH}_{3}$ were used to arrive at $\mathrm{Na}_{2} \mathrm{CO}_{3}, \mathrm{~N}_{2}$ and $\mathrm{H}_{2} \mathrm{O}$ as products, the reaction would be exothermic and less overall heat input (about $20 \mathrm{~kW}$ ) would be required. Carbon dioxide (stream 4) is added to the recycle stream to convert $\mathrm{NaOH}$ to $\mathrm{Na}_{2} \mathrm{CO}_{3}$. The amount of excess $\mathrm{CO}_{2}$ required to ensure complete conversion of $\mathrm{NaOH}$ to $\mathrm{Na}_{2} \mathrm{CO}_{3}$ under $\mathrm{MBE}$ operating conditions is not known; the material balance shown assumes $50 \%$ excess. Gases evolved in the MBE and recycled to the MBE exit as stream 5. Reactions assumed to occur in the MBE include $95 \%$ decomposition of the nitrates and nitrites to $\mathrm{NaOH}$ and $\mathrm{NO}_{\mathrm{x}}$ (section 2.2). The $\mathrm{NO}_{\mathrm{x}}$ is then assumed to react to form $\mathrm{N}_{2}$ and $\mathrm{O}_{2}$ with $99 \%$ efficiency and $100 \%$ of the $\mathrm{NaOH}$ reacts to form $\mathrm{Na}_{2} \mathrm{CO}_{3}$.

${ }^{74}$ D. L. Herting, D. B. Bechtold, B. A. Crawford, T. L. Weish, L. Jensen, "Laboratory Characterization of Samples Taken in May 1991 from Hanford Waste Tank 241-SY-101," WHC-SD-WM-DTR-024, REV 0, Westinghouse Hanford Company, Richland, Washington, 1992. 


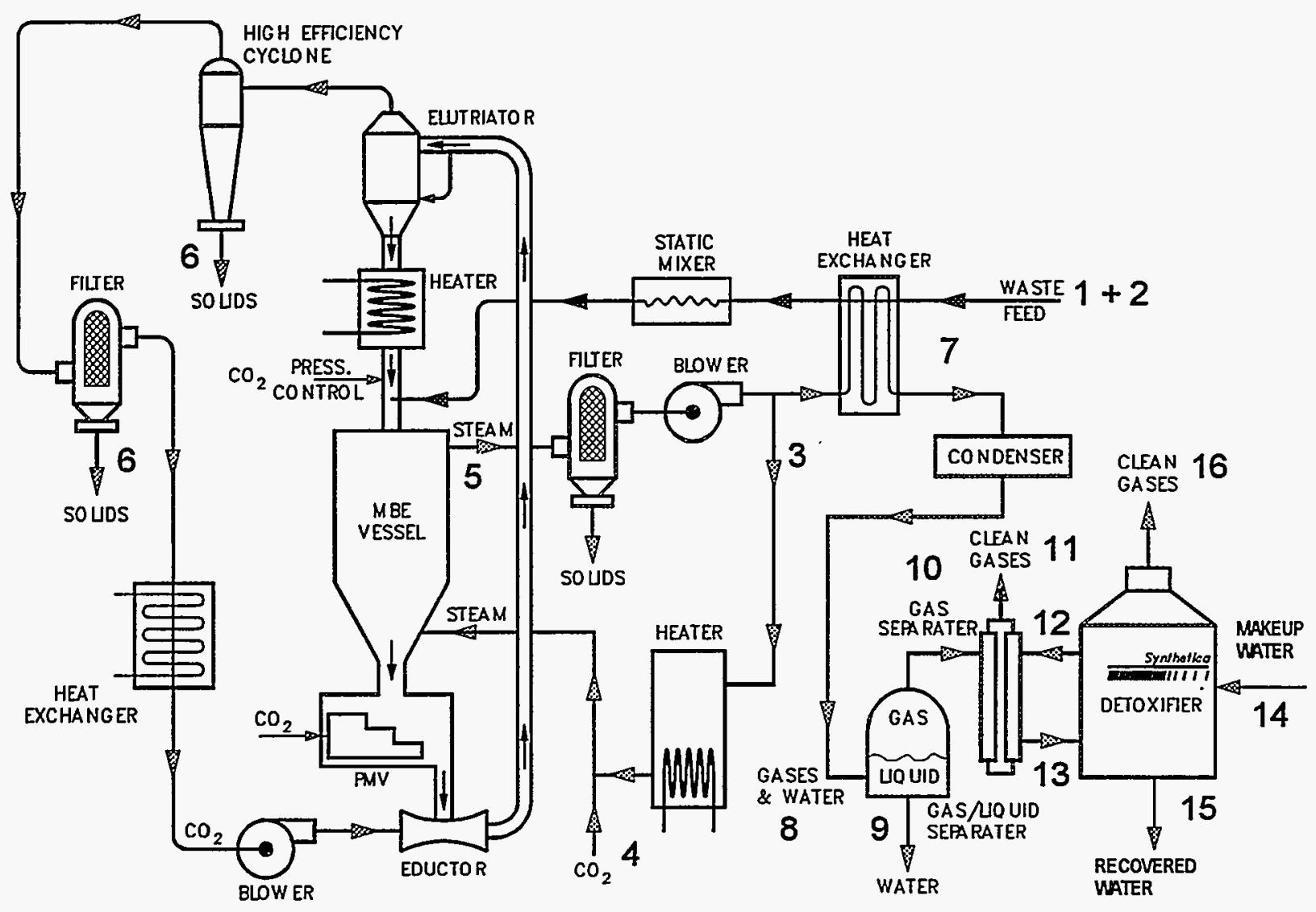

Figure 4.11 Identification of Process Streams

Recall that, if necessary additives can be added to achieve this level of $\mathrm{NO}_{\mathrm{x}}$ conversion as discussed in section 2.2. Also, $99 \%$ of the cyanide species are assumed to decompose to $\mathrm{CO}_{2}$ and $\mathrm{N}_{2}$, (section 2.3) and $100 \%$ of the phosphates react to form $\mathrm{NaOH}$ (which converts to $\mathrm{Na}_{2} \mathrm{CO}_{3}$ ) and $\mathrm{PO}_{x}$. $\mathrm{NH}_{3}$ reacts to form $\mathrm{N}_{2}$ and $\mathrm{H}_{2} \mathrm{O}(99 \%)$. Finally, the organics in the waste feed are vaporized ( $97.5 \%$ gasification) and partially decomposed (section 2.1). Due to the thermal and radiolytic history of the tanks, the current state of organics in the USTs is not well known. It is likely that many of the organics have decomposed or polymerized. It is known that most of the organics were originally the chelating agents ethylenediaminetetraacetic acid (EDTA), hydroxyethylethylenediaminetetraacetic acid (HEDTA), hydroxyacetic acid, and citric acid. Organic solvents were also introduced into the waste. These include di(2-ethylhexyl)phosphoric acid, hexane, tributyl phosphate, normal paraffin hydrocarbons, and carbon tetrachloride. Other possible constituents include sodium gluconate, sucrose, alcohols, organic acids, aliphatics, aromatics, chlorinated aromatics, amines, ketones, esters, and acetates. ${ }^{73}$ 


\begin{tabular}{|c|c|c|c|c|c|c|c|c|c|c|}
\hline Streain: & $1 \%$ & 1 & $2 /$. & 3. & 84 & 5 & 6.1 & 7 & \$ & $90 \%$ \\
\hline & $\begin{array}{l}\text { Waste In } \\
\text { lb/hr }\end{array}$ & $\begin{array}{l}\text { Waste In } \\
\text { Ibmolhr }\end{array}$ & $\begin{array}{l}\text { Slumry } \\
\mathrm{H}_{2} \mathrm{O} \\
\mathrm{Ib} / \mathrm{hr}\end{array}$ & $\begin{array}{l}\text { MBE } \\
\text { recycle } \\
\mathrm{lb} / \mathrm{hr}\end{array}$ & $\begin{array}{l}\mathrm{CO}_{2} \\
\text { feed } \\
\mathrm{lb} / \mathrm{hr}\end{array}$ & $\begin{array}{l}\text { MBE } \\
\text { gases } \\
\text { lb/hr }\end{array}$ & $\begin{array}{l}\mathrm{MBE} \\
\text { solids } \\
\mathrm{lb} / \mathrm{hr}\end{array}$ & $\begin{array}{l}\text { Condenser } \\
\text { feed } \\
\mathrm{lb} / \mathrm{hr}\end{array}$ & $\begin{array}{l}\text { Candeoser } \\
\text { exit } \\
\mathrm{lb} / \mathrm{hr}\end{array}$ & $\begin{array}{l}\text { Recovered } \\
\mathrm{H}_{2} \mathrm{O} \\
\mathrm{lb} / \mathrm{hr}\end{array}$ \\
\hline souxto & & & & अభ & & & & \%ڤ\% & & \\
\hline $\mathrm{NaNO}_{3}$ & 15.38 & 0.18 & 0 & 0 & 0 & 0 & .77 & 0 & 0 & 0 \\
\hline $\mathrm{NaNO}_{2}$ & 13.78 & 0.20 & 0 & 0 & 0 & 0 & .69 & 0 & 0 & 0 \\
\hline $\mathrm{Na}_{3} \mathrm{PO}_{4}$ & 1.03 & $6.25 \mathrm{E}-3$ & 0 & 0 & 0 & 0 & 0 & 0 & 0 & 0 \\
\hline $\mathrm{Na}_{2} \mathrm{SO}_{4}$ & 1.68 & $1.18 \mathrm{E}-2$ & 0 & 0 & 0 & 0 & 1.68 & 0 & 0 & 0 \\
\hline $\mathrm{Na}_{2} \mathrm{CO}_{3}$ & 7.40 & $6.98 \mathrm{E}-2$ & 0 & 0 & 0 & 0 & 33.58 & 0 & 0 & 0 \\
\hline $\mathrm{NaOH}$ & 5.13 & 0.13 & 0 & 0 & 0 & 0 & 0 & 0 & 0 & 0 \\
\hline $\mathrm{NaAlO}_{2}$ & 7.58 & $9.24 \mathrm{E}-2$ & 0 & 0 & 0 & 0 & 8.75 & 0 & 0 & 0 \\
\hline Metals & ঋ. & $3 x$ x & & భै & m & & & \% & & १ి \\
\hline $\mathrm{Ca}$ & $5.6 \mathrm{E}-2$ & $1.40 \mathrm{E}-3$ & 0 & 0 & 0 & 0 & $5.6 \mathrm{E}-2$ & 0 & 0 & 0 \\
\hline $\mathrm{K}$ & 0.28 & $7.24 \mathrm{E}-3$ & 0 & 0 & 0 & 0 & 0.28 & 0 & 0 & 0 \\
\hline $\mathrm{Na}$ & 0.30 & $1.32 \mathrm{E}-2$ & 0 & 0 & 0 & 0 & 0.30 & 0 & 0 & 0 \\
\hline Cr & $9.75 \mathrm{E}-3$ & $1.88 \mathrm{E}-4$ & 0 & 0 & 0 & 0 & 9.75E-3 & 0 & 0 & 0 \\
\hline $\mathrm{Fe}$ & $4 \mathrm{E}-3$ & $7.17 \mathrm{E}-5$ & 0 & 0 & 0 & 0 & $4 \mathrm{E}-3$ & 0 & 0 & 0 \\
\hline Mo & $8.25 \mathrm{E}-3$ & $8.59 \mathrm{E}-5$ & 0 & 0 & 0 & 0 & $8.25 \mathrm{E}-3$ & 0 & 0 & 0 \\
\hline $\mathbf{N}$ & $5.00 \mathrm{E}-3$ & 8.52E-5 & 0 & 0 & 0 & 0 & $5.00 \mathrm{E}-3$ & 0 & 0 & 0 \\
\hline $\mathrm{Zn}$ & $9.00 \mathrm{E}-3$ & $1.38 \mathrm{E}-4$ & 0 & 0 & 0 & 0 & $9.00 \mathrm{E}-3$ & 0 & 0 & 0 \\
\hline Anions & Wै. & א. & & & & & & & & 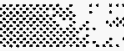 \\
\hline CN & $1.38 \mathrm{E}-2$ & $5.29 \mathrm{E}-4$ & 0 & 0 & 0 & 0 & $1.38 \mathrm{E}-2$ & 0 & 0 & 0 \\
\hline $\mathrm{Cl}$ & 0.72 & $3.76 \mathrm{E}-2$ & 0 & 0 & 0 & 0 & 0.72 & 0 & 0 & 0 \\
\hline$F$ & $4.88 \mathrm{E}-2$ & $1.37 \mathrm{E}-3$ & 0 & 0 & 0 & 0 & $4.88 \mathrm{E}-2$ & 0 & 0 & 0 \\
\hline $811 \mathrm{ct}$ & אוא & \% & & m & 4 & "mభ & א⿵冂. & k. & & $\therefore$ \\
\hline Organics & 2.42 & $7.84 \mathrm{E}-3$ & 0 & 0.24 & 0 & 2.58 & $6.63 \mathrm{E}-2$ & 2.35 & 2.35 & 0.00 \\
\hline $\mathrm{NH}_{3}$ & $8.13 \mathrm{E}-3$ & $4.78 \mathrm{E}-4$ & 0 & 7.43E-6 & 0 & $8.13 \mathrm{E}-5$ & 0 & $7.39 \mathrm{E}-5$ & $7.39 \mathrm{E}-5$ & 7.39E-5 \\
\hline Water & 29.38 & 1.63 & 187.50 & 21.92 & 0 & 239.96 & 0 & 218.04 & 217.84 & 217.84 \\
\hline $\mathrm{HNO}_{3}$ & 0 & 0 & 0 & 0 & 0 & 0 & 0 & 0 & 0.21 & 0.21 \\
\hline $\mathrm{H}_{3} \mathrm{PO}_{4}$ & 0 & 0 & 0 & 0 & 0 & 0 & 0 & 0 & 0.61 & 0.61 \\
\hline Gasus & \% & w. & 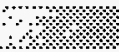 & & & & & & & m. \\
\hline $\mathrm{N}_{2}$ & 0 & 0 & 0 & 0.51 & 0 & 5.53 & 0 & 5.03 & 5.03 & 0 \\
\hline $\mathrm{O}_{2}$ & 0 & 0 & 0 & 1.13 & 0 & 12.46 & 0 & 11.32 & 11.27 & 0 \\
\hline $\mathrm{co}$ & 0 & 0 & 0 & 0 & 0 & 0 & 0 & 0 & 0 & 0 \\
\hline $\mathrm{CO}_{2}$ & 0 & 0 & 0 & 0.60 & 16.77 & 6.53 & 0 & 5.93 & 5.93 & 0 \\
\hline $\mathrm{H}_{2}$ & 0 & 0 & 0 & 0 & 0 & 0 & 0 & 0 & 0 & 0 \\
\hline NO & 0 & 0 & 0 & 4.96E-3 & 0 & $5.43 \mathrm{E}-2$ & 0 & 4.93E-2 & 0 & 0 \\
\hline $\mathrm{NO}_{2}$ & 0 & 0 & 0 & $7.60 \mathrm{E}-3$ & 0 & $8.32 \mathrm{E}-2$ & 0 & $7.56 \mathrm{E}-2$ & 0 & 0 \\
\hline POx & 0 & 0 & 0 & 4.46E-2 & 0 & 0.49 & 0 & 0.44 & 0 & 0 \\
\hline Total & $85 \% 13$ & 1139 & 13740 & 248 & 616 & 26760 & 1698 & 243.24 & 3486 & 218666 \\
\hline Rralúario & fós & \%. & & & \%. & m & \%. & & $\%$ & an \\
\hline Total alpha & $4.25 \mathrm{E}-3$ & & 0 & 0 & 0 & 0 & $4.25 \mathrm{E}-3$ & 0 & 0 & 0 \\
\hline Total Beta & 24.63 & & 0 & 0 & 0 & 0 & 24.63 & 0 & 0 & 0 \\
\hline${ }^{239240} \mathrm{Pu}$ & $3.88 \mathrm{E}-6$ & & 0 & 0 & 0 & 0 & $3.88 \mathrm{E}-6$ & 0 & 0 & 0 \\
\hline${ }^{241} \mathrm{Am}$ & $5.03 \mathrm{E}-5$ & & 0 & 0 & 0 & 0 & $5.03 \mathrm{E}-5$ & 0 & 0 & 0 \\
\hline${ }^{137} \mathrm{Cs}$ & 16.33 & & 0 & 0 & 0 & 0 & 16.33 & 0 & 0 & 0 \\
\hline $\mathrm{U}(\mathrm{g} / \mathrm{hr})$ & $4.65 \mathrm{E}-2$ & & 0 & 0 & 0 & 0 & $4.65 \mathrm{E}-2$ & 0 & 0 & 0 \\
\hline
\end{tabular}

Table 4-3 Material Balance for 0.5 GPM MBE and Balance of Plant

Due to the unknown nature of the organics in the tanks, a hypothetical compound with the empirical formula of $\mathrm{C}_{10} \mathrm{H}_{14} \mathrm{O}_{10} \mathrm{~N}$ was assumed for the mass balance. The hypothetical compound was arrived at by assuming the atomic constituents were present in 
approximately the same ratios as are present in surrogate wastes containing EDTA and citric acid. ${ }^{75}$

\begin{tabular}{|c|c|c|c|c|c|c|c|}
\hline Stracama & 80. & $1 \mathrm{f}$ & $2 \%$ & 13 & & 15 & 16. \\
\hline & $\begin{array}{l}\text { Gassep. } \\
\text { feed } \\
\mathrm{lb} / \mathrm{hr}\end{array}$ & $\begin{array}{l}\text { Gas } \\
\text { vent } \\
\text { lb/hr }\end{array}$ & $\begin{array}{l}\text { Reformer } \\
\text { recycle } \\
\text { Ib/hr }\end{array}$ & $\begin{array}{l}\text { Reformer } \\
\text { feed } \\
\mathrm{Ib} / \mathrm{hr}\end{array}$ & $\begin{array}{l}\text { Makeap } \\
\text { water } \\
\text { Ib/hr }\end{array}$ & $\begin{array}{l}\text { Recovered } \\
\text { water } \\
\mathrm{lb} / \mathrm{hr}\end{array}$ & $\begin{array}{l}\text { Reformer } \\
\text { vent } \\
\text { lbhhr }\end{array}$ \\
\hline & 025 & & ? דיטמי & & & & \\
\hline $\begin{array}{l}\text { Utganics } \\
\mathrm{NH}_{3}\end{array}$ & $\begin{array}{l}2.35 \\
0\end{array}$ & 0 & $\begin{array}{l}2.31 \mathrm{E}-3 \\
0\end{array}$ & $\begin{array}{l}2.35 \\
0\end{array}$ & 0 & 0 & 0 \\
\hline Water & 0 & 0 & 11.62 & 11.62 & 0.64 & 0.21 & 0 \\
\hline $\mathrm{HNO}_{3}$ & 0 & 0 & 0 & 0 & 0 & 0 & 0 \\
\hline $\mathrm{H}_{3} \mathrm{PO}_{4}$ & 0 & 0 & 0 & 0 & 0 & 0 & 0 \\
\hline Cases & & & \%. & & & 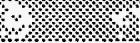 & $\%$ \\
\hline $\mathrm{N}_{2}$ & 5.03 & 5.03 & 5.81 & 5.81 & 0 & 0 & 0.11 \\
\hline & 11.27 & 11.27 & & & 0 & 0 & \\
\hline $\mathrm{CO}$ & & & 80.23 & 80.23 & 0 & 0 & 1.47 \\
\hline $\mathrm{CO}_{2}$ & 5.93 & 5.93 & 56.64 & 56.64 & 0 & 0 & 1.04 \\
\hline $\mathrm{H}_{2}$ & 0 & 0 & 8.39 & 8.39 & 0 & 0 & 0.15 \\
\hline No & 0 & 0 & 0 & 0 & 0 & 0 & 0 \\
\hline $\mathrm{NO}_{2}$ & 0 & 0 & 0 & 0 & 0 & 0 & 0 \\
\hline POx & 0 & 0 & 0 & 0 & 0 & 0 & 0 \\
\hline Total & 24,58 & 2223 & $162 \% 20$ & 655,44 & 0.64 & 0.21 & $2,8 \%$ \\
\hline
\end{tabular}

Table 4-4 Material Balance for $0.5 \mathrm{gpm}$ Balance of Plant and Detoxifier

Solid material is removed from the MBE and collected by the elutriation system (stream 6). This stream consists primarily of $\mathrm{Na}_{2} \mathrm{CO}_{3}$. The radionuclides (section 2.4), metals, and unreactive salts also exit the system as part of this waste stream. In addition, the solid stream also includes $0.73 \mathrm{Ib} / \mathrm{hr}$ of $\mathrm{Al}_{2} \mathrm{O}_{3}$ from sphere abrasion (section 3.1). The $\mathrm{Al}_{2} \mathrm{O}_{3}$ is assumed to exit the system as $\mathrm{NaAlO}_{2}$.

The majority of the steam and other gases exiting the MBE are fed to a condenser (stream 7). In the condenser and downstream where gas and liquid are in contact, the remaining $\mathrm{NO}_{x}$ is converted to $\mathrm{HNO}_{3}$ and $\mathrm{PO}_{x}$ is converted to $\mathrm{H}_{3} \mathrm{PO}_{4}$. For simplicity, the reactions are shown as occurring solely in the condenser (stream 8). Approximately $70 \mathrm{~kW}$ of heat is removed from the process stream by the condenser. The liquid exiting the condenser is recovered for recycle to the waste recovery system (stream 9) or used to slurry the solids exiting the MBE for further processing. The gases are scrubbed and sent to the gas separation system (stream 10) where the lighter gases (stream 11) are separated from the organic vapors.

The organics are stripped from the adsorption media in the gas separation system by a hot recycle stream (12) and carried into the high temperature detoxifier (stream 13). Makeup steam (stream 14) is added to the reactor to accomplish the desired reforming chemistry (99.99\% conversion of the hydrocarbons to $\mathrm{CO}, \mathrm{H}_{2}, \mathrm{~N}_{2}$ and $\mathrm{CO}_{2}$ ) and prevent carbon deposition. Although the organics are expected to undergo some reactions in the MBE, the calculations assume that reactions of organics are limited to the detoxifier. This is

${ }^{75}$ E. O. Jones, N. G. Colton, J. R. Bloom, "Hanford Single-shell Tank Waste Preliminary Pretreatment Testing of Simulated Waste," Pacific Northwest Laboratories \& Westinghouse Hanford Company, Richland, Washington, 1991. 
appropriate and necessary due to the unknown nature of the organics. The vent stream exiting the reformer is fed to a condenser to recover water (stream 15). The condensate can be mixed with makeup water and fed to the steam generator supporting the high temperature reactor. The gases are either vented (stream 16), or further treated to convert $\mathrm{CO}$ and $\mathrm{H}_{2}$ to other chemical species (for example, $\mathrm{CO}_{2}$ and $\mathrm{H}_{2} \mathrm{O}$ ). The detoxifier consumes about $110 \mathrm{~kW}$ of electrical energy.

\section{$4.320 \mathrm{gpm}$ System}

\subsubsection{Description}

The 20 gpm Hanford UST waste pretreatment system design includes two independent 10 gpm modules as depicted in Figure 4.12. Consistent with the modular, compact processing unit philosophy, each $10 \mathrm{gpm}$ module contains two parallel $5.0 \mathrm{gpm} \mathrm{MBE's}$ supplying volatilized organic waste to a $10 \mathrm{gpm}$ capacity Synthetica Technologies, Inc. Detoxifier unit. The $5.0 \mathrm{gpm}$ MBEs are anticipated to be a direct scale-up of the $0.5 \mathrm{gpm}$ intermediate scale unit. The $5.0 \mathrm{gpm} \mathrm{MBE}$ has been selected as an appropriate module size because it results in a processing system that is reasonably compact and portable. Components and sub assemblies of the system should be easily transported to the processing site and assembled with standard handling and erection equipment. Each 10 gpm module would operate as a completely independent processing system. However, to keep the handling of high-level radioactive waste handling to an absolute minimum, they would receive Hanford UST waste from the same supply and deliver the solid radioactive residue to the same waste collection tank for appropriate processing and transfer to the Hanford waste collection point. Current designs result in collecting the solid residue as dry powder. This allows it to be transferred to the Hanford radioactive waste collection point either as dry powder or as a water slurry.

For economic reasons, the dual $5.0 \mathrm{gpm}$ MBE's would share BOP components consistent with requirements for operational safety and reliability. The design approach is to configure each of the $10 \mathrm{gpm}$ modules such that it can operate safely and reliably at half capacity while maintenance operations are in progress on major subassemblies such as one of the MBE reaction vessels or sphere metering systems. Where redundant components are required, e.g., circulation blowers, filters etc., each $10 \mathrm{gpm}$ module would use three units in place of two to provide the backup for maintenance/repair of an individual unit. Balance of plant components, such as steam generators, heaters and heat exchangers, would be sized to support both MBE's where operational safety is not compromised and reliability has been demonstrated by past industrial experience. 


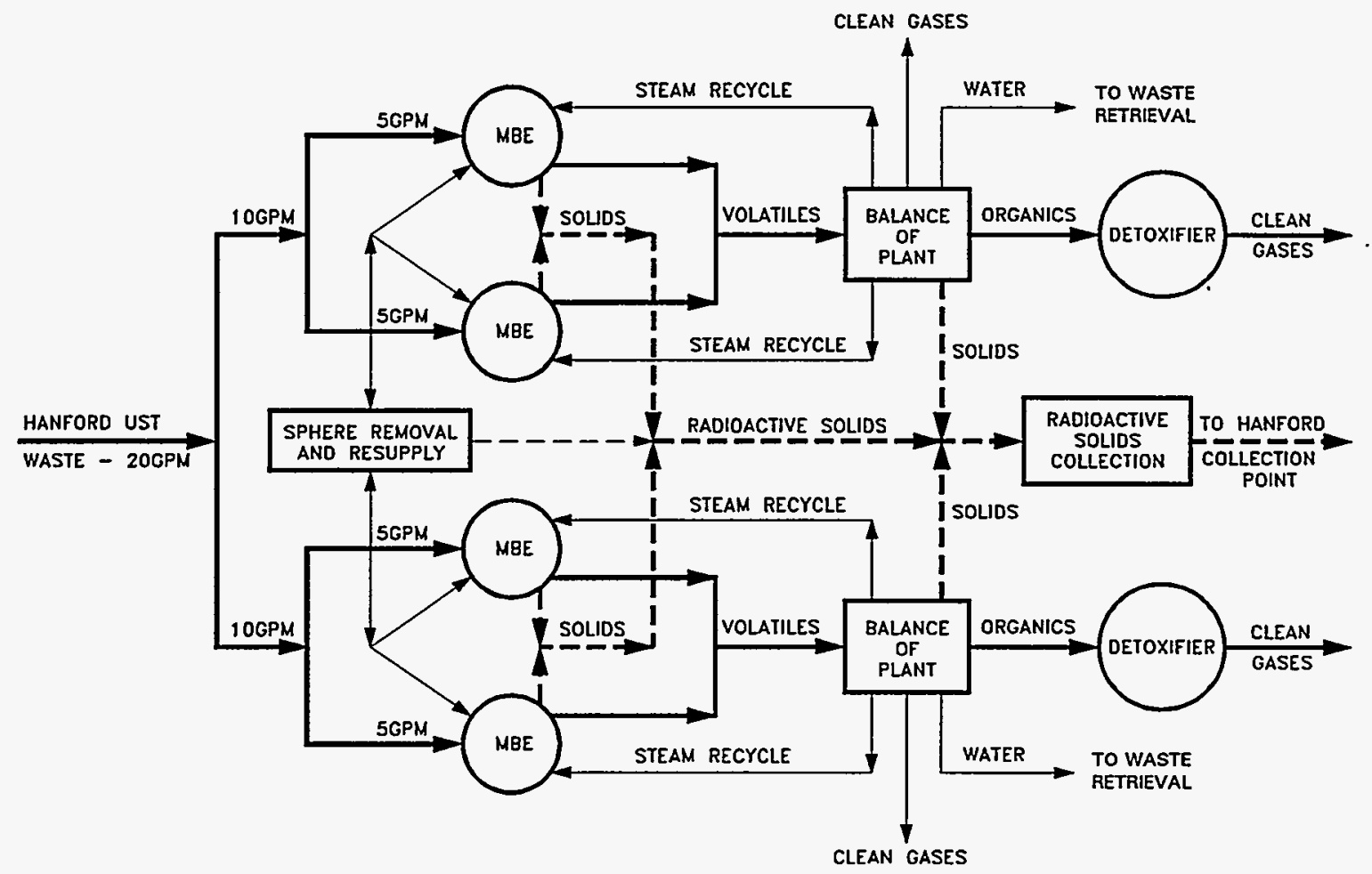

Figure $4.1220 \mathrm{gpm}$ Steam Reforming System

The ceramic spheres in the MBE would be slowly eroded by physical abrasion and chemical erosion and will require replacement periodically throughout the operating life of the system. It might be necessary to empty a MBE vessel of spheres at some time during its operational life to perform maintenance or replace a component such as the pneumatic metering valve. The sphere removal and resupply system (SRRS) shown in Figure 4.13 is provided to accomplish both functions. The SRRS includes a hopper with sufficient capacity to hold one MBE-load of spheres. It is interconnected with each MBE pneumatic transport system such that all or part of the spheres from any of the four MBE's can be moved to, and stored in, the SRRS hopper and later returned to the MBE. In addition, it will be connected to the radioactive solids collection tank so spheres that have been eroded, abraded or broken beyond usability can be included in the solids that are transferred downstream for further waste processing. New spheres could also be introduced to the system through the SRRS.

Because high-level radioactivity is the unique requirement that separates Hanford UST waste processing from a routine chemical process, the design intent for the system was to restrict the migration of radionuclides to the greatest extent possible. This would allow those equipment items that are not exposed to the high-level radioactive environment to be specified and manufactured the same as commercially available chemical processing industry equipment. The radioactive solids generated in the MBE would be collected by a high efficiency cyclone and submicron filter system in the pneumatic conveyance gas loop and by a high efficiency submicron filter system in the steam circulation loop. The purpose for these particulate collection systems is to restrict all of the radioactive solids to 
the MBE subsystem where they are collected and subsequently transferred to the Hanford collection point. In addition to restricting the migration of radionuclides in the system, double containment would be employed as appropriate to further reduce risks.

The small portion of radionuclides that are volatile at MBE operating conditions will migrate through the BOP components. Most of these are expected to condense out of the gas stream with the steam in the condenser. Since the condensate stream, with any entrained radionuclides, would be separated from the gas stream by the gas/water separator, the Detoxifier units should remain almost entirely radiation free. The condensate stream has the two potential uses of being returned for reuse in the tank retrieval operation or as slurry water for pumping the solid waste residue to the Hanford collection point. In either case the entrained radionuclides would be returned to a point where further processing is expected.

\subsubsection{Scale-up from 0.5 GPM System}

The 20 gpm system design consists of two $10 \mathrm{gpm}$ modules each supplying volatilized organic waste to a Synthetica Technologies, Inc. Detoxifier unit. Each $10 \mathrm{gpm}$ module contains two-5.0 gpm MBE's operating in parallel. Scaling up from the $0.5 \mathrm{gpm}$ unit to the $20 \mathrm{gpm}$ System in this modular approach results in factors of 1.0, 10, and 20 for the Detoxifier units, MBE, and balance of plant equipment respectively. The material and energy balance presented for the $0.5 \mathrm{gpm}$ system in section 4.2 .5 scales accordingly. Factors of 10-20 appear very moderate considering that scale-up factors in excess of 100 are achievable when accurate performance data are available. ${ }^{76}$

One very important requirement that separates Hanford UST waste treatment from a routine chemical process is the high-level radioactive environment. The impact of this environment is manifested, principally, in requirements for equipment with increased operational reliability, reduced and/or remote maintenance operations and greater leak tightness. Depending on the degree to which radionuclides migrate through the system, many of the commercially available equipment items, such as blowers and filters etc. might have to be manufactured to nuclear service-like specifications. This would likely have important cost and delivery ramifications. In the analysis that follows no attempt has been made to specifically address the impact of radioactivity on the design requirements of the various equipment items that make up the steam reforming waste treatment system.

Considerations, other than radiation related, that affected the choice of scaling factors for the $20 \mathrm{gpm}$ Hanford waste pretreatment system are discussed by subsystem as follows.

- Detoxifier units: The standard, commercially available Detoxifier has the capacity to destroy organics at a rate in excess of that contained in $10 \mathrm{gpm}$ of slurried waste. As a result, the standard capacity Detoxifier was chosen as the base module for organic destruction in the steam reforming process. Two Detoxifier units would be used in parallel operation to achieve the $20 \mathrm{gpm}$ waste processing requirement.

${ }^{76}$ M. S. Peters, K. D. Timmerhaus, Plant Design and Economics for Chemical Engineers, Fourth Edition, McGraw-Hill, New York, 1991. 
- Moving bed evaporator: The MBE, like many bulk material handling systems, depends primarily on gravity for ceramic sphere movement through the heating and processing cycles. Movement of material by gravitational force generally results in tall systems. Thus the decision was made to use four- $5.0 \mathrm{gpm}$ MBE's rather than two-10 gpm units, to achieve the least height possible and still retain reasonable processing capacity. The $5.0 \mathrm{gpm}$ system would be reasonably compact and transportable. Components and subassemblies would be readily transportable to the processing site and could be assembled with standard handling and erection equipment. Additionally, it would still be possible to build truly portable, truck-mounted systems at this scale. Such systems may have to be built in modules on multiple trucks and interconnected at the processing site. Additionally, the scale-up factor of 10 , from the $0.5 \mathrm{gpm}$ system, appears nominal and readily achievable. ${ }^{72-78}$ Its application to MBE components is summarized as follows.

The MBE system consists of a reactor vessel, pneumatic metering valve, pneumatic conveyance system, particulate separation and collection equipment, sphere heater, sphere conveyance blower and blower inlet gas heat exchanger. While the flow capacities of the various MBE components would all be increased by the scaling factor, the vessel/sphere temperatures, waste residence time, conveyance gas and sphere transport velocities and sphere heater overall heat transfer coefficient would remain the same as those established and test-proven for the intermediate scale system. This would result in an increase of vessel volume by the factor of ten while maintaining the diameter/height ratio between 2 to 2.5 , an increase in the sphere conveyance pipe diameter by the square root of 10 and similar capacity increases for the pneumatic metering valve, elutriator, cyclone and filter system. The resulting heat exchanger and blower capacities for the recirculation system would be about $250 \mathrm{~kW}$ and $4,000 \mathrm{scfm}$ respectively. The filter system would be expected to capture particulate solids at the rate of about $500 \mathrm{lb} /$ hour. Equipment with these capacities, manufactured from compatible materials, should be readily available from commercial suppliers.

The sphere heater is not a commercially available unit and the surface area/size required for heating the spheres isn't known with certainty at this time. Work has begun in designing a prototype contact heater. This unit could be built and tested to experimentally determine the overall heat transfer coefficient. Once the overall heat transfer coefficient has been measured, a heater could be designed and fabricated for the $0.5 \mathrm{gpm}$ MBE. After demonstration at the intermediate scale system level, it will be scaled up to the size required for the $5.0 \mathrm{gpm}$ system. In the event microwave or other techniques are selected for sphere heating, a similar prototype/scale-up process would be employed. The capacity required for the $5.0 \mathrm{gpm}$ sphere heater is $1.0 \mathrm{MW}$.

- Balance of plant: The BOP equipment includes steam generators, heaters, heat exchangers, condensers, steam circulation blowers, particulate filters and gas/liquid and gas/gas separation systems. The present approach is to use dedicated blowers and

${ }^{71}$ R. H. Perry, C. H. Chilton, Chemical Engineers' Handbook, Sixth Edition, McGraw-Hill, New York, 1984.

${ }^{78}$ T. Baumeister, E. A. Avallone, T. Baumeister III, Marks' Standard Handbook for Mechanical Engineers, Eighth Edition, McGraw-Hill, New York, 1978. 
filters for each MBE steam circulation loop with redundancy for increased reliability and backup during maintenance operations. This equipment would be scaled at a factor of 10 from the $0.5 \mathrm{gpm}$ system, and would require a steam circulation blower capacity in the 2,000 to $3,000 \mathrm{scfm}$ range and appropriate capacity ceramic filters to remove particulates.

The heaters, heat exchangers, condensers, gas/liquid and gas/gas separators would be sized for the $10 \mathrm{gpm}$ module requiring scale-up by a factor of 20 . This results in heater capacities up to $200 \mathrm{~kW}$, heat exchangers up to $250 \mathrm{~kW}$ and condensing capacity of about 1.5 MW. The gas/liquid separation system would have a gas flow rate of approximately $475 \mathrm{lb} /$ hour (principally nitrogen and oxygen) and would require a water handling capacity of about $8.0 \mathrm{gpm}$. The gas/gas separator would have a gas flow rate of about $475 \mathrm{lb} /$ hour and would vent approximately $440 \mathrm{lb} / \mathrm{hour}$ of gas. The requirements for the steam reforming system BOP equipment are routine for normal industrial practice and components with these capacities, manufactured from compatible materials, should be readily available from commercial suppliers.

\subsubsection{Environmental Issues and Permitting}

Steam reforming is a non-incineration approach to waste destruction. Reforming reactions of organics with steam are endothermic and therefore inherently controllable. The reducing environment of steam reforming precludes the formation of environmentally problematic species formed by incinerators, such as polychlorinated dioxins and dibenzofurans. Extensive testing carried out on a wide range of waste feeds as part of Synthetica's State of California/EPA Grant program showed that no dioxins were formed (0.2 pg sensitivity). Furthermore, steam reforming does not suffer from a negative public perception as demonstrated by a recent call from a public coalition opposed to incineration to consider steam gasification as a method to destroy chemical weapons. ${ }^{79}$

Detailed permitting discussions have been carried out with the State of Washington Department of Health regarding the siting of a low level radioactive waste treatment unit employing Synthetica steam reforming equipment in Richland. Tentative permits have been granted. Through this process Synthetica has maintained good relations with the State of Washington Department of Health. These preliminary efforts should facilitate the permitting of the system for treating the Hanford underground storage tank waste. Air emission estimation, modeling, and health risk analysis are expected to be the primary technical components of the permit applications.

\subsubsection{Economics}

An initial cost estimate for the 20 gpm Hanford steam reforming system has been developed. The cost estimate for the Hanford system is based on a cost estimate performed by Bechtel in August 1989 for the field deployment of a 100 ton/day oil shale

${ }^{79}$ L. Ember, Chemical and Engineering News, 4, March 28, 1994. 
process demonstration unit. ${ }^{80}$ The 100 ton/day unit is a scale-up of the pilot test facility at Lawrence Livermore National Laboratory described in chapter 6. The major expenditures identified for the oil shale project were the compressor needed for solids recirculation and the compressor for combustion air to bum residual carbon providing process heat. The solids recirculation system for the steam reforming application is simpler than the oil shale system. However, additional heat exchanger capacity would be required to replace the combustion system designed for the oil shale case.

Using the compressor capacity of the 100 ton/day unit, a similarly sized plant for the current application would have the ability to circulate $1500 \mathrm{~kg} / \mathrm{min}$ of ceramic spheres. This 100 fold increase in solids recirculation rate over that used in the pilot plant studies (chapter 5) would provide a processing capacity of $\sim 5 \mathrm{gpm}$. Both the oil shale and waste processing plants contain condensation, filtration, and gas/liquid separation units which are assumed to be equivalent cost items. The steam reforming system includes additional items such as a Synthetica detoxifier and a gas separation system which are estimated to cost about $\$ 1$ million total. These costs are assumed to be covered in the price range quoted below.

Cost estimates for construction of the 100 ton/day oil shale unit ranged from $\$ 10-20$ million. The original cost reported by Bechtel was $\$ 20$ million. However, private communications with a second vendor in 1991 produced a cost quote closer to $\$ 10$ million. Therefore, the cost range in 1995 dollars for a steam reforming system capable of processing up to $5 \mathrm{gpm}$ of Hanford tank waste is $\$ 11-24$ million. Economies of scale should allow a full implementation of the technology at a $20 \mathrm{gpm}$ scale to be constructed for \$29-63 million. Operating costs for 24 hour operation are estimated from the Bechtel study to be $\$ 2-3$ million per year.

\subsubsection{Decontamination and Decommissioning}

The Hanford UST waste treatment systems are defined as nuclear facilities and fall under criteria applied to the design and operation of a nonreactor nuclear facility. ${ }^{81,82}$ Decommissioning requirements for nuclear facilities and equipment are specified and controlled by many DOE orders and federal regulations. Decontamination and decommissioning are defined as follows: ${ }^{83}$

- Decontamination: The removal of radioactive contamination from facilities, equipment or soils by washing, heating, chemical or electrochemical action, mechanical cleaning, or other techniques.

- Decommissioning: Actions taken to reduce the potential health and safety impacts of DOE contaminated facilities, including activities to stabilize, reduce or remove radioactive materials or to demolish the facilities.

\footnotetext{
80 "Western States Enhanced Oil Shale Recovery Program, Shale Oil Production Facilities, Conceptual Design Studies Report," Bechtel Job Number 20227, August 1989.

${ }^{81}$ DOE/TIC 11603-Rev.1 DE87 00986, Nonreactor Nuclear Facilities: Standards and Criteria Guide.

${ }^{82}$ DOE 6430.1, General Design Criteria.

${ }^{83}$ DOE 5820.2A, Radioactive Waste Management.
} 
Requisite decommissioning measures depend upon the specific radionuclides that have been processed or handled. This in turn determines the type and level of contamination or waste that must be either remediated or prepared for disposal. Five major alternatives are provided for the decommissioning and retirement of a nonreactor nuclear facility. ${ }^{77}$

- Safe Storage (considered as temporary)

- Entombment

- Dismantlement

- Conversion to other uses

- Backfill and sealing

Dismantlement, the preferred alternative, specifies that: ${ }^{84}$ "The facility is decontaminated, and then either dismantled or renovated for other use. All radioactive materials having activities above unrestricted use activity levels should be removed from the facility. The facility is then available for unrestricted use." For any of the above retirement alternatives, decontamination is considered a major preparatory activity.

The DOE requires that the initial design of nonreactor nuclear facilities must include measures to limit dispersion and simplify periodic decontamination and also consider requirements for ultimate facility decommissioning and disposal or reuse. The design intent to limit radionuclide dispersion throughout the steam reforming waste treatment system has been described and discussed in section 4.3.1 of this report. Other design criteria include keeping surfaces reasonably smooth, eliminating cracks and crevices where particulates may collect, and using generous radii in transitions. This should facilitate decontamination by washing the system to remove and flush away any solid radionuclide material.

If the design intent is achieved, i.e. if the particulate material can be effectively flushed out of the equipment, it may be possible to meet the surface contamination limits for unrestricted use. However, the Hanford UST tank wastes are the result of reprocessing nuclear fuel for the purpose of extracting plutonium. As such, they contain a combination of transuranic waste and fission products and are classified as high-level waste (HLW). This may affect the waste classification of the decommissioned equipment and limit the alternatives available for the ultimate disposal of the MBE subsystem. However, if the design intent to restrict the migration of the particulate radioactivity is successful, the balance of plant components and Detoxifier unit may still be easily decontaminated to unrestricted use levels and reused for other purposes.

Although the worker related radiation environment is dominated by beta and gamma emission, the waste contains radionuclides that decay both through alpha emission and spontaneous fission. However, neutron activation is not expected to be a concern. The fissile radionuclide concentrations are very small, and proper operating controls should prevent the collection of amounts that will result in neutron activation of the steam

${ }^{84}$ DOE/TIC 11603-Rev.1 DE87 00986, Nonreactor Nuclear Facilities: Standards and Criteria Guide. 
reforming system structural materials. Thus, volume contamination restrictions should not be a consideration for the release of decommissioned materials. ${ }^{85}$

\subsubsection{Integration with TWRS System}

Tri-Party negotiations conducted during 1993 resulted in several important decisions impacting the role of organic destruction within a tank waste remediation system. Specifically, organic destruction became a backup technology to achieve tank safety. Organic destruction was also recognized as a pretreatment step to support vitrification of the low-level waste stream. For example, the Tri-Party Agreement modifications indicated that the LLW glass plant should be designed so that contact maintenance can be performed. To achieve this goal, both cesium and strontium separations will have to be performed prior to LLW vitrification. Since strontium is complexed with organics, ionexchange separation processes may not be successful until after the organics are destroyed.

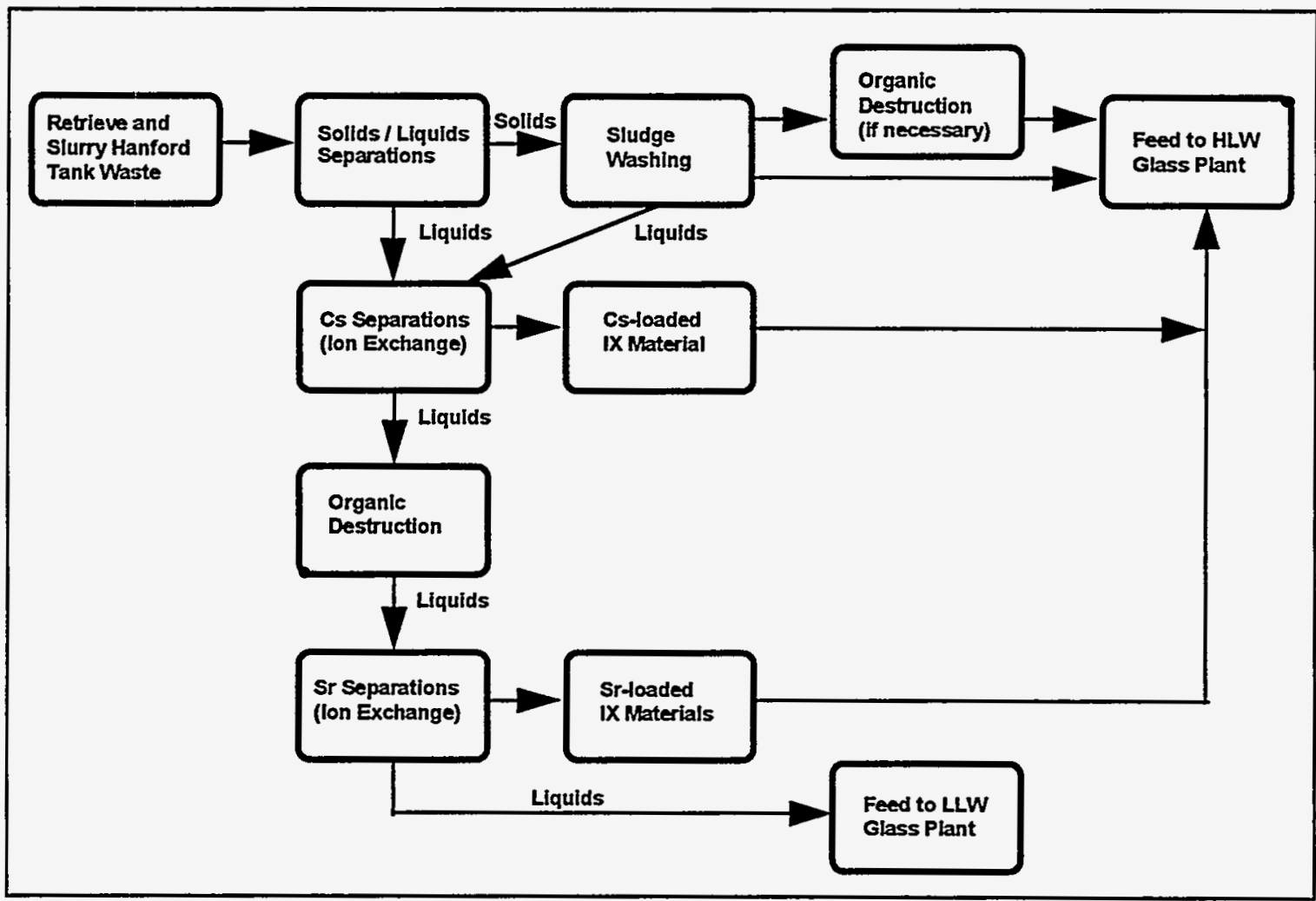

Figure 4.13 Integration of Organic Destruction Process with TWRS Treatment

Figure 4.13 illustrates a proposed treatment process for Hanford tank waste. Upon retrieval of the waste from Hanford tanks, the solids are separated from the liquids. The liquids undergo cesium separations, followed by organic destruction, followed by

${ }^{85} \mathrm{DOE} 5400.5$, Residual Radioactive Material. 
strontium separations. The liquids exiting the strontium separations are sent to the LLW glass plant. Solids from the solids/liquids separation process are sent to the HLW glass plant. Likewise, ion-exchange materials loaded with cesium or strontium are also sent to the HLW glass plant. Since some tank sludges (solids) are believed to contain significant quantities of organics which may interfere with efficient operation of the HLW glass plant, some destruction of organics in tank sludges may also be necessary. Additional

investigation is required to determine if this processing step also enhances the solubility of selected sludge components, which could lower HLW glass volumes. Steam reforming is an appropriate method to perform organic destruction for both the liquids and the solids waste forms. It may also provide benefit with respect to tank waste solubility issues. Some technical issues important to integrate steam reforming into the overall TWRS program are:

- Organic destruction requirements: The organic destruction efficiency achieved on the liquid waste stream will impact the strontium separations efficiency. Likewise the organic destruction efficiency achieved on the solids waste stream may impact the efficiency of the HLW glass vitrification process. Steam reforming provides organic destruction efficiencies comparable to other leading processes.

- Capability to process both liquids and solids: A moving bed evaporator can accept both suspended solids and liquids as a waste input stream.

- Reduced radionuclide volatilization: The steam/carbon dioxide atmosphere of the moving bed evaporator would significantly reduce the volatility of many radionuclides, thus reducing down stream requirements.

- Reduced NO generation: Steam reforming may reduce the overall TWRS system need for $\mathrm{NO}_{\mathrm{x}}$ off-gas treatment processes since the nitrogen decomposition products might be manipulated to favor production of $\mathrm{N}_{2}$ over $\mathrm{NO}_{\mathrm{x}}$.

- Impact of sodium carbonate on LLW glass production: Conversion of the sodium nitrate to sodium carbonate by the moving bed evaporator would lead to $\mathrm{CO}_{2}$ generation during LLW glass production. Preliminary discussions with melter and glass experts indicate that a Vortec melter, a cold-cap resistance melter, and a stirred tank melter could accommodate sodium carbonate feed material

- Impact of $\mathrm{CO}_{2}$ addition to the MBE on sodium fusion reactions: Conversion of the sodium nitrate to sodium hydroxide during a nine minute residence time within the MBE might support sodium fusion reactions, leading to enhanced solubility of Hanford tank sludge waste. However, adding $\mathrm{CO}_{2}$ to the $\mathrm{MBE}$ as the sodium hydroxide is formed so that it is quickly converted to sodium carbonate will likely limit the benefits of sodium fusion reactions during steam reforming. However, the formation of carbonates may effect the solubilities of actinides and $\mathrm{Sr}$ (section 2.5). The overall impact of steam reforming on sludge solubility must be addressed in the future. 


\subsection{Process Demonstration}

\subsection{Pilot Test on Organic Destruction}

Three-hundred-fifty pounds of Raschig rings were placed in a 55 gallon drum producing a 20 inch deep bed of rings. The drum was then placed in the Synthetica Drum Feed Evaporator where it was exposed to steam $\left(440^{\circ} \mathrm{C}\right.$ at the drum inlet; $315^{\circ} \mathrm{C}$ at the drum outlet). While the steam was flowing through the drum, $23 \mathrm{lbs}$ of the spiked PNL tank waste surrogate (section 2.1.2) was pumped onto the bed of Raschig rings. At the end of the test the material coated on the Raschig rings was analyzed for TOC and for nitrate ion by Ion Chromatography (IC). Comparison of the results to an analysis of the spiked surrogate feed indicated that both the organics and the metal nitrates had destruction efficiencies of about $97 \%$.

\section{$5.2 \quad 0.03$ GPM Nitrate Test}

The decomposition of $\mathrm{NaNO}_{3}$ was carried out on a pilot scale for several reasons. First, $\mathrm{NaNO}_{3}$ is a major constituent of the waste and $\mathrm{NaNO}_{3}$ solutions are therefore a simple waste surrogate. Second, processing $\mathrm{NaNO}_{3}$ solutions provides many of the challenges of processing real waste, including the difficulty of handling phase changes and molten materials. Third, $\mathrm{NaNO}_{3}$ decomposition is more of a technical challenge than organic gasification and as such drives the processing conditions. Finally, the gases evolved during decomposition and methods of manipulating them impacts the overall process design.

Pilot testing of $\mathrm{NaNO}_{3}$ decomposition was first done using Synthetica's mechanical MBE and detoxifier. For this test, $100 \mathrm{lbs}$ of technical grade sodium nitrate was dissolved in 30 gallons of water. Two gallons of this solution were pumped into the MBE's $300 \mathrm{lb}$ bed of vitrified, non-porous $3 / 8$ inch diameter alumina spheres over a 45 minute interval. Analysis of salt residues from the test indicate that $80-90 \%$ of the nitrate fed into the system decomposed.

Additional pilot testing was conducted in a pilot plant Lawrence Livermore National Laboratory constructed to process oil shale using recirculating hot solids. This pilot plant, shown in Figure 5.1, was adapted in the fall of 1993 to demonstrate the feasibility of continuously decomposing sodium nitrate in a pneumatically operated steam reforming system.

The modifications to the plant shown in Figure 5.2, including steam and $\mathrm{CO}_{2}$ injection capabilities, allowed it to operate in a manner similar to the MBE described previously. Heated $1 / 4$ inch alumina spheres were circulated, providing the energy required for thermal decomposition, and allowing an aqueous solution of sodium nitrate to be dispersed, evaporated and processed over a large surface area, while avoiding sticking and agglomeration. The energy necessary to evaporate water and maintain the circulating solids at or above $550^{\circ} \mathrm{C}$ was supplied using electric heaters strapped to exterior surfaces 
and electric gas heaters. The maximum water injection rate possible, given the heater capacity available was $0.03 \mathrm{gpm}$.

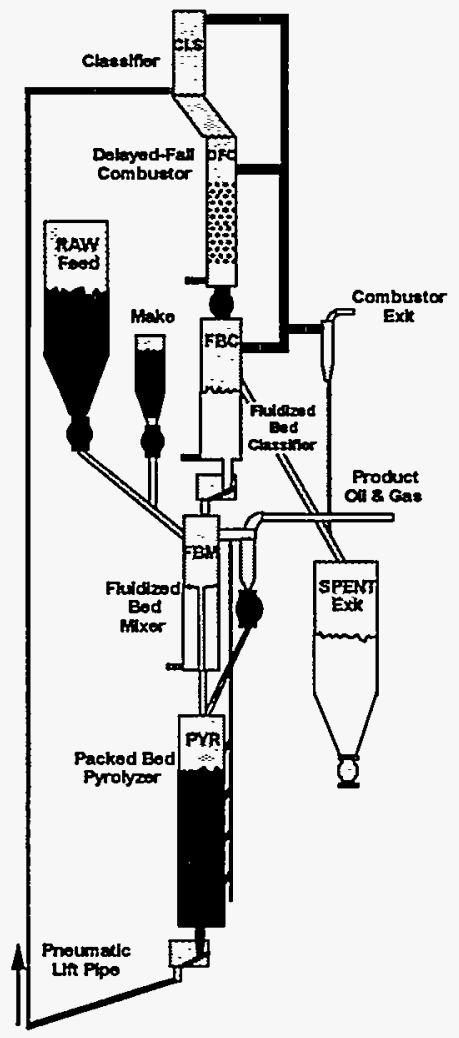

Figure 5.1 Schematic of LLNL Hot-Recycled-Solid (HRS) Oil Shale Retorting Pilot Plant

Once the system was fully operational, extended solids recirculation tests with continuous injection of a $10 \%$ by weight sodium nitrate solution were performed for a period of approximately four hours per day. The tests were performed for four consecutive days with each day consisting of a startup, an operating period and a shutdown period. During startup, solid circulation was established and steam and $\mathrm{CO}_{2}$ injection initiated. During the operation period, $\mathrm{NaNO}_{3}$ solution was injected and the rate adjusted to maintain a reactor temperature at or above $550^{\circ} \mathrm{C}$ (approximately $0.03 \mathrm{gal} / \mathrm{min}$ ). During shutdown, sodium nitrate injection was stopped and the system was allowed to degas with solids circulation continuing for approximately 30 minutes.

Continuous monitoring of off-gases, especially $\mathrm{NO}, \mathrm{NO}_{2}$ and $\mathrm{N}_{2} \mathrm{O}$, was invaluable in tracking the progress of the experiment and quantifying the reaction stoichiometry. Within a few minutes after $\mathrm{NaNO}_{3}$ injection started, the Fourier Transform Infra-red Spectroscopy (FTIR) reported a sharp rise in $\mathrm{NO}$ and $\mathrm{NO}_{2}$ concentration with no detection of $\mathrm{N}_{2} \mathrm{O}$ noted. The sharp drop in $\mathrm{NO}_{x}$ production following termination of the $\mathrm{NaNO}_{3}$ injection was also tracked using the FTIR instrument. As shown in Table 6-1, the stoichiometry of decomposition observed in the pilot plant varied from that observed in the laboratory. The pilot plant produced higher amounts of $\mathrm{NO}_{2}$ relative to $\mathrm{NO}$ and did not produce measurable amounts of $\mathrm{N}_{2} \mathrm{O}$. In the laboratory, higher $\mathrm{NO}$ and less $\mathrm{NO}_{2}$ was 
produced along with the $15 \% \mathrm{~N}_{2} \mathrm{O}$ production. The difference between the pilot plant results and those obtained from bench testing may be explained by the presence or absence of secondary reactions. In the fluidized bed test, the reaction products were rapidly swept away by argon from a relatively small, clean, quartz bed, thus minimizing the time for any secondary reactions to occur. In the pilot tests, reaction products are swept more slowly through a large bed in the presence of oxygen, thereby allowing more time for secondary reactions to occur. This is consistent with other pilot plant tests showing $\mathrm{NO}_{2}$ and $\mathrm{N}_{2} \mathrm{O}$ production vary depending on operating conditions, gas-solid residence times and contacting patterns. The percentage of $\mathrm{N}_{2}$ shown for the Pilot Plant test and marked with an asterisk $\left(^{*}\right)$ is a result of inference.

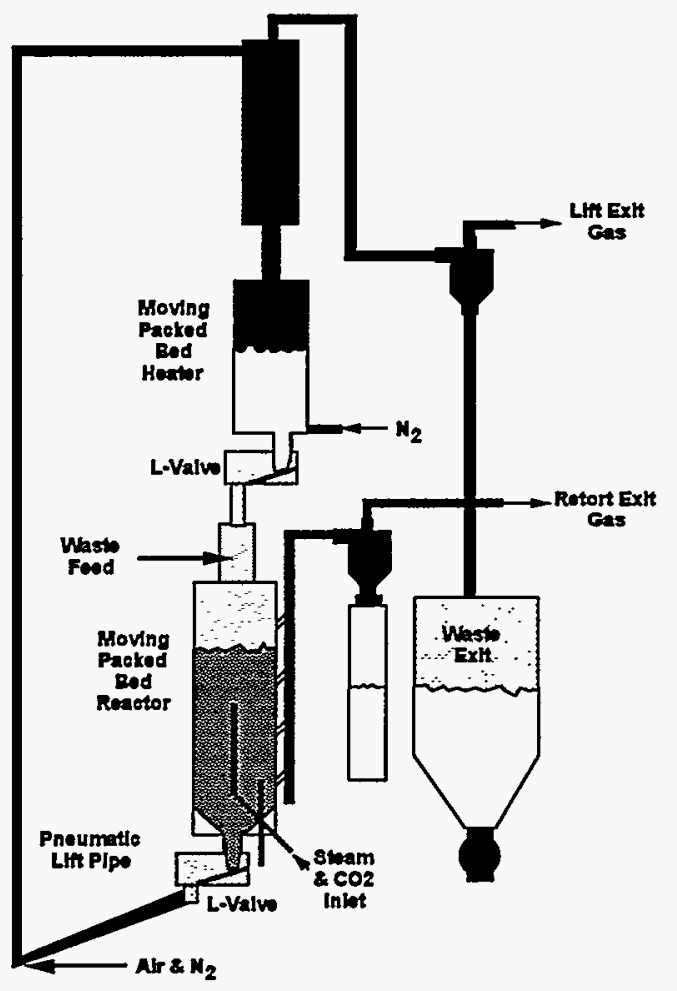

Figure 5.2 Schematic of Hot-Recycled-Solid Pilot Plant for Demonstration of Sodium Nitrate Decomposition

\begin{tabular}{|c|c|c|c|c|c|}
\hline (1). & $\begin{array}{l}\text { Uareacted } \\
\text { NaNo, \% }\end{array}$ & 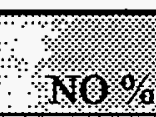 & $\mathrm{N}_{2} \mathrm{O}$ & $1,10 \%$ & $\mathrm{~N}_{2} \%$ \\
\hline Laboratory & 5 & 70 & 15 & 5 & 5 \\
\hline Pilot Plant & 5 & 65 & 0 & 25 & $5^{*}$ \\
\hline
\end{tabular}

Table 5-1 Comparison of Nitrogen Containing Products From Laboratory and LLNL Pilot Scale Sodium Nitrate Tests (\% Products in Off-Gas)

The collected solids and condensate were analyzed for nitrate along with samples of the circulating spheres and solids recovered from internal vessel walls. The results of these 
analyses indicate that over $95 \%$ of the sodium nitrate which entered the process decomposed. Eleven percent of the injected nitrate was found in the reactor exit cyclone and collected condensate, indicating that approximately $89 \%$ of the injected solution was processed. Sixty percent of the sodium injected was accounted for in the collected effluent samples. The remaining $40 \%$ accumulated within the reactor vessels as evidenced by a thin coating of sodium carbonate observed on internal surfaces. Due to the short duration of the test, the steady-state loading on the vessel walls is not known.

\section{$5.3 \quad 0.12$ GPM Nitrate/Organic Test}

A second test of $\mathrm{NaNO}_{3}$ destruction was conducted to further elucidate process chemistry and explore the effect of solution loading on system performance. The system was simplified and improved with the elimination of the upper L-valve, increased heater capacity and installation of a gas recycle pump. The recycle pump supplied working gas for the lift and L-valve system, thus eliminating the need for air and nitrogen as supply gases. This allowed the determination of $\mathrm{N}_{2}$ produced during $\mathrm{NaNO}_{3}$ decomposition. The increased heater capacity allowed for the exploration of a four-fold increase in solution injection rate, from .03 to $.12 \mathrm{gal} / \mathrm{min}$. The solution concentration was also increased from ten to twenty percent by weight, permitting the exploration of an eight-fold increase in solution loading. In addition to the twenty $\% \mathrm{NaNO}_{3}$, the feed solution contained small amounts of disodium EDTA (7\%), cyclohexanone and methyl i-butyl ketone (.09\% each). This was done to determine the fate of both volatile and non-volatile organics in an MBE environment. If not destroyed, the volatile ketones were expected to be collected in the systems condensers.

The test proceeded in two stages. In the first stage, conducted over a five hour period, the recycle pump was used to determine reaction stoichiometry for decomposition. During this stage, $\mathrm{NaNO}_{3}$ solution was fed at an average rate of $0.6 \mathrm{gal} / \mathrm{min}$. No measurable $\mathrm{N}_{2}$ was produced during the $\mathrm{NaNO}_{3}$ decomposition. The relative amounts of other nitrogen containing gas species was determined to be similar to that measured during the $0.03 \mathrm{gal} / \mathrm{min}$ test (section 5.2). A comparison of nitrogen containing species generated in the two tests is shown in Table 5-2. These pilot scale results highlight the need for further bench testing to fully understand the decomposition pathways of $\mathrm{NaNO}_{3}$.

\begin{tabular}{|c|c|c|c|c|}
\hline Sest & $\times X_{0} \%$ & $\mathrm{~N}_{2} \mathrm{O} \%$ & $1 \mathrm{NO}_{2} \%$ & $1 \% 1 \%$ \\
\hline $0.03 \mathrm{gal} / \mathrm{min}$ & 69 & 0 & 26 & 5 \\
\hline $\begin{array}{c}0.12 \mathrm{gal} / \mathrm{min} \\
\text { stage } 1\end{array}$ & 60 & 0 & 40 & 0 \\
\hline
\end{tabular}

Table 5-2 Comparison of Nitrogen Containing Products From LLNL Pilot Scale Sodium Nitrate Tests (\% Products in Off-Gas)

In the second stage of the test, the effect of solution loading on the spheres was explored with once through supply gases used to limit contamination of the recycle pump. The feed solution was increased to eight times that of the $0.03 \mathrm{gal} / \mathrm{min}$ test and two times that of the first stage loading. Continuous monitoring of off-gases throughout the test clearly showed 
that increased $\mathrm{NaNO}_{3}$ loading did not produce a corresponding increase in decomposition. Whereas the gaseous effluents evolved during the $0.03 \mathrm{gal} / \mathrm{min}$ test could account for over sixty percent of the injected nitrate (analysis of the solids indicated $>95 \%$ decomposition), only forty percent of the nitrate could be accounted for as gaseous products during the first stage of the high loading test and as little as eighteen percent could be accounted for during the second stage. Analyses of collected solids verified incomplete nitrate destruction during the high loading tests. This is consistent with laboratory experiments that show negligible decomposition of bulk $\mathrm{NaNO}_{3}$ compared with $\mathrm{NaNO}_{3}$ thinly coated on a surface under identical operation conditions. This clearly demonstrates the positive effect of surface area on $\mathrm{NaNO}_{3}$ decomposition.

This test also demonstrated that the system could be recovered from an upset condition that prevented $\mathrm{NaNO}_{3}$ decomposition, such as loss of temperature or a process overload. Upon completion of the first day of testing, the system was shut down and allowed to cool with unreacted $\mathrm{NaNO}_{3}$ still on the spheres. The system was restarted the next day by heating the system back to operating temperatures and feeding water.

Analyses of samples collected after the test indicate that the organics were almost completely destroyed. As expected, no EDTA was detected in the products by heavy metal $\left(\mathrm{Pb}^{2+}\right)$ titration and back titration. The volatile ketones were expected to flash over and be collected in the condensers. However, the total organic carbon (TOC) of condensates was $<1 \%$ of ketone carbon added to the system. Thus it appears that the organics were largely destroyed during the tests. 
Distribution:

MS 0104 Technical Publications, 12615

Lawrence Livermore National Laboratory

MS 0100 Document Processing for

Robert J. Cena

DOE/OSTI, 7613-2

P.O. Box 808

Thomas T. Coburn

Livermore, CA 94550

Synthetica Technologies, Inc.

Enrique S. del Solar

Terry R. Galloway

5327 Jacuzzi Street, \#3-O

Richmond, CA 94804

MS 0337 Alton D. Romig, 1800

MS 0607 Peter F. Green, 1845

MS 0607 S. Jill Glass, 1845

MS 0985 John H Stichman, 2600

MS 0329 Jere G. Harlan, 2652

MS 0329 Vincent M. Loyola, 2652

MS 0726 James K. Rice, 6600

MS 0734 Larry D. Bustard, 6624 (5)

MS 0734 Paul B. Kuehne, 6624 (7)

MS 0709 James E. Miller, 6212 (5)

MS 0718 Jeremy L. Sprung, 6641

MS 9105 Leonard A. Hiles, 8400

MS 9101 William C. Peila, 8411

MS 9101 Patrick D. Gildea, 8411 (5)

MS 9406 Howard Hirano, 8412

MS 9406 Linn W. Derickson, 8412

MS 9406 Davina M. Kim, 8412

MS 9401 Richard C. Wayne, 8700

MS 9404 Jill M. Hruby, 8716

MS 9404 Robert W. Bradshaw, 8716

MS 9402 Mark W. Perra, 8714

MS 9402 Steven H. Goods, 8714

MS 9044 Wendell A. Kawahara, 8746

MS 9018 Central Technical Files, 8523-2

MS 0899 Technical Library, 13414 (5) 